\title{
AN EVALUATION OF THE SENSITIVITY OF U.S. ECONOMIC SECTORS TO WEATHER
}

\author{
A Thesis \\ Presented to the Faculty of the Graduate School \\ of Cornell University \\ In Partial Fulfillment of the Requirements for the Degree of \\ Master of Science
}

by

Peter Hallick Larsen

May 2006 
(C) 2006 Peter Hallick Larsen 


\begin{abstract}
This study quantifies the impact of weather on eleven two-digit SIC sectors of the U.S. economy ranging from agriculture and construction to retail trade and utilities. Although it is obvious that weather affects the output of most sectors in some way, the magnitudes of these effects are not well known. This research effort estimates the historical sensitivity of production to annual weather variability. In addition to defining what it means for a sector to be sensitive to weather relative to another sector, industry productivity from 1977-2000 was modeled against measures of temperature and precipitation along with more traditional inputs to production like capital, labor and energy consumption. Specifically, sector output is modeled using a transcendental logarithmic production function (TRANSLOG) with measures of regional weather included. In order to estimate the aggregate sensitivity of the U.S. economy to weather, Monte-Carlo simulation of the four measures of weather is employed for each region by randomly drawing from historically observed weather combinations (i.e. temperature and precipitation) to produce distributions of sector-region output variability holding the conventional economic inputs constant.

As expected, the results show that the impact of weather varies from region to region and sector to sector. It is also evident that traditional methods used to model economic production such as the Cobb-Douglas and TRANSLOG specifications are improved statistically with the inclusion of measures of weather as factors of production. Given the available data at the annual level, the econometric results show that in general and across regions, the manufacturing sector is more sensitive to weather (e.g. cooling degree-days) than previously thought. The results also indicate that economic sectors in the Western U.S. are more sensitive to weather than they are in the Midwest and East Coast. It is also reported that as the standard deviation of
\end{abstract}


precipitation changes by $1 \%$, average U.S. transportation and utilities sector output drops between $.02 \%$ and $.09 \%$ (respectively). For context, actual year 2000 output for the utilities sector was over $\$ 200$ billion and actual transportation output exceeded $\$ 300$ billion at the national level. Similar data is reported for nine additional sectors and four measures of weather across eight regions of the country. Although small with respect to traditional factors of production, it is shown that U.S. GDP has expanded on average by $\$ 20.8$ billion ( $\$ 2004$ U.S.) annually with measured, historical weather variability. In contrast to the subjective estimates made by Dutton (2003) indicating that "one-third of private industry activities are sensitive to weather", this research finds that only $16.2 \%$ of the aggregate U.S. economy is sensitive to weather on an annual basis. Nevertheless, the effects of weather variability on specific sectors, particularly in Western states, is substantial. 


\section{BIOGRAPHICAL SKETCH}

Pete Larsen grew up in Minneapolis, Minnesota as the eldest son of a reference librarian/union steward and a private middle school teacher/church music director. Pete attended public schools throughout his early life and graduated from Hopkins High School in 1994. He spent his summers at his family's cabin on the St. Croix River, occasionally caddying at Interlachen Golf Course, and volunteering for the National Ski Patrol. In his free time, Pete enjoyed playing football and alpine ski racing for high school. After graduating high school, Pete immediately enrolled at the University of Montana at Missoula. He decided to move West because he fell in love with the mountains as a kid visiting family in and around Western Montana. As an undergraduate student, Pete majored in Economics, minored in Mathematics and graduated in three and a half years from the Davidson Honors College at Montana. Immediately following his graduation in 1997, Pete entered a fierce job market during the first technology boom. After nearly fifty interviews with over a dozen companies, he took a job at a small technology firm in Minnesota that specializes in designing sophisticated, real-time forecasting software for the hospitality industry. After a couple of years as a Systems Analyst, Pete returned to the mountains. In the fall of 1999, Pete moved to Colorado and worked for a survey design firm in Denver and an

environmental and energy consulting firm in Boulder (Stratus Consulting). In this role, Pete wrote dozens of papers on such diverse topics as electricity market deregulation in the Northeastern United States and climate change impacts on the country of Nepal. In the summer of 2003, Pete left Stratus Consulting as a Senior Associate to pursue an advanced degree 
at Cornell University. In 2004, Pete Larsen was hired as an economist in the Societal Impacts Program at the National Center for Atmospheric Research (NCAR) in Boulder, Colorado. Currently, Pete is a resource economist studying the impacts of climate change at the Institute of Social and Economic Research in Anchorage, Alaska. 
I would like to dedicate this thesis to all of the family, friends, advisors, authors, musicians, and pets who helped me through this research effort.

"Most people live dejectedly in worldly sorrow and joy; they are the ones who sit along the wall and do not join in the dance. The knights of infinity are dancers and possess elevation. They make the movements upward, and fall down again; and this too is no mean pastime, nor ungraceful to behold." 


\section{ACKNOWLEDGMENTS}

This thesis could not have been completed without insight from many influential people in my life both professional and personally. First, I would like to thank the sponsors of my research including John Gaynor at the U.S. Weather Research Program/NOAA and my employers at the National Center for Atmospheric Research (NCAR). I would also like to thank Dr. Asim Zia, Barbara Brown, Bill Mahoney, and Dr. Rebecca Morss, all colleagues from NCAR, who provided constructive feedback on the model input and results specifically related to weather. Megan Harrod, Dr. Murat Iyigun, and Dr. Don Waldman of the Department of Economics at the University of Colorado at Boulder generously donated their time to help ensure the specification and results made sense from an economics standpoint. Joel Smith at Stratus Consulting pointed me in the right direction on climate change literature related to this subject. Dr. Jean Agras of RW Beck Consulting gave ideas on how to efficiently organize and clean the input data in order to perform a sophisticated panel data regression. SAS experts from the University of Georgia's SAS-LISTSERV provided programming advice. I would like to gratefully acknowledge the support provided by my supervisor, Dr. Jeff Lazo, at NCAR's Societal Impacts Program. Without Jeff's vision this project would not have been possible. I am gratefully indebted to Professors Tim Mount and Duane Chapman at Cornell University for their patience and trust in me during an immensely difficult, but equally rewarding graduate experience in Ithaca. Professor Mount is known for his generosity to advisees and his great English sense of humor. Both Dr. Mount and Dr. Chapman also happen to have been the Cornell advisors for at least three supervisors I have worked for in the field of resource economics. I owe the greatest debt to my parents Laurie and Greg Larsen and to my dear friend Jody Johnson. Errors and omissions are the author's. 


\section{TABLE OF CONTENTS}

Chapter 1. Introduction..................................................

Chapter 2. Definition of Weather and Sector Sensitivity........................4

Chapter 3. Literature Review...........................................10

Chapter 4. Discussion of Production Theory.................................16

Chapter 5. Theoretical Specification.....................................21

Chapter 6. Sources, Summary and Transformation of Data.......................33

Chapter 7. Discussion of Model Results...................................46

Chapter 8. Direction of Future Research................................... 75

Chapter 9. Conclusion................................................ 79

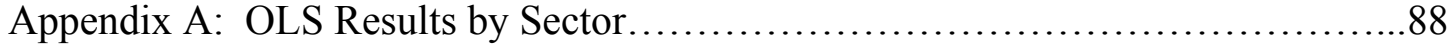

Appendix B: Selected Sector-level Plots from Monte-Carlo Simulation.............110

References................................................................. 121 


\section{LIST OF FIGURES}

Figure P.1 National Model Results..........................................xi

Figure 2.1: Timeline of Weather vs. Climate.................................

Figure 2.2: The Qualitative and Theoretical Definitions of Sensitivity...............8

Figure 4.1: Graphical Depiction of Supply and Demand....................... 16

Figure 5.1: Depiction of Least Squares Regression Technique....................25

Figure 5.2: Plot of Model Errors over Time (Finance, Insurance, and Real Estate)...27

Figure 5.3: Plot of Degree of Autocorrelation................................. 32

Figure 5.4: Model to Evaluate Sensitivity of U.S. Economic Sectors to Weather.....33

Figure 6.1: Gross State Product (GSP) as a Measure of Economic Output............35

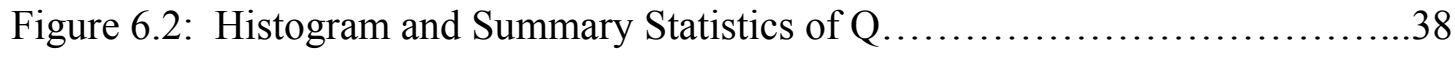

Figure 6.3: Histogram and Summary Statistics of L........................... 38

Figure 6.4: Histogram and Summary Statistics of KAP ........................... 39

Figure 6.5: Histogram and Summary Statistics of E........................... 39

Figure 6.6: Histogram and Summary Statistics of HDD......................40

Figure 6.7: Histogram and Summary Statistics of CDD .......................40

Figure 6.8: Histogram and Summary Statistics of $\mathrm{P}_{-}$TTL $\ldots \ldots \ldots \ldots \ldots \ldots \ldots \ldots \ldots . \ldots . \ldots \ldots$

Figure 6.9: Histogram and Summary Statistics of P_STD $\ldots \ldots \ldots \ldots \ldots \ldots \ldots \ldots \ldots . \ldots 1$

Figure 7.1: Identifying Outliers: Historical State Output per Capita................47

Figure 7.2: Annual Estimated Super-Sector Growth Rates......................48

Figures 7.3: Sector Output Elasticities to Four Measures of Weather...............53

Figures 7.4: Sector Output Elasticities to Four Measures of Weather...............56

Figures 7.5: Sector Output Elasticities to Four Measures of Weather................58

Figures 7.6: Sector Output Elasticities to Four Measures of Weather..............60

Figures 7.7: Sector Output Elasticities to Four Measures of Weather...............62

Figures 7.8: Sector Output Elasticities to Four Measures of Weather................64 
Figures 7.9: Sector Output Elasticities to Four Measures of Weather................66

Figures 7.10: Sector Output Elasticities to Four Measures of Weather..............68

Figure 7.11: Calculating the Sensitivity of U.S. Economic Sectors to Weather.......70

Figures 7.12: Example Output from Model Simulations...........................74

Figures 7.13: Example Output from Model Simulations........................75

Figures 7.14: Example Output from Model Simulations.........................76

Figures 7.15: Example Output from Model Simulations........................77

Figures 7.16: Example Output from Model Simulations.........................78

Figures 7.17: Example Output from Model Simulations..........................79

Figures 7.18: Example Output from Model Simulations........................79

Figures 7.19: Example Output from Model Simulations.........................80

Figure 8.1: Average U.S. precipitation forecast improvements (1977-2000).........81

Figure 8.2: Average U.S. temperature forecast errors $(1977-2000) \ldots \ldots \ldots \ldots \ldots \ldots . \ldots 2$

Figure 8.3: Historical Trading Volume of Weather Derivatives.....................84 


\section{LIST OF TABLES}

Table 2.1 Weather Impacts in the Netherlands: Utility Regression Results..........12

Table 6.1: Correlation Coefficients of Independent Variables.....................44

Tables 7.1: Output Elasticities.........................................51

Tables 7.2: Output Elasticities.........................................54

Tables 7.3: Output Elasticities.........................................57

Tables 7.4: Output Elasticities.......................................59

Tables 7.5: Output Elasticities.........................................61

Tables 7.6: Output Elasticities........................................63

Tables 7.7: Output Elasticities........................................65

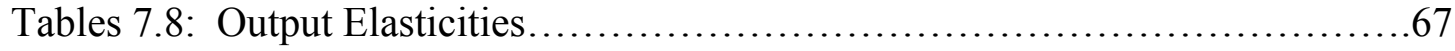

Table 7.9: Region-Supersector Simulated Standard Deviations from Weather

Variability.................................................. 71

Table 7.10: Region-Supersectors Ranked by Output Variance due to Weather........72 


\section{LIST OF ABBREVIATIONS}

BEA: $\quad$ U.S. Bureau of Economic Analysis

BLUE: $\quad$ Best Linear Unbiased Estimator

BLS: $\quad$ Bureau of Labor Statistics

CD: $\quad$ Cobb-Douglas Production Function

CDD: $\quad$ Cooling Degree Days

DOE: $\quad$ U.S. Department of Energy

DOL: $\quad$ U.S. Department of Labor

FE: $\quad$ Fixed Effects Estimator

FIRE: $\quad$ Finance, Insurance and Real Estate (Sector)

RE: $\quad$ Random Effects Estimator

GDP: $\quad$ Gross Domestic Product

GSP: $\quad$ Gross Sector/State Product

HDD: $\quad$ Heating Degree Days

IPCC: Intergovernmental Panel on Climate Change

MVLUE: Minimum Variance Linear Unbiased Estimator

NOAA: National Oceanic and Atmospheric Administration

NCAR: National Center for Atmospheric Research

NCDC: National Climatic Data Center

OLS: $\quad$ Ordinary Least Squares

TRANSLOG: Transcendental Logarithmic Production Function

USWRP: United States Weather Research Program 


\section{LIST OF SYMBOLS}

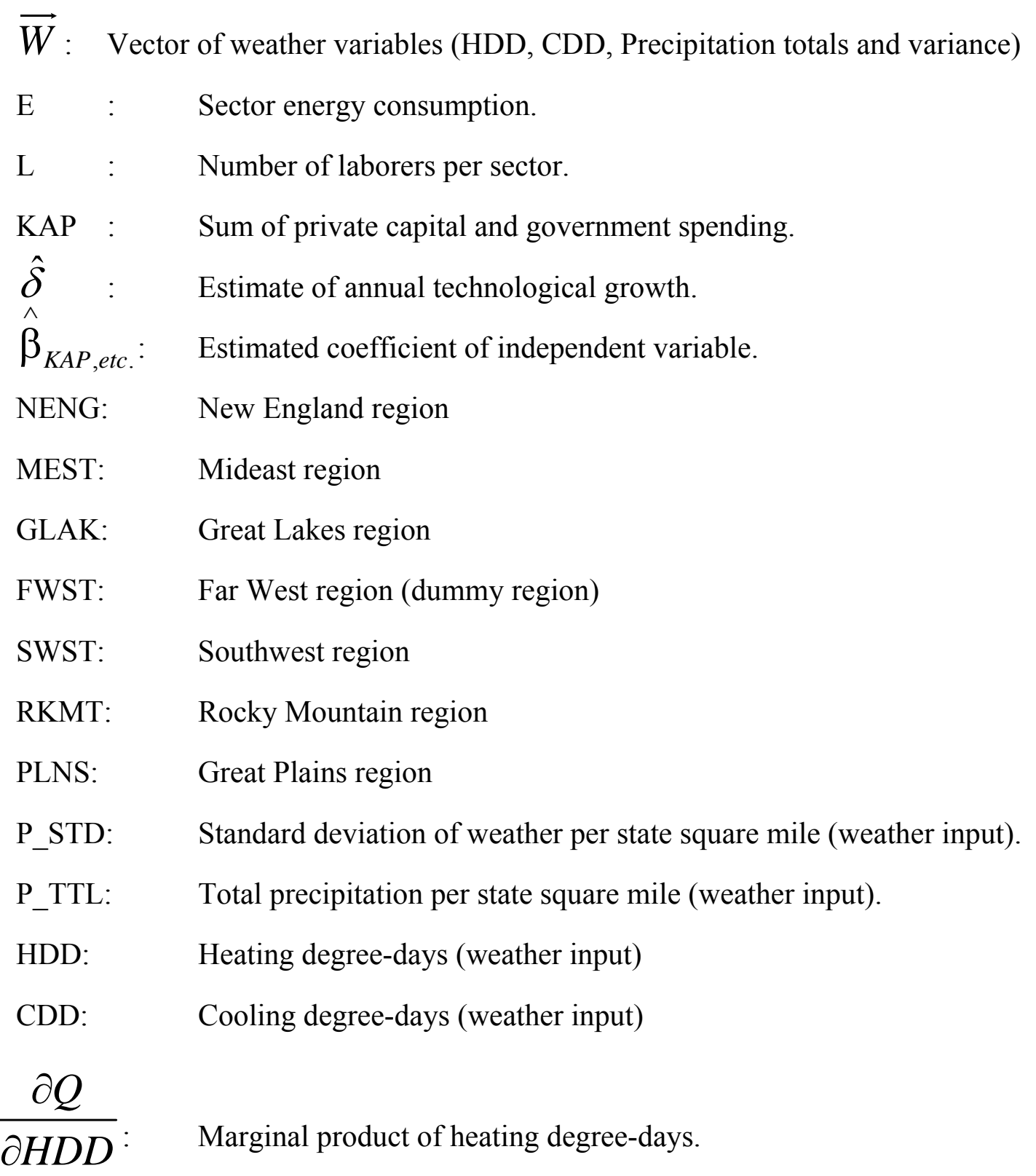




\section{PREFACE}

It is obvious that weather affects economic output to some degree. Some meteorologists have speculated that nearly all sectors of the U.S. economy are sensitive to weather, but have not defined what it means to be sensitive or how sensitivity can be empirically estimated at the national level. Consequently, officials in the weather and climate industries have been stating that some $\$ 3$ trillion dollars of the U.S. economy is sensitive annually to weather. Unfortunately, there has been little or no valid economic research conducted to confirm this subjective estimate.

Accurate, objective estimates of sensitivity could be used by policymakers to correctly assess sector vulnerability and optimally direct resources to mitigate the economic impact of weather to entire industries. It is demonstrated in this paper that U.S. economic output (GDP) expands on average by \$20.8 billion (\$2004) annually with weather variability. To put this expansion in perspective, total GDP output of the U.S. economy exceeded $\$ 10$ trillion in 2000 (\$2004). In reality, approximately $\underline{\mathbf{1 6 . 2 \%}}$ of the aggregate U.S. economy is "sensitive" to weather on an annual basis. Figure P.1 depicts a histogram of the annual output change attributed to weather variability calculated by this model. This figure, based on a Monte-Carlo simulation technique, demonstrates that aggregate economic output (i.e. GDP for the contiguous U.S.) expands (and contracts) with weather variation following a probabilistic distribution.

Over the past eighteen months, the Societal Impacts Program (SIP) at NCAR has been undertaking applied econometric model development in the area of sensitivity of U.S. economic super-sectors (e.g. agriculture, communications, construction, etc.) to weather. This paper is both a culmination and base for applied research into the economic impacts of weather and weather information. 


\section{Change to Economic Output from Regional Weather Variability National Estimate \\ 11 Sector Total}

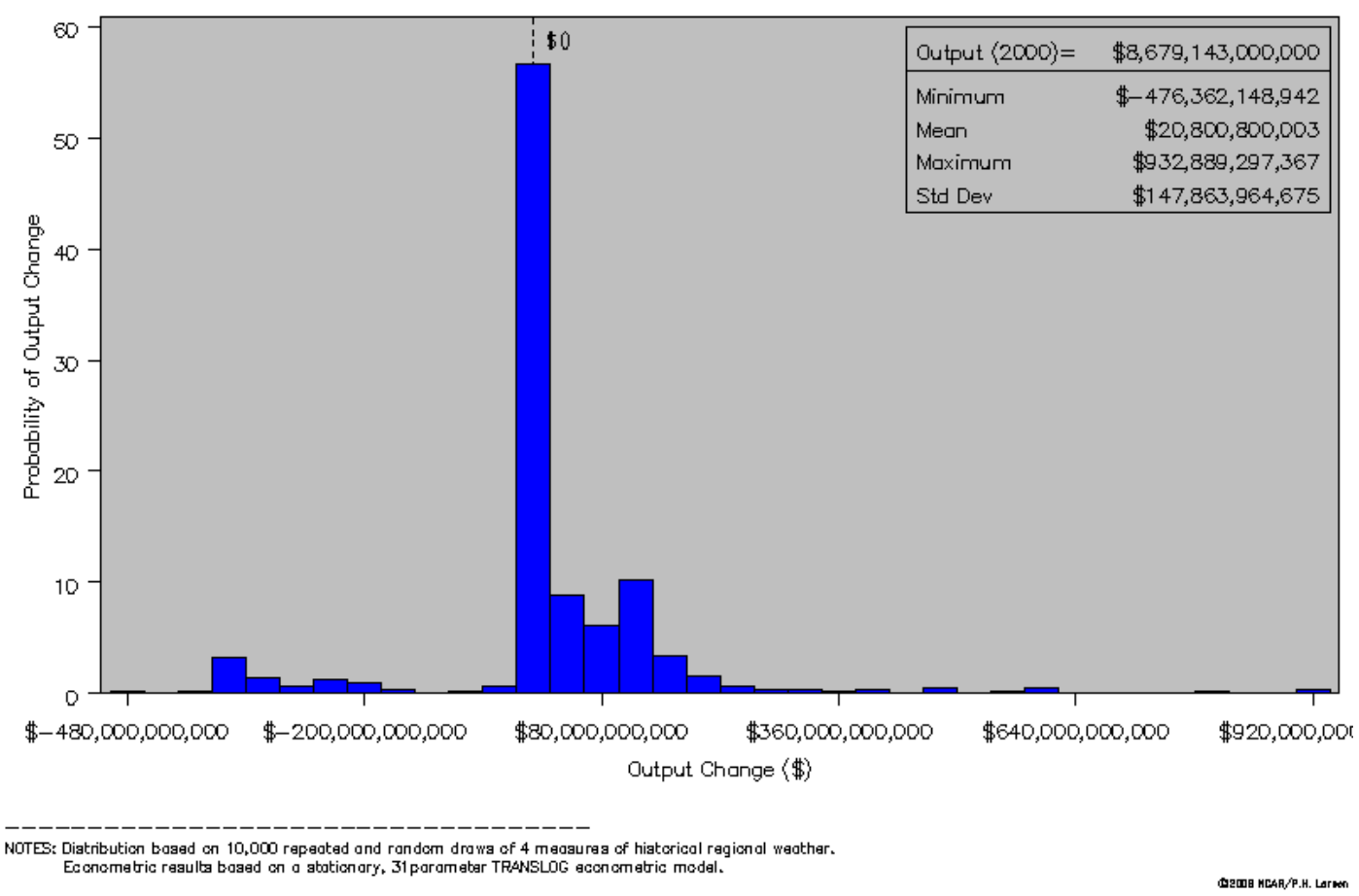

Figure P.1. National Model Results Depicting Average Economic Expansion of \$20.8 Billion Attributed to Weather Variability 


\section{CHAPTER 1}

\section{INTRODUCTION}

Dutton (2002) purports to identify weather sensitive components of the U.S. economy (in $\$ 2000$ ). Dutton suggests that $\$ 3,859.1$ billion of the $\$ 9,872.9$ billion (39.1\%) 2000 Gross Domestic Product (GDP) is weather sensitive. Dutton states that: “... some one-third of the private industry activities, representing annual revenues of some \$3 trillion, have some degree of weather and climate risk. This represents a large market for atmospheric information." Despite the subjective approach taken in this analysis, this result is now widely cited in the weather community as indicating the importance of current and improved weather forecast capacity.

Although there have been a handful of qualitative sector assessments conducted in the past few years, there are no known studies that objectively ascertain the aggregate effect that weather has on the U.S. economy. It is clear that nearly all sectors are directly or indirectly affected by weather. For example, the aviation industry relies on short-term forecasts of precipitation and wind speeds to determine optimal routing of aircraft. The energy industry uses forecasted temperature and load to determine the most efficient dispatch of power plants within a determined control area. The financial services industry profits from designing financial hedges for clients to protect against losses due to weather uncertainty. The retail sector observes predictable sales patterns related to seasonal weather, but often sustains losses during times of abnormal precipitation and temperature. 
The purpose of this study is to undertake an evaluation of the overall sensitivity of U.S. economic sectors and agents to weather. This thesis is designed to address several key questions including:

- What is the difference between weather and climate in the context of decision making?

- What does it mean for a sector to be relatively 'sensitive' to weather?

- Which sectors are highly sensitive to weather?

- Does the inclusion of weather observations (as a factor input) improve the overall fit of a traditional production function?

Although there are numerous models that calculate long-term sectoral sensitivity to climate change, there are very few known studies that quantify the sensitivity of economic sectors to weather in the United States. In addition to conducting a literature review and developing a theoretical model, objectives of this research include:

1. Estimating the variability of U.S. sector output (measured in gross state product) to weather variability (later defined as $\frac{\partial Q}{\partial \vec{W}}$ ) over time.

2. Calculating aggregate economic impacts of increased temperature and precipitation variability for eight regions within the contiguous United States. 
This paper is organized into several chapters. Chapter 2 defines what it means for an industry (or economy) to be sensitive to weather. This chapter also details the differences between climate and weather. Chapter 3 presents a literature review of similar studies related to weather/climate impacts on economic sectors. Chapter 4 is a discussion of production theory. Chapter 5 proposes an economic methodology to evaluate sector output sensitivity to weather variability. Chapter 6 discusses the source, summary and transformation of the model data. Chapter 7 outlines model caveats and Chapter 8 details sector-specific results of sensitivity to weather. Chapter 9 identifies needs and opportunities for future research into this subject. Chapter 10 is the conclusion. 


\section{CHAPTER 2}

\section{DEFINITION OF WEATHER \& SECTOR SENSITIVITY}

\subsection{The Difference Between Climate and Weather}

The content of this report focuses on the sensitivity of economic sector production to weather. However, because of concern over global climate change many studies similar in scope, but different in their timeframe of analysis have been commissioned. Therefore, it is important to make the distinction between weather and climate for the purposes of this study.

Climate change studies use mid to long-term projections of temperature and/or precipitation to estimate the future effects of change on ecological and societal populations. Climate studies are focused on individual sectors like agriculture and often extend out decades or more and have a relatively high degree of uncertainty in their accuracy. The Intergovernmental Panel on Climate Change (IPCC) defines climate as:

"Climate in a narrow sense is usually defined as the "average weather", or more rigorously, as the statistical description in terms of the mean and variability of relevant quantities over a period of time ranging from months to thousands or millions of years. The classical period is 30 years, as defined by the World Meteorological Organization (WMO). These quantities are most often surface variables such as temperature, precipitation, and wind." (IPCC, 2001) 
For the purposes of this study, we use average temperature and precipitation measures such as heating degree days (HDD), cooling degree days (CDD), standard deviation of precipitation (based on monthly totals) and total annual precipitation as our measures of weather. Typically, weather information is grouped into short range forecasts (up to 3 days), medium range forecasts (3 to 7 days), long or extended range (7 to 14 days), and seasonal (14 days to 1 year).

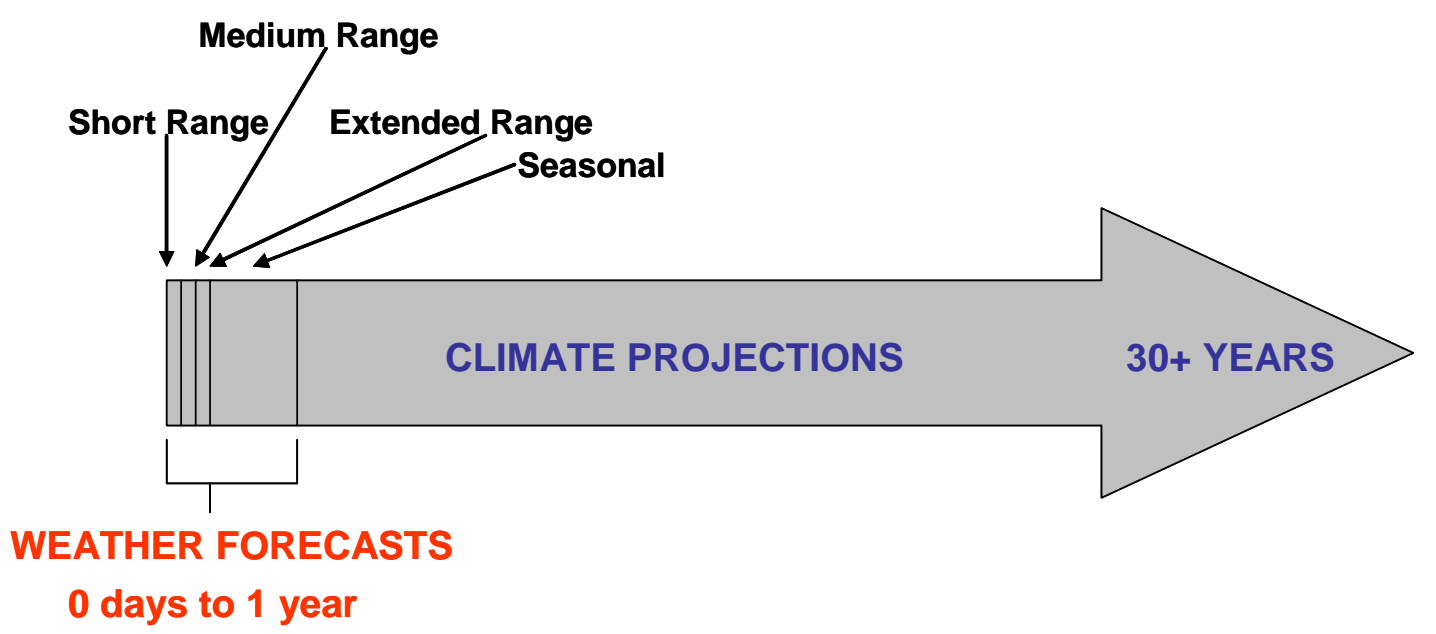

Figure 2.1 Timeline of Weather vs. Climate 


\subsection{Definition of Sector Sensitivity to Weather}

There are no known economic definitions of what it means for a sector (region) to be economically sensitive to weather (or weather information) relative to another sector or region. However, applicable qualitative definitions of sensitivity exist in the literature on climate change. By itself, sensitivity is the degree to which a group, place or system is affected by exposure to a perturbation or stress. (Kasperson, 2002) In addition, The United Nations Environment Programme (UNEP) defines sensitivity as the "degree to which a system will respond to a change in climatic conditions. E.g. extent of change in ecosystem composition, structure and functioning." (UNEP, 1995)

Although the time horizon for climate projections is much longer than that of weather forecasts, the definitions of sensitivity are relevant for both. That is, sectors are economically sensitive to weather if weather (e.g. precipitation totals) adversely

(or beneficially) affects the behavior or output of an economic sector either directly or indirectly.

For an example of sector sensitivity to weather, an unusually hot summer could cause power plants to offer their power to the grid at a premium to meet the excess demand from widespread air conditioner use. The increase in electricity prices due to the increased temperature reflects this industry's change in behavior (i.e. sensitivity) to weather. Another example of sector sensitivity is the effect of an abnormally moist winter on recreation. When there is excessive winter precipitation, trips to ski resorts tend to increase as skiers take advantage of above average snow conditions. It is important to note that each super-sector reacts differently to weather and weather information. In some cases, hot weather may be beneficial to a sector (e.g. tourism) and in other cases it may be detrimental (e.g forestry). Both of these examples focus on shifts in the demand for the good or service. Additional information presented in 
Chapter 4 distinguishes between demand shifts, weather as a factor input, and weather as an exogenous influence on production for a given sector.

It is also important to define economic sensitivity in a way that is not entirely subjective. It is clear that weather variables like precipitation and temperature affect the output of many industries. Alternatively, it is useful to develop an objective, theoretical framework to evaluate the degree of output variation that can be explained by weather variation. Although this will be discussed further in Chapter 8, a supersector could be deemed objectively sensitive to weather (relative to another supersector) if repeatedly drawing from a distribution of observed weather variables (e.g. temperature, precipitation) in a geographic region produces measurable changes in the variance of the dependent variable (e.g. sales of cars, agricultural yields, or some measure of sector output) estimated from a robustly fit regression equation. In short, sector-region combinations can be said to more sensitive to weather (relative to others) if the variance of one combination's estimated output is greater than another.

\subsection{Analysis of Output Variance from Monte-Carlo Estimation Technique}

Substitution of observed regional distributions of weather measures ( $\mathrm{x} \& \mathrm{z}$ in Figure 2.2) into a robustly estimated regression equation will produce observable distributions in sector output (y'). Super-sector distributions with large output dispersions around the mean (i.e. average weather) indicate that a particular supersector's economic output (measured in \$2004 dollars) is more sensitive relative to another. In other words, traditional measures of a distribution's dispersion such as variance, etc. can be used to detect the degree a sector/region is sensitive to weather. Accordingly, region-supersector combinations including agriculture in the Rocky Mountain region or utilities in the Northeastern United States, etc. can be ranked in 
terms of dollar output changes relative to one another. For example, given a distribution of historical weather (i.e. jointly dependent combinations of precip./temp. by region), it can be repeatedly demonstrated that production for the transportation sector in the Southeast is more sensitive to various weather measures (e.g. low temperature) than its counterpart in New England.

Employing a monte-carlo estimation technique is one way to single out the dollar impact on output caused by weather variability for a particular region. For a further discussion of the theoretical foundations of monte-carlo simulations, please see Greene (2003) or Kennedy (2003).

Although not the focus of this paper, calculus can be performed to estimate the elasticities of each of the weather inputs as an alternative method of singling out the impact of abnormal weather.

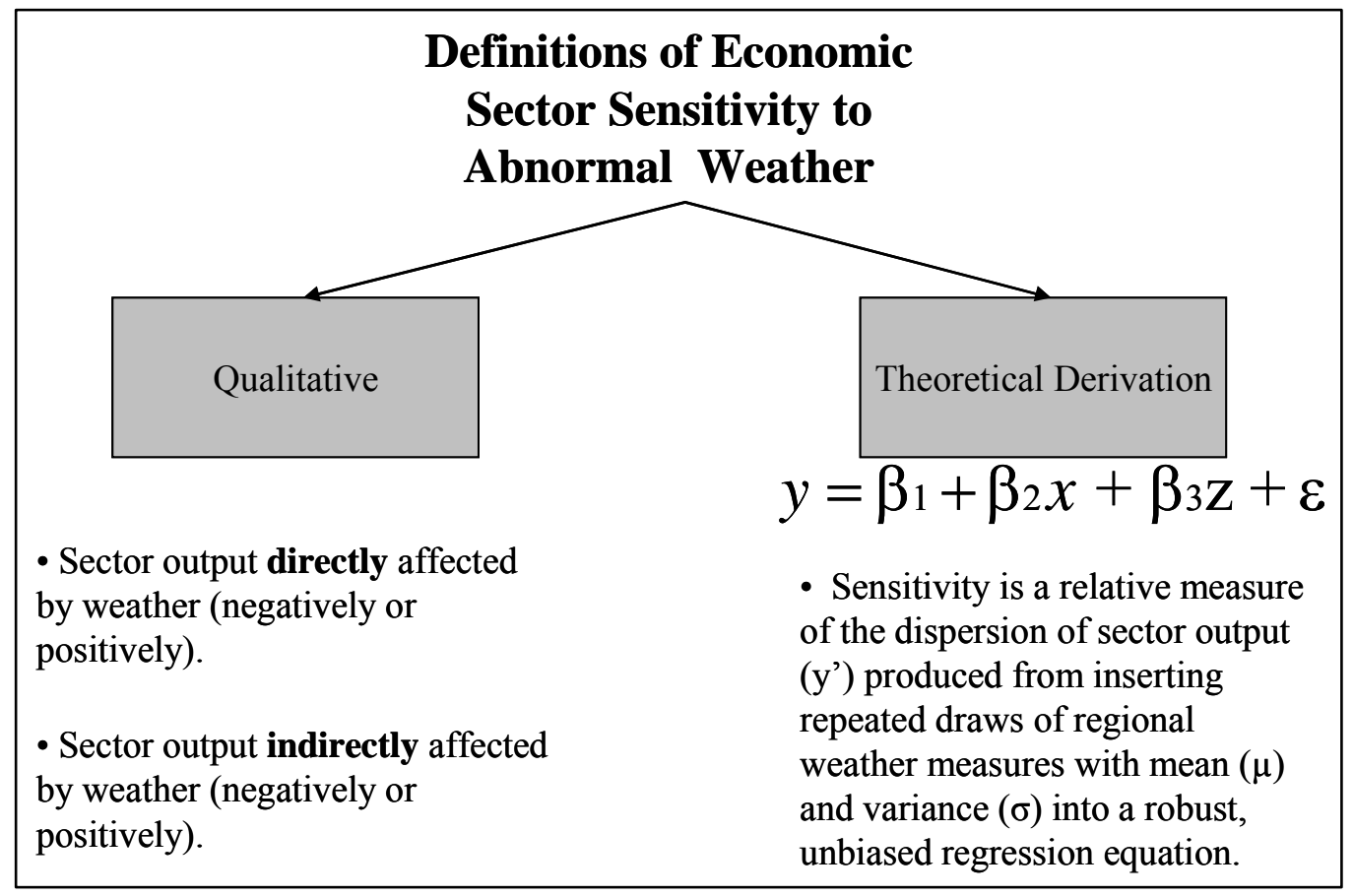

Figure 2.2 The Qualitative and Theoretical Definitions of Sensitivity 


\subsection{Economic Analysis of Elasticities of WeatherVariables}

Taking a partial derivative of the parameter estimates of the weather variables that are generated from an econometric regression represent the elasticity of economic output to weather inputs (e.g. increasing the precipitation by $\mathrm{X} \%$ causes output to increase/decrease by $\mathrm{Y} \%$ ). As discussed in Chapter 8, parameter estimates are generated from this model via Ordinary Least Squares (OLS) regression on a log-log model of production. Statistically significant results at the $95 \%$ confidence level indicate that a particular economic or weather input significantly contributes to explaining output at the annual level.

In the following chapter, sensitivity of sectors to both climate change and weather measures is discussed in the context of applicable literature. 


\section{CHAPTER 3}

\section{LITERATURE REVIEW}

The purpose of this literature review is twofold. First, previous studies of weather/climate sensitivity are discussed. Second, research into relevant production functions is detailed. The results of this literature review provide the foundation for the model's functional form which is expanded upon in Chapter 5.

\subsection{Sensitivity of Economic Sectors to Climate}

There are a number of studies that analyze the economic effects of climate change on sectors of the U.S. economy. For a few examples, see Nordhaus (1994, 1996), Cline (1992), Fankhauser (1995), Tol (1995), and Titus (1992). Most of these

estimates are derived from running a general equilibrium model that takes into account many different environmental and economic variables.

Although there are numerous models that calculate long-term sectoral sensitivity to climate change, there are very few known studies that quantify the sensitivity of economic sectors to weather in the United States.

\subsection{Sensitivity of Economic Sectors to Weather}

The most widely cited study on the sensitivity of economic sectors to weather comes from Dutton (2002). Dutton uses the term 'weather sensitive industries,' but gives no definition (or criteria) of what it means for an industry to be sensitive to weather. In addition, an entirely subjective approach is used to both determine the industries sensitive to weather and climate variation and the proportion of GDP for each industry that is sensitive to weather. In addition, Dutton defines weather and 
climate risk as the 'possibility of injury, damage to property, or financial loss owing to severe or extreme weather events, unusual seasonal variations such as heat waves or droughts, or long-term changes in climate or climate variability.' Finally, it is noted by Dutton that weather effects can often be managed with A) adequate preparation using accurate forecast information and/or B) effective insurance and risk hedging strategies.

Tol (2000) studied weather impacts on tourism, fire, water consumption, energy consumption, and agriculture in the Netherlands. Agricultural products considered in this study include wheat, sugar beets, strawberries, apple, pig, and potatoes. Weather impacts on fire were broken down into two categories: built environment and natural. Gas and electricity consumption made up the energy sector analysis and tourism was separated into foreign visitors and locals on vacation. This research indicated that some crops (wheat, sugar beets) are more sensitive to weather effects than other agricultural products studied. The study also found that gas consumption falls during particularly warm winters and unlike the United States market, electricity consumption is not affected by weather. Not surprisingly, more tourists (both national and international) chose to travel during a hot summer and visits declined the year immediately following. Table 2.1 presents Tol's results for the utilities sector in the Netherlands (Tol 2000). The coefficient in front of the T variables indicate the relationship between summer (winter) temperature and water usage, electricity consumption, domestic gas consumption, and gas consumption from the electricity industry. For example, as the winter temperature $\left(T_{\text {win }}\right)$ increases, gas consumption in the Netherlands falls significantly (shown by the negative sign for the coefficient of $\left.\mathrm{T}_{\text {win. }}\right)$. 
Table 2.1 Weather Impacts in the Netherlands: Utility Regression Results ${ }^{1}$

\begin{tabular}{|c|c|c|c|c|}
\hline & Water & Electricity & Domestic gas & Gas for electricity \\
\hline Constant & $\begin{array}{l}129.37 \\
(83.53)\end{array}$ & $\begin{array}{l}-6580.63 \\
(3325.20)\end{array}$ & $\begin{array}{l}-17358.97 \\
(11903.65)\end{array}$ & $\begin{array}{l}3904.71 \\
(880.37)\end{array}$ \\
\hline Trend & $\begin{array}{l}-5.34 \\
(1.46)\end{array}$ & $\begin{array}{l}170.84 \\
(72.14)\end{array}$ & $\begin{array}{l}201.06 \\
(84.30)\end{array}$ & $\begin{array}{l}243.23 \\
(94.68)\end{array}$ \\
\hline DV $(-1)^{b}$ & $\begin{array}{l}0.99 \\
(0.01)\end{array}$ & $\begin{array}{l}0.93 \\
(0.04)\end{array}$ & $\begin{array}{l}0.67 \\
(0.17)\end{array}$ & $\begin{array}{l}0.44 \\
(0.19)\end{array}$ \\
\hline $\mathrm{T}_{\text {sam }}$ & $\begin{array}{l}10.73 \\
(3.11)\end{array}$ & & & \\
\hline $\mathrm{T}_{\operatorname{cam}}(-1)$ & $\begin{array}{l}-9.91 \\
(3.15)\end{array}$ & & $\begin{array}{l}1014.88 \\
(433.09)\end{array}$ & \\
\hline $\mathrm{T}_{\tan }(-2)$ & $\begin{array}{l}-6.80 \\
(3.21)\end{array}$ & & & \\
\hline $\mathrm{T}_{\text {min }}$ & & & $\begin{array}{l}-674.10 \\
(253.04)\end{array}$ & $\begin{array}{l}-630.56 \\
(249.37)\end{array}$ \\
\hline $\begin{array}{l}\text { Adj. } R^{2} \\
\mathrm{~N}^{\mathrm{c}}\end{array}$ & $\begin{array}{l}1.00 \\
45\end{array}$ & $\begin{array}{l}1.00 \\
48\end{array}$ & $\begin{array}{l}0.36 \\
23\end{array}$ & $\begin{array}{l}0.49 \\
17\end{array}$ \\
\hline
\end{tabular}

Flechsig (2000) studied weather impacts on natural, social, and economic systems in Germany. In particular, this study focused on agriculture, fire, human health, electricity and gas consumption, insurance, and tourism. Unlike the Netherlands study, Flechsig concludes that demand for energy falls during mild winters. It was reported that a $1^{\circ} \mathrm{C}$ increase in winter temperature above the average saves more than 420 million EURO in avoided electricity demand. Adequate summer rainfall was an important predictor in sensitive potato yields in Germany. The article mentioned that the U.K. seems to be adapting to this crop's sensitivity by irrigating over $45 \%$ of their potato farms, whereas in Germany, this is not the case.

Starr-McCluer (2000) estimated the effect of weather on retail sales in the United States. Using data from the National Weather Service (NWS) and the Census Bureau, this study found that weather had a small, but statistically significant role in explaining monthly retail sales. However, it was noted that the weather influence

\footnotetext{
${ }^{1}$ As reported in Tol (2000).
} 
estimated at the monthly level was often "washed out" at the quarterly frequency using lagged variables (i.e. the previous time period's value).

Unlike reports on sensitivity to climate change which rely heavily on scenarios and long-range predictions, the preceding studies used historical time-series data to estimate the impact of weather on different sectors. The primary means of statistical analysis used by both Tol (2000) and Flechsig (2000) was a classic linear regression with an "indicator of interest" (e.g. sector output, yield, etc.) as the dependent variable and summer temperature, winter temperature, and various lagged weather variables as additional independent variables. Starr-McCluer (2000) used a similar, but slightly different approach with a dependent variable (monthly sales) and independent variables including: heating degree days (HDDs), cooling degree days (CDDs), the lagged change in real labor income, the lag of real stock prices, and the lagged change in the level of interest rates. Both the Flechsig and Tol papers make the critical assumption that the relationship between weather and output is of a linear form.

It is important to note that other studies assume that the weather-production relationship is non-linear with researchers concluding that it would be inappropriate to model this relationship using a simple linear regression.

One such study, Solomou et al (1999) researched weather effects on agricultural output in Germany, France, and the U.K. covering a period of over 60 years using a semi-parametric model. Their research concluded that weather shocks, significant deviations from the climatological average, had significant effects on agricultural output over the period of analysis. The observed effects of weather were non-linear and accounted for somewhere between one-third and two-thirds of the variation in annual production for the agricultural sector. Although this paper did not go into the details on the types of agriculture studied, it did mention that soil moisture 
levels were used as an aggregate proxy for temperature, precipitation, and other relevant variables.

\subsection{Research into Production Functions}

A large amount of research into production functions was conducted in the early twentieth century by a number of economists. The seminal Cobb-Douglas work: A Theory of Production, introduced an aggregate neoclassical production function relating economic output to inputs of capital and labor. (Cobb \& Douglas, 1928) Since this important paper was released, other economists including Arrow et al (1961) and Fraser (2002) have improved upon the basic concept that output is a function of labor and capital by modeling non-constant time/technology trends and allowing for the substitution of inputs. Most researchers agree that production data may be better explained by using a less-restrictive form of the Cobb-Douglas (CD) model known as the transcendental logarithmic production function (TRANSLOG).

\section{3a Cobb-Douglas Model Specification}

The Cobb-Douglas is a model of production where output is a function of the varying levels of inputs including: capital (KAP), energy consumption (E), and labor (L) in an economy. Because the $\mathrm{CD}$ is a functional form and not an input driven model, other relevant inputs such as weather measures can be included. The CD function has also proved to be useful in many applications because it becomes a linear model in the logarithms (see Chapter 5). Making the model linear by transforming the data is appealing to researchers because estimating the elasticity of output with respect to labor and capital can be done using the Ordinary Least Squares technique (OLS) popular in many statistical programming languages. Many researchers choose to evaluate production starting with a CD model because the number of variables is limited. In addition, the complexity in interpreting the results is also kept to a 
minimum. Related functional forms, like the translog, often improve the fit of the model, but can be extremely onerous when interpretation begins. In general, the CD specification is attractive because it is consistent with economic theory, is mathematically tractable, and allows for empirical estimation of several issues of production (e.g. constant returns to scale, technological change, input substitution, marginal products, etc.).

\section{3b Translog Model Specification}

A variation of the $\mathrm{CD}$ is the translog production function first described by Berndt and Christensen $(1973)^{2}$. This functional form has both linear and quadratic terms with an arbitrary number of factor inputs. It is important to note that the model reduces to a multiple input Cobb-Douglas function as a special (and testable) case. The underlying principle of the translog specification is that factor inputs can be substituted for one another. In general, this form allows for a richer specification of factor input interactions including substitutability, complementarity, and non-linearity. The parameter estimate of capital (KAP) versus labor (L) is analogous to stating that the estimate represents the marginal product of KAP with respect to L. In short, translog specification allows the researcher to determine if higher capital levels lead to reduced labor levels through substitution, and other interactions, etc.

Another feature of the translog is the presence of quadratic terms which are able to capture certain non-linear relationships between the independent variables and dependent variable. For example, a significant independent variable may indicate that output increases as capital is increased. A significant squared (i.e. quadratic) independent variable, such as $\mathrm{L}^{2}$ provides information on the rate of change of output with respect to labor. A significant, negative quadratic term indicates that as labor is increased, output increases at a decreasing rate.

\footnotetext{
${ }^{2}$ The Cobb-Douglas specification is a restricted form of the translog specification.
} 


\section{CHAPTER 4}

\section{DISCUSSION OF PRODUCTION THEORY}

\subsection{General Discussion of Production}

Production of goods and services, from an economics perspective, is the process in which inputs are turned into outputs. Famous economists like Malthus, Cobb, Douglas, and Arrow began experimenting with abstract models of production known as production functions. Simply put, some measure of output such as the number of computers a firm builds, can be related in a mathematical way to the level of homogenous inputs like capital (e.g. the machines used to produce the computers), labor (e.g. the hours of employee time needed to build computers), and energy consumption at the factory. Production functions have been used to describe the decision processes made at the individual firm level all the way up to the collective decision process for an entire sector or economy. Functions describing sectors or economies are essentially aggregations of many individual firms' production decisions.

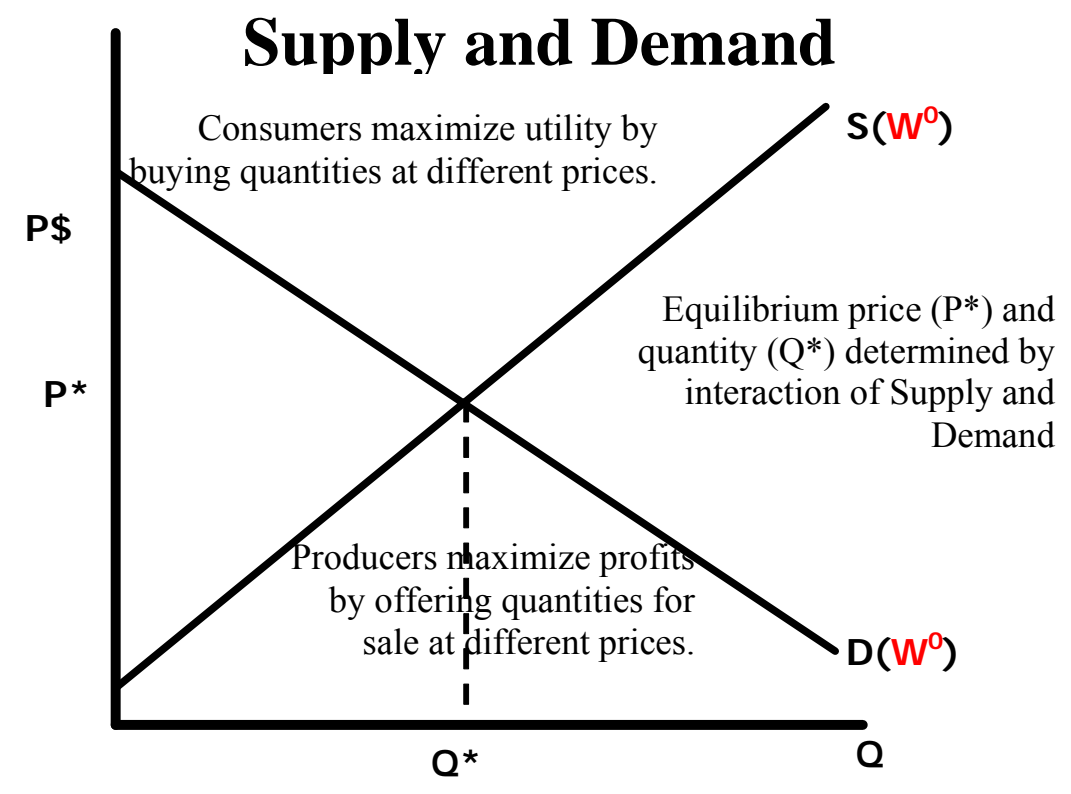

Figure 4.1 Graphical Depiction of Supply and Demand 
For example, by studying the production processes of the agriculture sector, a researcher is in fact studying the aggregation of many farms individual production processes. It has been shown empirically that production functions of entire sectors are relatively accurate proxies for modeling the collective production of many firms.

Constructing production functions allows social scientists to explain the process in which firms (or governments) convert inputs to outputs. Production economists have been long interested in measuring the relationship between the amount of output and varying levels of inputs. Returns to scale, how output expands when all inputs are increased proportionately, is one topic that has been studied extensively. Research into production functions also addressed the degree of substitution between one input and another while holding output constant. Researchers can also investigate technical progress, or the amount by which output increases over time given measured input levels.

In addition to testing for sensitivity to weather, the appendices to this paper also report results on tests for constant returns to scale, technical progress, and the degree of input substitution. The next section addresses weather as it relates to production. The following two sections detail how economists evaluate the change in output that is brought about by a change in one of the productive inputs.

\subsection{Weather as Inputs to Production}

Traditional inputs to production functions include measures of labor (L), capital (KAP), energy consumed (E) and occasionally worker education level. In this model, four additional inputs are studied as factors of production: heating degree-days, cooling degree-days, precipitation total, and variance of precipitation.

Heating (cooling) degree-days are measures directly related to temperature. Heating degree-days (HDD), a measure of cooler temperatures, are calculated by 
subtracting the daily average temperature from 65 degrees Fahrenheit and summing for all 365 days in a year. For example, a daily average temperature of 45 degrees Fahrenheit represents 20 heating degrees for that day. Cooling degree-days (CDD), a measure of high temperature, is calculated by subtracting 65 degrees Fahrenheit from the average daily temperature and summing for all 365 days in a year. For example, a daily average temperature of 95 degrees would represent 30 cooling degrees (95-65).

It is obvious that weather affects production to a certain extent. In the agriculture sector, drought conditions hinder crops from growing to maturity ${ }^{3}$. Excessively hot temperatures may harm manufacturing where large machinery may be forced to run under less-than-ideal conditions. Colder than normal temperatures delaying ice thaw may prevent ships from accessing certain trade routes thereby reducing production from the transportation and mining sectors.

Unlike traditional factors of production, levels of weather cannot be optimally selected by firms to ensure profit maximization through efficient production. Instead, firms are forced to adapt to or mitigate weather uncertainty using financial hedging or altering other input levels (and absorbing additional costs) in order to maximize production given this uncertainty.

Research into agricultural and other forms of production, indicate that production processes operate under a wide range of weather scenarios. Within this range are optimal levels of precipitation and temperature that maximize production for each firm and industry. Less than optimal levels of weather, such as little or no precipitation, cause production to fall off in all industries with some expressing more sensitivity to the drought than others.

\footnotetext{
${ }^{3}$ It should be mentioned that some researchers do not consider drought to be weather. For the purposes of this study, drought conditions represent below average seasonal (14 days to 1 year) precipitation.
} 
With traditional inputs like labor, above average labor rates increase costs thus reducing the amount of money available to invest in new capital hurting production in the long run. Accordingly, above average temperatures may increase replacement costs of capital as machines break down driving down production below optimal levels. Therefore, it is important to study weather conditions as factors that affect production.

\subsection{Notes on Marginal Product}

In developing a model to quantify the sensitivity of economic sectors to weather, it is important to be able to single out the effects weather has on the economy by holding the other inputs (labor, capital, etc.) constant. To study variation in a set of single inputs like HDD, CDD or precipitation, it is necessary to define the term marginal product.

Nicholson (1992) defines marginal product of an input as the additional output that can be produced by employing one more unit of that input while holding all other inputs constant. Given the simple production function: $\mathrm{Q}=f(\mathrm{~L}, \mathrm{KAP}, \mathrm{E}, \mathrm{HDD}$, etc.), mathematically, the marginal product of heating degree-days $\left(\mathrm{MP}_{\mathrm{HDD}}\right)$ equals:

$\partial \mathrm{Q} / \partial \mathrm{HDD}$.

\subsection{Partial Differentiation of Production Functions}

It is important to note that the mathematical definition of marginal product defined above uses partial derivatives, thereby allowing researchers to hold all other input usage (L, E, KAP, etc.) constant while the input of interest is being varied. Partial differentiation allows researchers to study the sensitivity of output (Q) to weather while temporarily ignoring the other inputs. 


\subsection{Sector-specific Sensitivity Analyses using Monte-carlo Simulation Techniques}

As first discussed in Chapter 2, monte-carlo simulations allow for sensitivity analyses to be conducted by taking repeated draws from different distributions of input data and estimating the mean and variance of the Monte-carlo estimator $(\theta)$ (Wooldridge, 2002). Inferences can then be made about the variation in economic output from altered input variable states including various measures of weather. Future research is being undertaken to investigate the sensitivity of U.S. economic sectors to weather by evaluating output after varying historical and future temperature and precipitation measures by some degree (e.g. 10\% more precipitation or a $5 \%$ improvement in forecasting may increase agricultural output). 


\section{CHAPTER 5}

\section{THEORETICAL SPECIFICATION}

\subsection{Functional Form}

In this model, economic output (reported as super sector revenues per capita) is a function of U.S. government agency (D.O.E., B.L.S., etc.) reported factor inputs over time:

$$
Q=f(L, K A P, E, \vec{W})
$$

where $Q, L, K A P, E$ and $\vec{W}$ are gross state product at the super sector level, labor, capital (public and private), energy consumption, and weather ${ }^{4}$ respectively. The popular, but restrictive Cobb-Douglas (CD) production function is of the form (Cobb and Douglas, 1928):

$$
Q=A(t) L^{\beta_{L}} K A P^{\beta_{K A P}} E^{\beta_{E}} \vec{W}^{\beta_{\bar{W}}}
$$

where $\beta_{L}, \beta_{K A P}, \beta_{E}$, and $\beta_{\vec{w}}$ are constants. Technical change is addressed by following the lead of Handsaker and Douglas (1937) and Williams (1945) who identified the need to include technological advances in the estimation process. Fraser (2002) assumes a non-constant value, A(t), to capture technical change using a time trend $(\mathrm{t})$. This model of technical change is similar to Fraser's approach where:

$$
\mathrm{A}(\mathrm{t})=\mathrm{Ae}^{\delta t}
$$

\footnotetext{
${ }^{4}$ Weather input is represented by a vector of weather measures (e.g. annual temperature, precipitation variability, measured storm events, etc.).
} 
$A$ and $\delta$ are constants with $\hat{\delta}$ equaling the estimated change in output (Q) per time period $\mathrm{t}$ (i.e. rate of technological improvement); $A$ represents a measure of total factor productivity. The assumption for technical change is also assumed to be Hicks-neutral (i.e. technical change does not disproportionally affect the optimal choice of $L, K A P$, or E).

One of the restrictions of a traditional CD production function, is that of constant returns to scale (CRS). This assumption implies that the sum of the estimated coefficients equals one or $\sum_{i=L}^{K A P} \beta_{i}=1$.

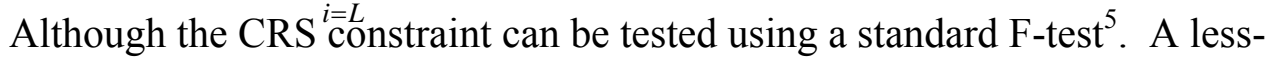
restrictive functional form is introduced to capture statistically significant quadratic relationships and cross-products of the coefficients. One such form, a two factor transcendental logarithmic (translog) functional form first described by Christensen et al $(1971,1973)$ can be written as: $\ln (Y)=\beta_{0}+\beta_{L} \ln (L)+\beta_{K A P} \ln (K A P)+\beta_{L K} \ln (L) \ln (K A P)+\frac{1}{2} \beta_{L L} \ln (L)^{2}+\frac{1}{2} \beta_{K A P K A P} \ln (K A P)^{2}$

Introducing the technical change equation (3) and adding in the additional factor inputs of the natural $\log$ of $\mathrm{E}$ and $\mathrm{W}$ we can measure sector productivity sensitivity using the following adapted translog form where ${ }^{6}$ :

\footnotetext{
${ }^{5}$ For this f-test, the null hypothesis is that the value of all parameter coefficients sums to one.

${ }^{6}$ Taking the natural log of both sides of (2) allows coefficients to be estimated using a standard ordinary least squares (OLS) regression. The coefficients of the independent variables yields input factor shares (i.e. the proportion of gross state product influenced by a given input)
} 


$$
\begin{aligned}
\ln \left(Q_{i j t}\right)= & \ln \left(A_{i j t}\right)+\delta t+\beta_{L} \ln \left(L_{i j t}\right)+\beta_{K A P} \ln \left(K A P_{i j t}\right)+\beta_{E} \ln \left(E_{i j t}\right)+ \\
& \beta_{\vec{W}} \ln \left(\overrightarrow{W_{i t}}\right)+\frac{1}{2} \beta_{\vec{W} \vec{W}} \ln \left(\vec{W}_{i t}\right) \ln \left(\vec{W}_{i t}\right)+\frac{1}{2} \beta_{L L} \ln \left(L_{i j t}\right) \ln \left(L_{i j t}\right)+ \\
& \beta_{L K A P} \ln \left(L_{i j t}\right) \ln \left(K A P_{i j t}\right)+\beta_{L E} \ln \left(L_{i j t}\right) \ln \left(E_{i j t}\right)+\beta_{L \vec{W}} \ln \left(L_{i j t}\right) \ln \left(\vec{W}_{i t}\right)+ \\
& \frac{1}{2} \beta_{K A P K A P} \ln \left(K A P_{i j t}\right) \ln \left(K A P_{i j t}\right)+\beta_{K A P E} \ln \left(K A P_{i j t}\right) \ln \left(E_{i j t}\right)+ \\
& \beta_{K A P \vec{W}} \ln \left(K A P_{i j t}\right) \ln \left(\overrightarrow{W_{i t}}\right)+\frac{1}{2} \beta_{E E} \ln \left(E_{i j t}\right) \ln \left(E_{i j t}\right)+\beta_{E W} \ln \left(E_{i j t}\right) \ln \left(\overrightarrow{W_{i t}}\right)+\varepsilon_{i j t}
\end{aligned}
$$

with $i$ representing contiguous U.S. states $(i=1, \ldots 48)$ and $j$ equaling sector $(j=1, \ldots 11)$ both at time $t(\mathrm{t}=1, \ldots 24){ }^{7}$ It is also important to note that dummy variables were added for eight regions along with interactive terms modeling weather against region.

For simplicity, private capital and government spending were summed into one variable: KAP representing private and public capital/spending ${ }^{8}$.

Finally, an error term and intercept are added to equation (4) producing equation $(5)^{9}$. Equation (5) is simplified using summation notation to produce the following functional form:

$\ln \left(Q_{i j t}\right)=\ln (A)_{i j}+\delta t_{i j}+\sum_{\bar{X}} \beta_{\bar{X}_{i j t}} \ln \left(\vec{X}_{i j t}\right)+\sum_{\bar{X}} \beta_{\bar{X}_{i j t} \bar{X}_{i j t}} \ln \left(\vec{X}_{i j t}\right) \ln \left(\vec{X}_{i j t}\right)+\varepsilon_{i j t}$

where $\varepsilon_{i j t}$ is the error term, $\ln (A)_{i j t}$ is the intercept, $\delta$ represents the technical change coefficient described above and $\vec{X}$ is a vector of the factors of production (KAP,L,E, and $\vec{W}$ ). The coefficient estimate of $\beta_{\vec{W}}$ (and $\beta_{\vec{W} \vec{W}}$, etc.) detailed in equation (5) represents the sensitivity of sector GSP to weather without fixed or

\footnotetext{
${ }^{7}$ Note: $\vec{W} \vec{W}$ may not be the correct notation for multiplying two vectors.

${ }^{8}$ This paper is primarily interested in addressing the relationship between weather and output therefore combining the private capital and public capital into one explanatory simplifies our interpretation of the results.

${ }^{9}$ Although this is technically a theoretical specification where no error term is needed, OLS estimation of this model produces the error term.
} 
random effects removed ${ }^{10}$. Before moving on to the applied section of this paper, it is important to briefly describe the process in which the model is fit to the raw data.

\subsection{Model Estimation}

\section{2a The Ordinary Least Squares Technique (OLS)}

Many econometricians use either the OLS method or some variation of it (e.g. Generalized Least Squares, etc.) for estimating coefficients. The OLS technique fits a linear model to the input data (KAP per capita, E per capita, etc.) in a way that minimizes the sum of the squared residuals from each data point to the modeled line. The term residual is analogous to the term error with both representing a measure of distance from each point to the modeled line. Figure 5.1 depicts the least squares process of modeling data.

Although advances in statistical programming allow researchers to run the OLS technique in seconds for very large panel datasets, considerable care should be taken when conducting the raw data and error term analysis. Robust estimation of the coefficients is carried out by testing for outliers (i.e. influential observations), correlations across the variables, patterns in the error term, and other potential biasing agents.

When the researcher is satisfied that all potential biases have been addressed, the model has been correctly specified, and the error term is distributed normally around a mean of zero, the model is said to be the Best Linear Unbiased Estimator (BLUE) or the Minimum Variance Linear Unbiased Estimator (MVLUE) and the coefficients are ready for interpretation. (Kennedy, 2003) (Greene, 2003)

\footnotetext{
${ }^{10}$ Fixed/Random effects represent assumed, but unmeasurable differences between the cross sections that need to be addressed before interpretation of the model takes place.
} 


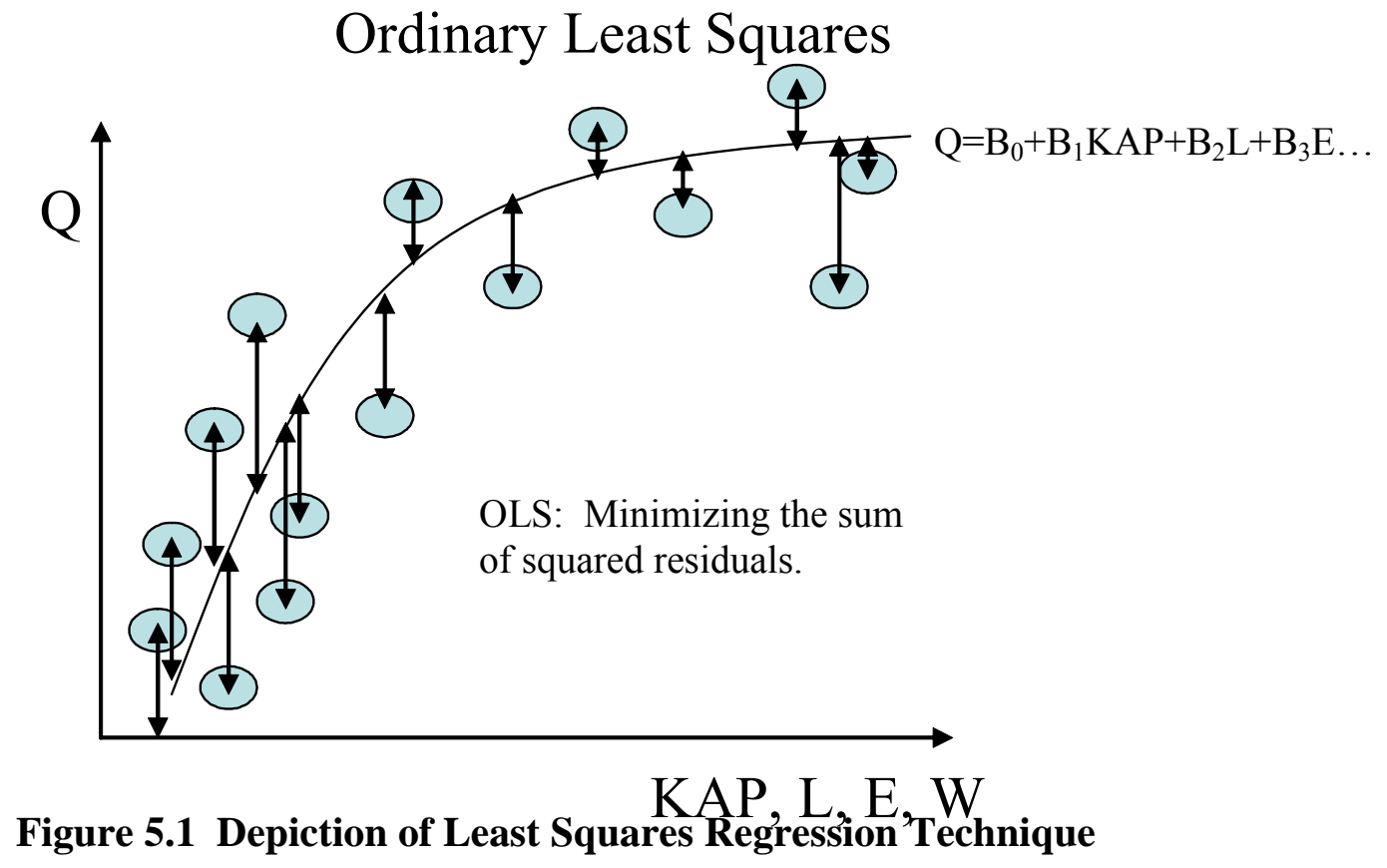

\section{2b Minimum Variance Linear Unbiased Estimator (MVLUE)}

Greene (2003) formally defines MVLUE as a model that:

"An estimator is the minimum variance linear unbiased estimator or best linear unbiased estimator (BLUE) if it is a linear function of the data and has minimum variance among linear unbiased estimators."

In the process of finding the MVLUE, econometricians point to the importance of identifying the disturbance (or error) term in the model. Tests and subsequent corrections for heteroskedasticity (i.e. non-spherical disturbances about the fitted model) and auto correlated errors (e.g. errors correlated to year) are stressed to ensure robust estimation of the parameters. ${ }^{11}$

\footnotetext{
${ }^{11}$ It is assumed that the error term is spherical within the sector regressions (i.e. the disturbances are uncorrelated and have uniform variation).
} 
In addition to addressing auto-correlated errors, fixed or random effects must be taken into consideration in order to make the data stationary (i.e. heteroskedasticity and autoregressive patterns have been removed from the error term) and ensure accurate statistical inference from the explanatory variables. Many econometric texts provide a set of assumptions about what being the MVLUE constitutes. If any of these assumptions are violated, econometricians have suggested modeling techniques like the fixed, Parks, and mixed model effects transformations to ensure that the model is the MVLUE.

\subsection{Testing for Fixed and Random Effects}

There are two standard methods for testing for the presence of fixed or random effects in a panel dataset and a handful of specialized procedures that can be applied to ensure that the data is stationary. ${ }^{12}$

\section{3a Standard F-test}

Statistical modeling packages are able to easily test for fixed effects by looking for significance in the intercept term by creating dummy variables for each cross sections within the panel data (e.g. states).

\subsection{Addressing Fixed or Random Effects}

As expected, this type of annual panel dataset exhibited signs of heteroskedasticity or non-spherical disturbances of the error term. Robust estimation of the parameters requires correcting the model for random or fixed effects. Several tests look for correlations across cross sections (in this case, 48 states). Once it has been determined that the model has random or fixed effects, several corrective techniques are available to econometricians including first differencing, two way fixed effects models, two way random effects models, and mixed error modeling techniques (Parks estimator or a

\footnotetext{
${ }^{12}$ Fixed/Random effects represent differences in the intercept term between cross-sections of the panel. In this production function, different intercepts account for assumed structural, but unmeasurable differences across states.
} 
variation of it). ${ }^{13}$ Figure 5.2 is a time-series plot of the model residuals with the vertical lines (i.e. slices) representing individual states model residuals over 24 years. Mixed Model: $\mathrm{AR}(1)$ and Heterscedasticity Correction Plot of Residuals

FIRE

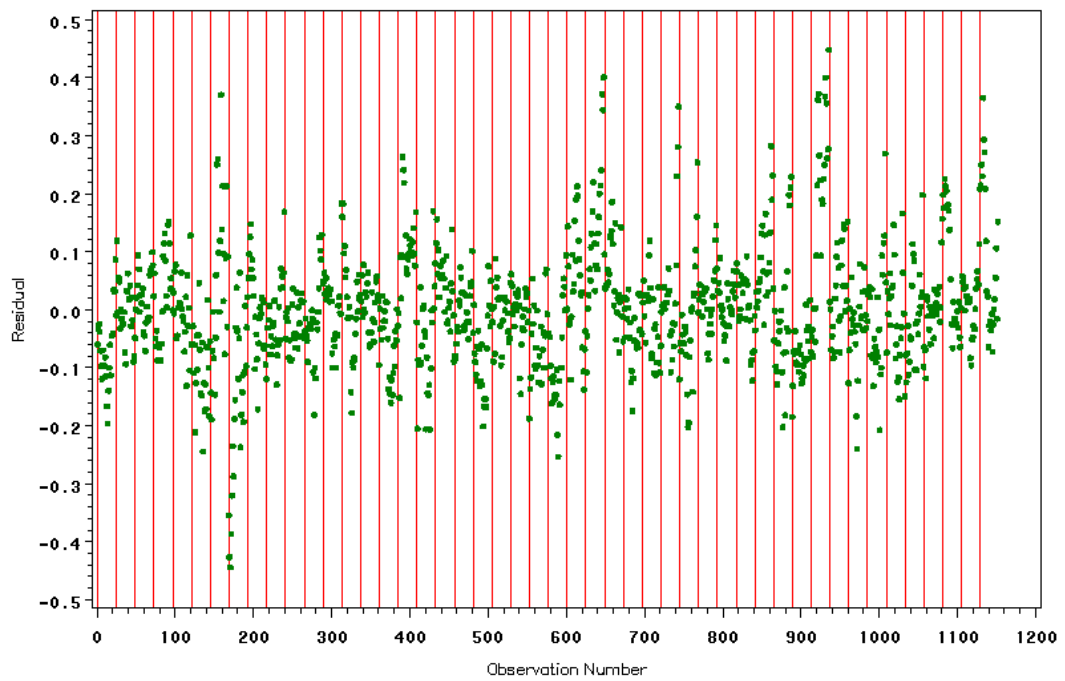

Figure 5.2 Plot of Model Errors over Time (Finance, Insurance, and Real Estate)

\section{4a First Differencing}

A fixed effects (FE) theoretical transformation is included to demonstrate one way to control for omitted variables that differ between sectors but are constant over time. Estimation of this model includes removing fixed effects using two common techniques: first differencing and the two way fixed effects method.

Subtracting observations from their average value will estimate any fixed effects in the model (Kennedy, 2003). Averaging the observations on the $\mathrm{i}^{\text {th }}$ state and $\mathrm{j}^{\text {th }}$ sector (over the entire time period, $\mathrm{T}$ ) produces the equation:

$\ln \left(\bar{Q}_{i j}\right)=\ln (A)_{i j}+\delta t_{i j}+\sum_{\bar{X}} \bar{\beta}_{\bar{X} i j} \ln \left(\vec{X}_{i j t}\right)+\sum_{\bar{X}} \bar{\beta}_{\bar{X} i \bar{X} \overline{i j}} \ln \left(\vec{X}_{i j}\right) \ln \left(\vec{X}_{i j}\right)+\sum_{\bar{X}} \bar{\beta}_{\bar{X}-1 i j} \ln \left(\vec{X}_{i j}\right)+\bar{\varepsilon}_{i j}$

Subtracting equation (7) from (6) completes the transformation for fixed effects:

\footnotetext{
${ }^{13}$ The Hausman test for the fixed and random effects regressions is based on the parts of the coefficient vectors and asymptotic covariance matrices that correspond to the slopes in models (ignoring the constant terms) (Greene, 2003) The null hypothesis that the errors are uncorrelated is tested by comparing the test statistic generated by SAS to the chi-squared table.
} 


$$
\begin{aligned}
\ln \left(Q_{i j t}\right)-\ln \left(\vec{Q}_{i j}\right)= & \sum_{\bar{X}} \beta_{\bar{X}_{*}}\left(\ln \left(\vec{X}_{i j t}\right)-\ln \left(\overline{\vec{X}}_{i j}\right)+\right. \\
& \sum_{\bar{X}} \beta_{\vec{X}_{* *}}\left(\ln { }^{2}\left(\vec{X}_{i j t}\right)-\ln ^{2}\left(\overline{\vec{X}}_{i j}\right)\right)+ \\
& \sum_{\bar{X}} \beta_{\vec{X}_{* * *}}\left(\ln \left(\vec{X}_{i j t-1}\right)-\ln \left(\overline{\vec{X}}_{i j}\right)+\right. \\
& \left(\varepsilon_{i j t}-\bar{\varepsilon}_{i j}\right)
\end{aligned}
$$

It is important to note that the fixed effects transformation removes the technology change term and intercept, $\ln (A)_{i j}+\delta t_{i j}$. Employing this transformation method

yields a coefficient estimate for the weather variables, $\vec{W}$, with fixed effects

removed. The new coefficients, $\beta{\overrightarrow{W^{*}}}$, can be interpreted as the change in output (Q) relative to a change in precipitation and/or temperature $\left(\frac{\partial Q}{\partial W}\right)$.

\section{4b The Two-way Fixed Effects Model}

Fixed effects represent the structural differences between cross-sections at each time interval. In other words, FE, or expected differences in the intercept, are due to known geographic, structural, and/or resource constraints between states. Using the first differencing technique described above is one way to address FE. Another technique, the two-way fixed effects method, is the preferred transformation in order to address these known differences. If found to be present in the model, fixed effects should be removed in order to make the data stationary and inference about the variables in question possible. Many statistical programming packages, including SAS, are able to remove two way fixed effects with a single command. The algorithm used by SAS to compute and correct for fixed effects is presented below. In SAS, the specification for the two-way fixed effects model is:

$u_{i t}=v_{i}+e_{t}+\varepsilon_{i t}$ 
where $V_{i}$ and $e_{t}$ are nonrandom. When using SAS, if the user does not specify the NOINT option, which suppresses the intercept, the estimates for the fixed effects are reported under the restriction that $v_{N}=0$ and $e_{t}=0$.

However, if the user specifies the NOINT option to suppress the intercept, only the restriction $e_{t}=0$ is imposed.

Let $\mathrm{X}^{*}$ and $\mathrm{Q}^{*}$ be the independent and dependent variables arranged by time and by cross section within each time period. Let $M_{\mathrm{t}}$ be the number of cross sections observed in year t and let $\sum_{\mathrm{t}} M_{\mathrm{t}}=M$.

Let $\mathrm{Dt}$ be the $\mathrm{Mt} \times \mathrm{N}$ matrix obtained from the $\mathrm{N} \times \mathrm{N}$ identity matrix from which rows corresponding to cross sections not observed at time thave been omitted.

Consider:

$\mathrm{Z}=\left(\mathrm{Z}_{1}, \mathrm{Z}_{2}\right)$

where $Z_{1}=\left(D^{\prime} 1, D^{\prime} 2, \ldots \ldots D^{\prime} T\right)^{\prime}$ and $Z_{2}=\operatorname{diag}(D 1 j N, D 2 j N, \ldots \ldots$ DTjN $)$. The matrix $\mathrm{Z}$ gives the dummy variable structure for the two-way model.

Let:

$$
\begin{aligned}
& \Delta_{N}=Z_{1}^{\prime} Z_{1}, \\
& \Delta_{\mathrm{T}}=Z_{2}^{\prime} Z_{2}, \\
& A=Z_{2}^{\prime} Z_{1}, \\
& Q=\Delta_{\mathrm{T}}-A \Delta_{N}{ }^{-1} A^{\prime}, \\
& P=\left(I_{M}-Z_{1} \Delta_{N}{ }^{-1} Z_{1}^{\prime}\right)-\bar{Z} Q-Z^{\prime}
\end{aligned}
$$

The estimators for the intercept and the fixed effects are given by the usual OLS expressions. The estimate of the regression slope coefficients is given by: 
$\tilde{\beta}_{*}=\left(X_{*}^{\prime} P X_{*}\right)^{-1} X_{*}^{\prime} P y_{*}$

where $X_{*}$ is the $X_{*}$ matrix without the vector of $1 \mathrm{~s}$.

The estimator of the error variance is:

$\hat{\sigma}_{\varepsilon}^{2}=\frac{\tilde{u}^{\prime} P \tilde{u}}{(M-T-N+1-(K-1))}$

where the residuals are given by:

$\tilde{u}=\left(I_{M}-\frac{j_{M} j_{M}^{\prime}}{M}\right)\left(y_{*}-X_{*} \beta_{*}\right)$

if there is an intercept in the model and by:

$\tilde{u}=y_{*}-X_{*} \beta_{*}$

if there is no intercept. (SAS Institute, 2005)

Occasionally, panel data sets have random components that better explain model variation than traditional fixed effects like state or region. If tests like the standard F-test indicated the need to address random effects, those corrections can be made using a similar model transformation available in SAS.

\section{4c Mixed Estimation(correcting for AR(1) and fixed state effects)}

There are other corrections for modeled error terms that exhibit symptoms of heteroskedasticity (i.e. errors varying with states/regions) and auto-correlation (i.e. errors attributed to time). A lucrative test, the Parks Estimator (Parks, 1966), allows researchers to correct for errors that have an $\mathrm{AR}(1)$ process (i.e. errors attributed to a one year time trend), are contemporaneously correlated, and are heteroskedastic across panels. 
Unfortunately, SAS was unable to solve the Parks model because of the unbalanced nature of the panel data. Also, weather observations at or near zero caused the optimization to fail when the inverse of a matrix was taken.

A model that corrects for two of the three error correcting elements of the Parks Estimator is proposed. A mixed model was programmed that is able to address the model's perceived state-level heteroskedasticity and a one year time trend modeled as an AR(1) process. As will be shown in Chapter 8, this mixed model is considered the best linear unbiased estimate (BLUE) of weather and other factors of production.

\subsection{Other Tests (Autocorrelation)}

Models built with annual time-series panel data can be expected to have autocorrelation issues (e.g. errors/residuals related to year). The presence of autocorrelation can be tested and models can be built to correct for this momentum in the error term. One common test is the classic Durbin-Watson (DW) test for autocorrelation.

\section{5a Durbin-Watson Test (DW)}

A standard DW test conducted indicates that the model exhibits signs of autocorrelation spanning about four years. In other words, the model is exhibiting signs of annual momentum that goes back a few years. As with many other economic models, autocorrelation is expected and does not lead to biased estimates. Figure 5.3 is a needle plot showing the degree of autocorrelation in this panel dataset. 


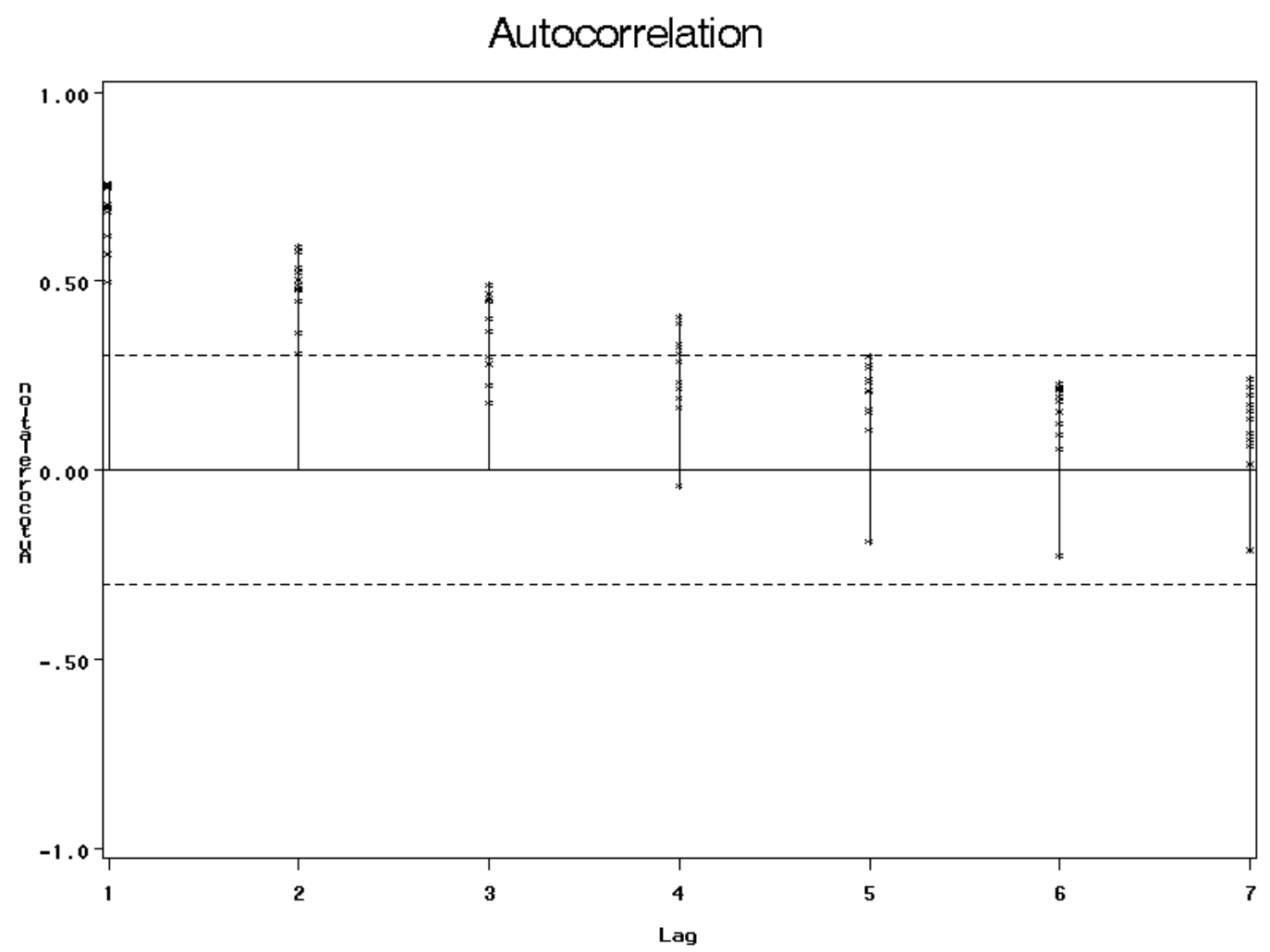

Figure 5.3. Degree of Autocorrelation (i.e. model becomes time stationary when corrected for four years of momentum in the error term).

\subsection{Comments on Serial Correlation}

The mixed model presented in Chapter 8 corrects for a one year time process (e.g. AR(1)). As mentioned earlier, time-series related errors are expected at the annual level and a one-year correction should be a sufficient transformation to infer economic sensitivities to weather. 


\subsection{Functional Form Selection}

The final functional form used in this modeling effort was selected based on a number of objective criteria including: 1) iterative F-tests, 2) the Akaike Information Criteria (AIC) measure, and 3) adjusted $\mathrm{R}^{2}$ values with (and without) many of the different input parameter combinations identified in previous sections. ${ }^{14}$ Figure 5.4 (below) lists the final model functional form based on this objective selection method that will be used to evaluate the sensitivity of the economy to weather variability.

Model Functional Form Selected to Evaluate Sensitivity of U.S. Economic Sectors to Weather

\section{Dependent Variable:}

Annual Output (Q)

$\begin{array}{ll}\text { Annual Capital (KAP), } & \mathrm{KAP}^{2}, \mathrm{E}^{2}, \mathrm{~L}^{2}, \\ \text { Annual Energy Consumption (E), } & \mathrm{KAP} \times \mathrm{E}, \mathrm{KAP} \times \mathrm{L}, \text { etc., } \\ \text { Annual Labor (L), } & \mathrm{HDD}^{2}, \mathrm{CDD}^{2} \text {, etc., } \\ \text { Annual Heating Degree Days (HDD), } & \mathrm{HDD} \times \mathrm{P} \text { TTL, CDD x P_STD, } \\ \text { Annual Cooling Degree Days (CDD), } & \mathrm{YEAR} \text {, and } \\ \text { Annual Total Precipitation (P_TTL), } & \text { Regional Dummies } \\ \text { Monthly Precipitation Deviation (P_STD), }\end{array}$

Figure 5.4. Functional Form Selected to Evaluate Sensitivity of U.S. Economic Sectors to Weather

\footnotetext{
${ }^{14}$ Although three competing models are presented in Appendix A, the functional form described in Figure 5.4 (i.e. Model III) is the model used in the Monte-Carlo simulation that allowed us to rank the sensitivity of different economic sectors (and regions) to weather. In addition, the AIC and adjusted R2 estimates, which were used as part of the model selection criteria, are presented in Appendix A.
} 


\section{CHAPTER 6}

\section{SOURCES, SUMMARY, AND TRANSFORMATION OF DATA}

Preparing this panel data for analysis was no simple undertaking. Government agencies ranging from the Department of Energy (DOE) to the Bureau of Economic Analysis (BEA) provided information in varying formats and incompatible units. The challenge of creating a panel dataset is to ensure that there is sufficient annual data to cover economic business cycles that occur every 7-8 years.

To minimize differences between states attributed to population and size, each input/output variable is transformed into applicable units including dollars per capita (based on annual population), inches per square mile (based on state area), or number of laborers per 100,000 citizens. The following list of variables, and their source, is used to model the sensitivity of sectors to weather.

\subsection{Data Sources}

Gross State Product $(\boldsymbol{Q})$

The dependent variable, Q, is gross state product for the years 1977 through 2001. This data, collected from the U.S. Bureau of Economic Analysis (BEA), is disaggregated by eleven major industrial sectors and includes observations for all 50 states. According to the BEA, an industry's GSP, or its value added, is equal to its gross output (sales or receipts and other operating income, commodity taxes, and inventory change) minus its intermediate inputs (consumption of goods and services

purchased from other U.S. industries or imported). The GSP accounts provide data by industry and state that are consistent with gross domestic product (GDP) in the national income and product accounts, and with the GDP by industry accounts. 
Real GSP is reported in millions of year 2000 dollars. (BEA, 2005a). The supersectors specifically modeled in this paper include:

1. Agriculture

2. Wholesale Trade

3. Retail Trade

4. Transportation

5. Utilities

6. Communications

7. Manufacturing

8. Services

9. Mining

10. Construction

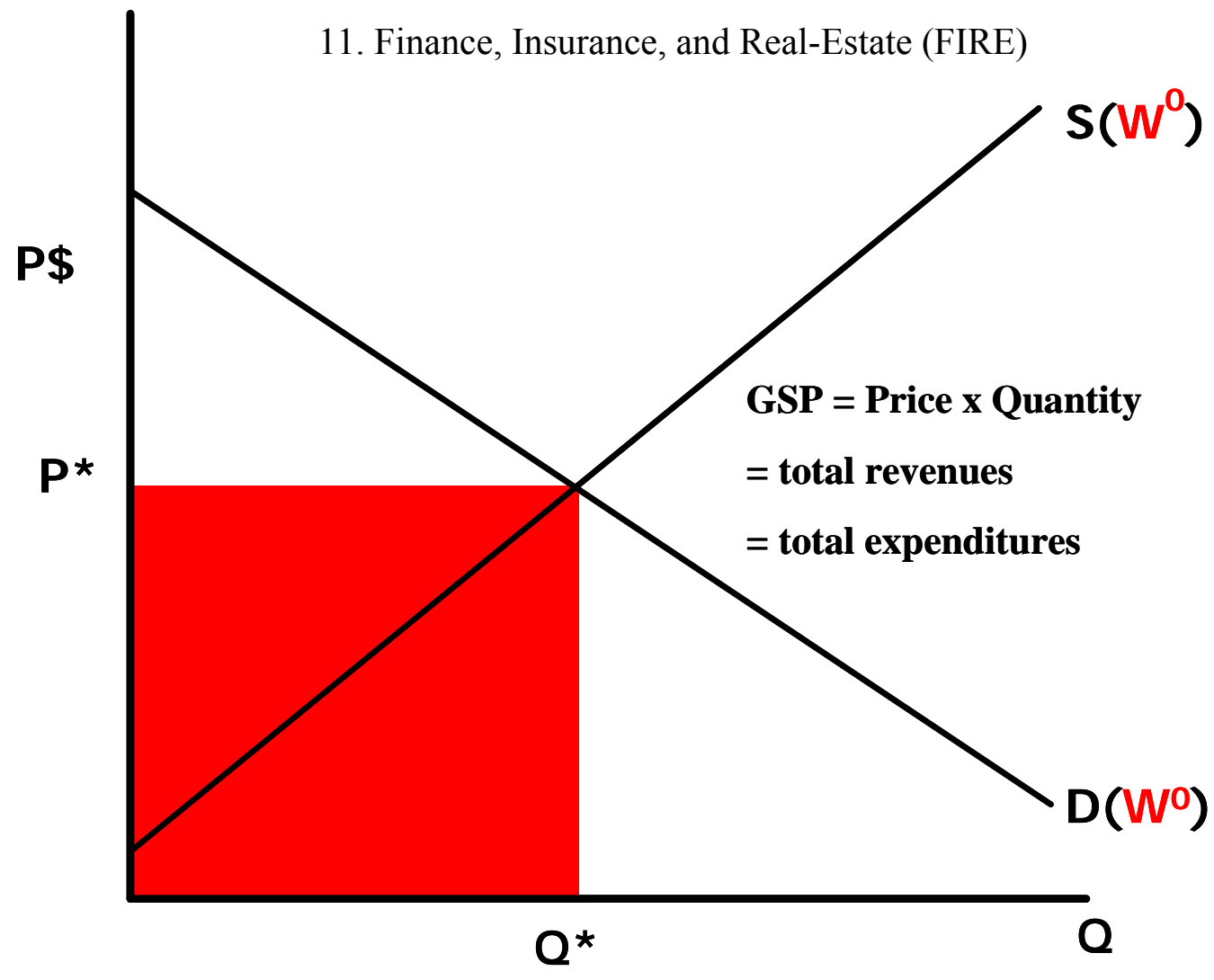

Figure 6.1 Gross State Product (GSP) as a Measure of Economic Output 
Technical Trend $(\delta)$

This estimated independent variable is calculated by measuring the change in output (Q) per time period. This variable is based on changes in gross state product with units of measure being millions of 2000 dollars.

\section{Labor $(\boldsymbol{L})$}

The independent variable for labor, $\mathrm{L}$, is sector specific employment data attained from the U.S. Department of Labor's Bureau of Labor Statistics (BLS) and includes statewide data from 1967 to 2003 in thousands of non-farm employees per month. Farm employment in total number of workers is reported by the REIS database. (BLS, 2005) (BEA, 2005c)

\section{Capital (KAP)}

Private and public capital, KAP, is represented by adding the:

1) BEA's net stock of private fixed assets by industry database.

This independent input is aggregated to the national level and contains observations from 1977 to 2003 . Nominal estimates in billions of U.S. dollars are reported as well as a chained (i.e. real) capital index with base year 2000. (BEA, 2005b)

$\underline{\text { and }}$

2) BEA's report of GSP for the government sector. This independent input is reported at the state level and contains observations from 1977 to 2003. Nominal estimates in billions of U.S. dollars are reported as well as a chained (i.e. real) capital index with base year 2000. (BEA, 2005a) 
Energy Resources $(\boldsymbol{E})$

Energy consumption is reported in quadrillion BTUs per sector per state collected

from the U.S. Department of Energy's Energy Information Administration (EIA) from 1960 through 1999. Energy consumption for super-sectors not reported by the EIA was estimated using disaggregation techniques originally developed by the author.

Weather $(\vec{W})$

$\vec{W}$ represents a vector of weather variables: precipitation totals, standard deviation of precipitation, heating degree-days (HDD), and cooling degree days (CDD). Area weighted annual precipitation totals/variance divided by state area (square miles), HDD, and CDD make up the weather factor inputs. Temperature proxies: HDD \& CDD and precipitation data was supplied by NOAA's National Climatic Data Center for the years 1970 to 2000. Additional weather variables under consideration include using the NOAA annual storm events database in addition to state-level annual wind data. Unfortunately, state-level storm data collection techniques structurally changed in the early 1990 s with new categories for classifying storms. This observable structural change in the collection technique prevented this research effort from including number of storms (including hurricanes) as a factor to production along with the other weather measures.

\subsection{Summary Statistics of Raw Data}

This section contains summary statistics of the core input/output variables used in this model. Figure 6.2is a histogram of the dependent variable, Q, with a normal distribution line overlaid and summary statistics inset. 


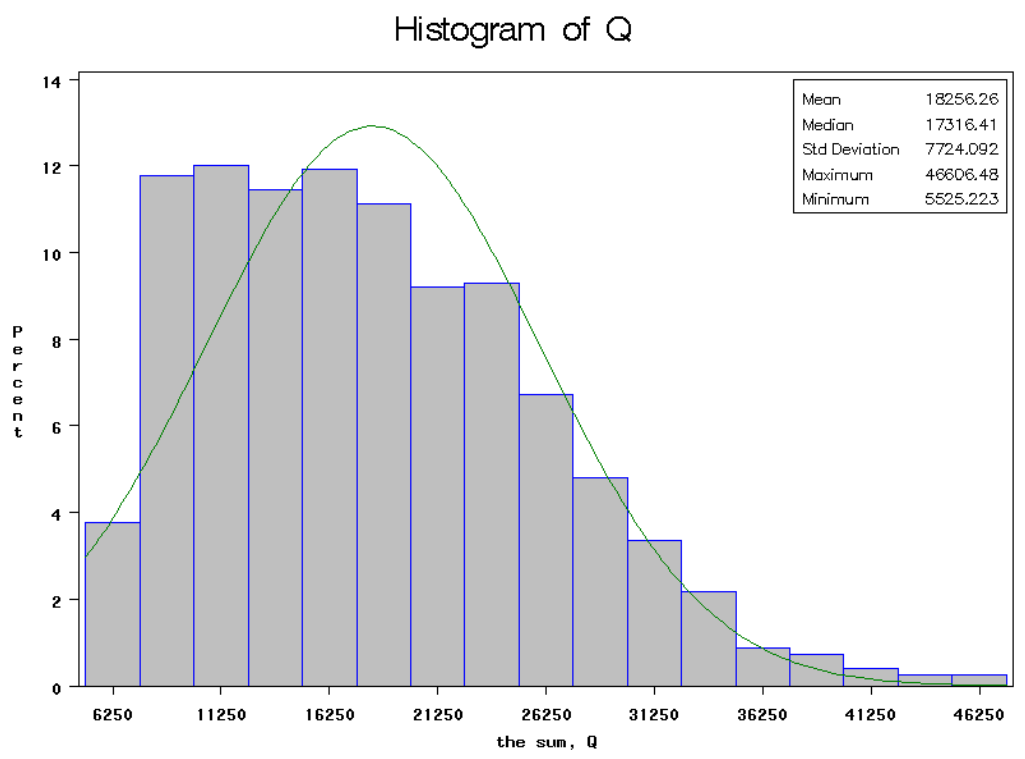

Figure 6.2 Histogram and Summary Statistics of Q (Gross Sector Product)

Figure 6.3 is a histogram of the independent variable, L, with a normal distribution line overlaid and summary statistics inset.

Histogram of $L$

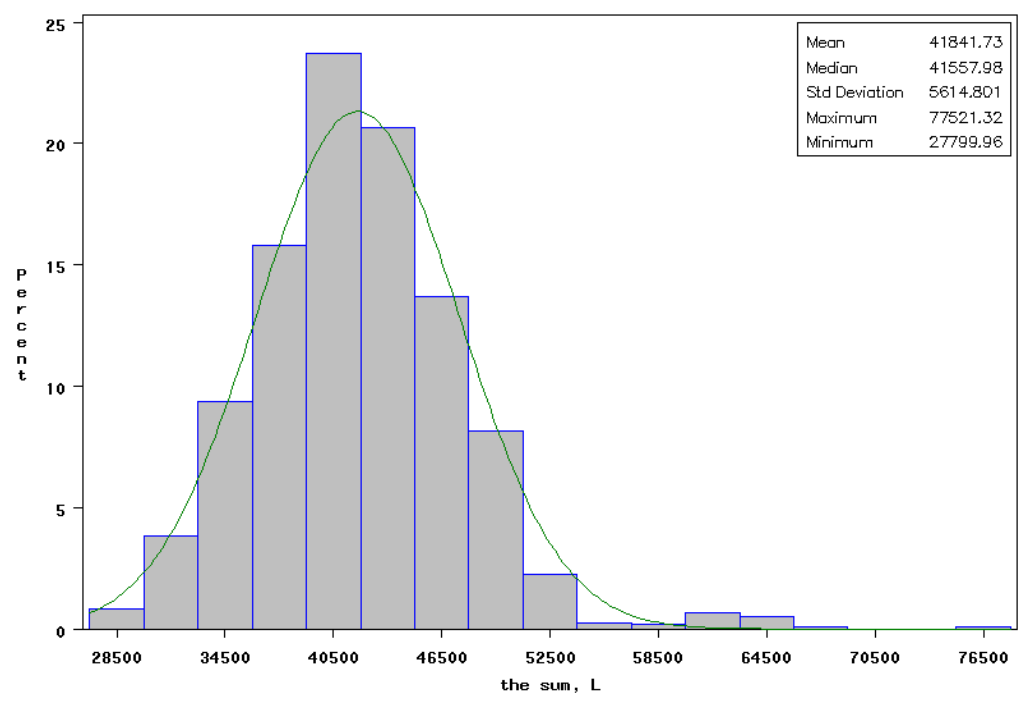

Figure 6.3 Histogram and Summary Statistics of Labor (workers per 100,000 citizens)

Figure 6.4 is a histogram of the independent variable, KAP, with a normal distribution line overlaid and summary statistics inset. 


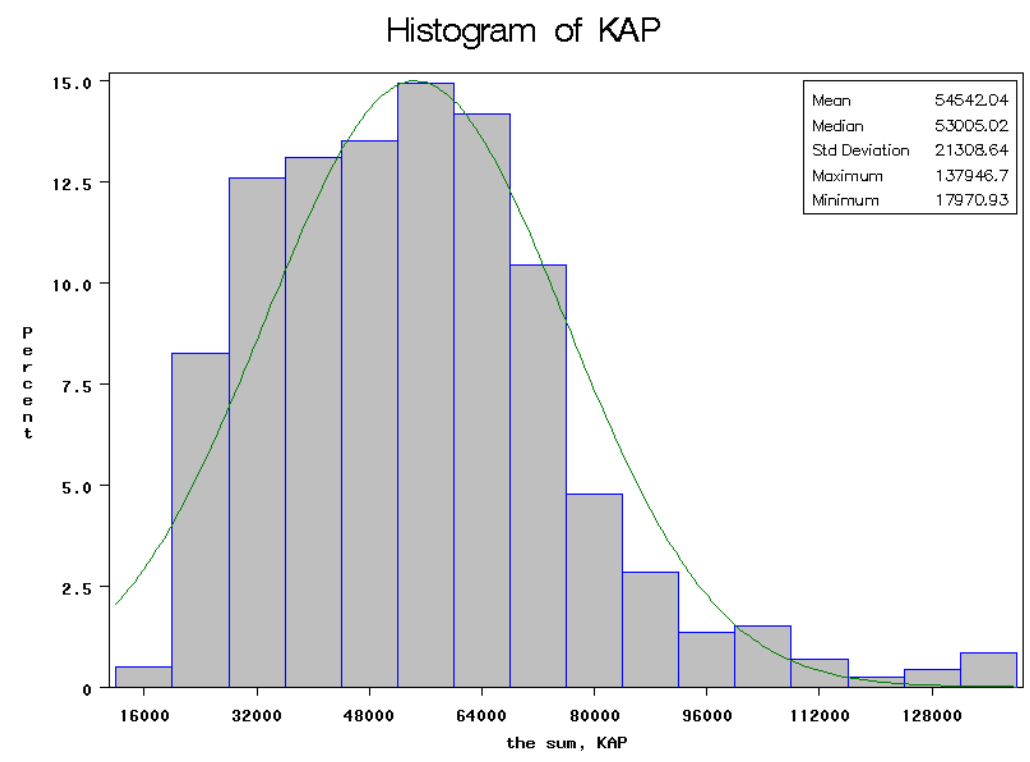

Figure 6.4 Histogram and Summary Statistics of Capital (\$2000)

Figure 6.5 is a histogram of the independent variable, E, with a normal distribution line overlaid and summary statistics inset.

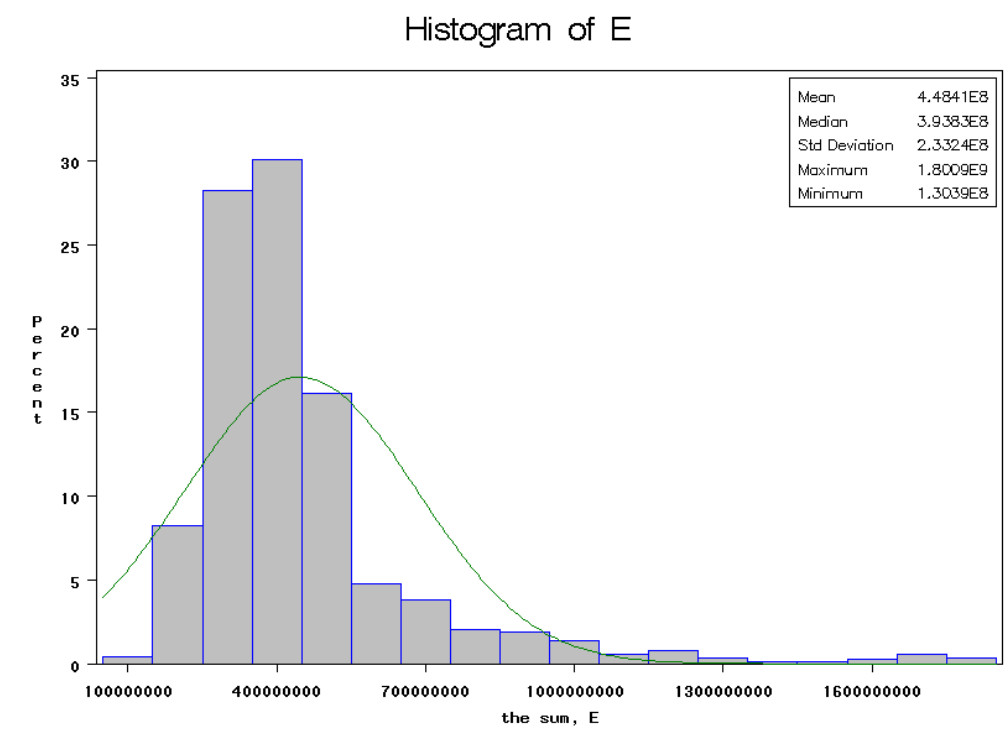

Figure 6.5 Histogram and Summary Statistics of HDD 
Figures 6.6 and 6.7 are histograms of the independent weather variables, HDD and $\mathrm{CDD}$, with a normal distribution line overlaid and summary statistics inset.

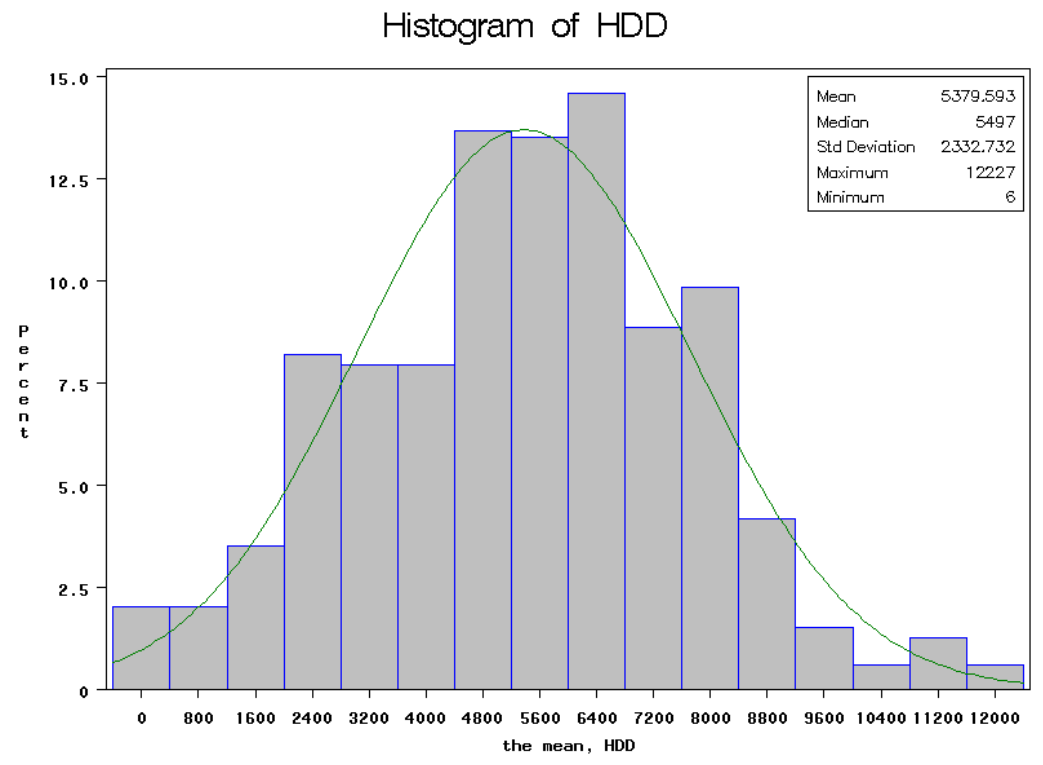

Figure 6.6 Histogram and Summary Statistics of HDD

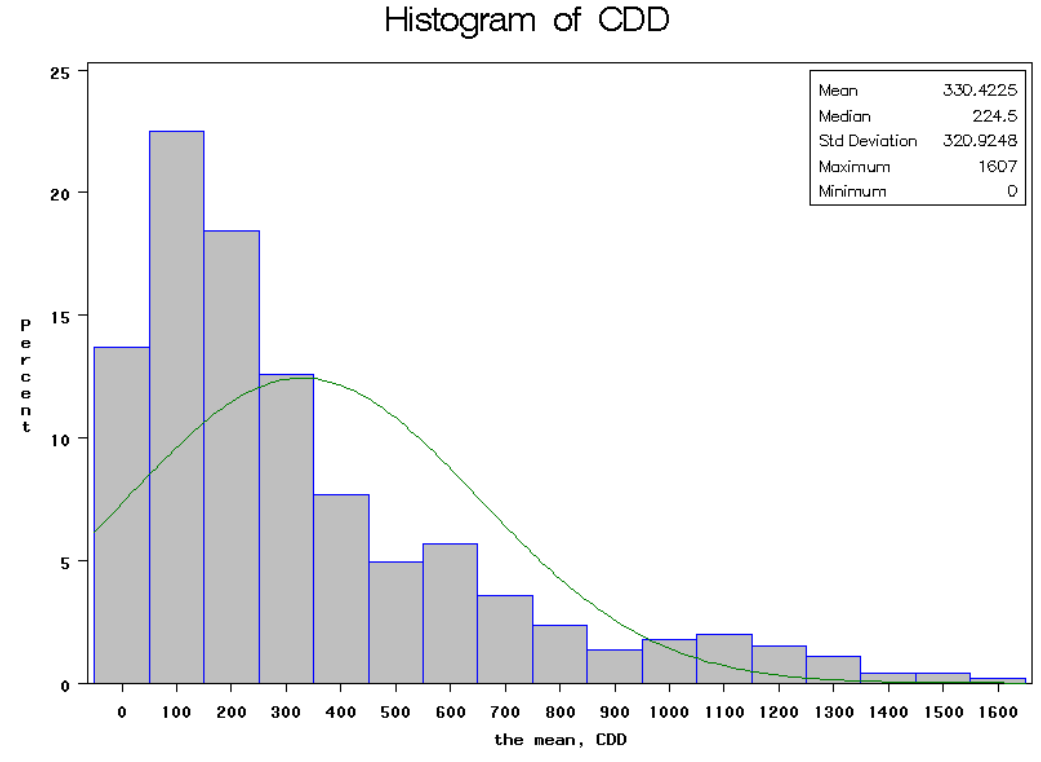

Figure 6.7 Histogram and Summary Statistics of CDD

Figures 6.8 and 6.9 are histograms of the independent weather variables, P_TTL and P_STD with a normal distribution line overlaid and summary statistics inset. 
Histogram of P_TTL

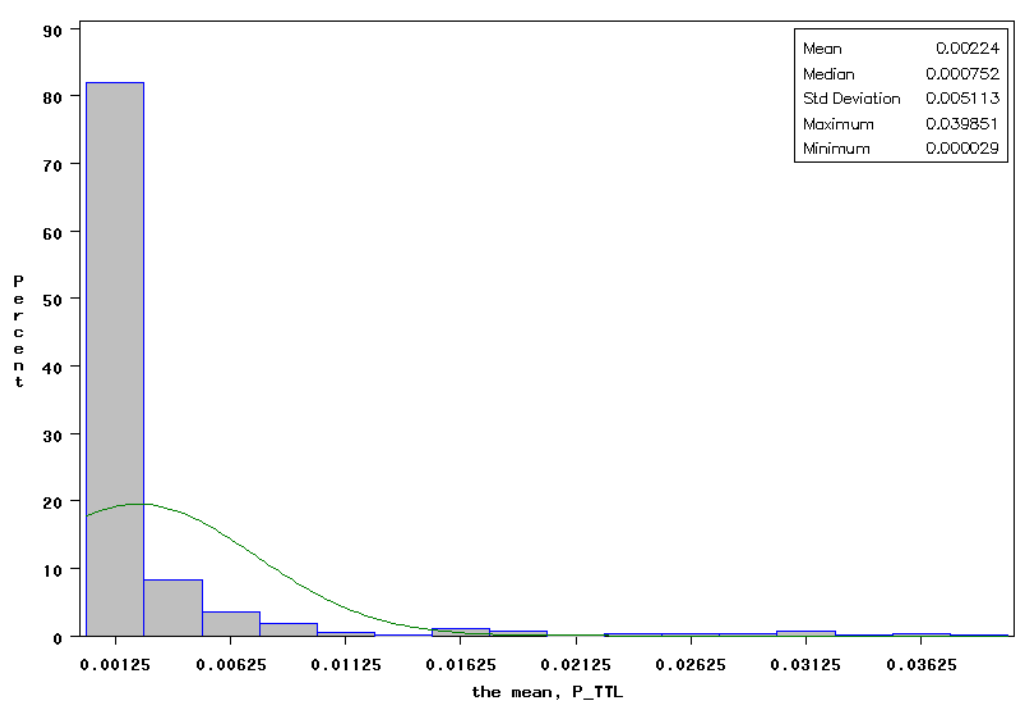

Figure 6.8 Histogram and Summary Statistics of P_TTL (inches/sq. mile of area)

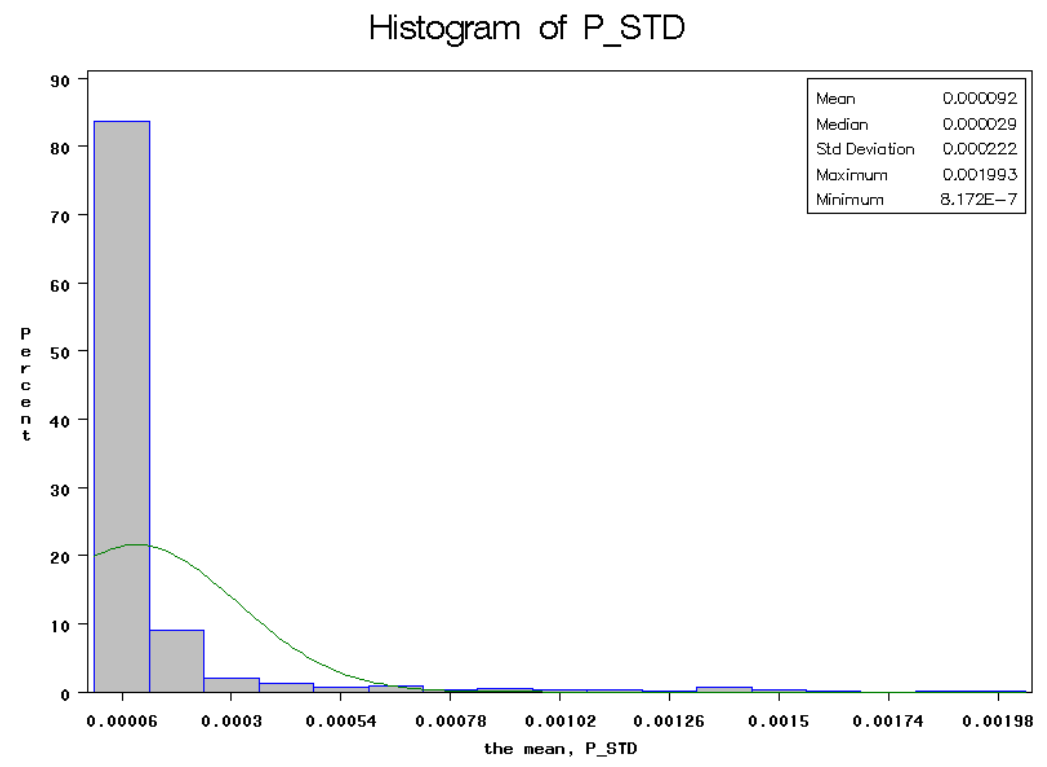

Figure 6.9 Histogram and Summary Statistics of P_STD (inches/sq. mile)

\subsection{Converting Raw Data to Appropriate Units}

To minimize state effects the raw data was transformed to dollars per capita (or where applicable inches/square mile). Data was also converted from nominal to 2004 
real dollars using standard government reported consumer price indices when applicable.

\subsection{Transforming Data using Natural Logs}

There are three reasons why transforming the model variables using logarithms makes sense:

1) Normality: Although many of the model inputs are already normally distributed, some variables including the weather inputs are not. Many statistical techniques, including those described in this paper, work best with data that are normally distributed.

2) Homoscedasticity: When comparing different groups of subjects (e.g. states, etc.), many techniques work best when the variability is roughly the same within each group.

3) Linearity: It is easier to describe the relationship between variables when the relationship is approximately linear.

When these conditions are not true in the original data, they can often be achieved by applying a logarithmic transformation to the inputs.

\subsection{Correlation of Independent Variables and Correct Model Specification}

Multi-collinearity (MC), the co-linear movement of two or more independent variables, does not bias the parameter estimates of the input variables. However, improper model specification in the form of including too many related variables, may cause variables to be reported as insignificant when they are indeed significant (by themselves). In this case, the estimates are said to be unbiased but the model may not be the BLUE. Table 6.1 contains the correlation coefficients, a number between -1 and 1 , that show the degree of multi-collinearity across independent variables. 
Table 6.1 Correlation Coefficients of Independent Variables.

\begin{tabular}{|c|c|c|c|c|c|c|c|c|}
\hline SECTOR & VARLABIES & LN KAP & LN L & LNE & LN HDD & LN_CDD & LN P STD & LN P TII \\
\hline Acrioulare & LN KAP & 1000 & 0.403 & 0.419 & -0.099 & -0.083 & -0.230 & .0206 \\
\hline Agroultuas & $\mathrm{LN}_{2} \mathrm{~L}$ & 0.403 & 1000 & 0.116 & 0.103 & -0.037 & -0.433 & $-0.4 \pi$ \\
\hline Aprovalture & LNE & 0.419 & 0.116 & 1000 & 0.415 & -0.288 & -0.426 & -0.420 \\
\hline Acrioulture & LN_HDD & .0009 & 0.103 & 0.415 & 1000 & -0.056 & -0.211 & -0.198 \\
\hline Acrialtous & $\mathrm{L} \mathrm{H}_{-} \mathrm{CDD}$ & .0003 & .0037 & -0.268 & -0.556 & 10 & 0.122 & 0.109 \\
\hline Asroultous & $L_{3}, P_{3}$ TD & -0230 & -0.433 & -0.426 & -0211 & 0.122 & 1000 & 0.975 \\
\hline A prioultan & LN P TTL & .0 .266 & .0 .473 & -0.420 & -0.198 & 0.109 & 0975 & 1000 \\
\hline Wholesse Trah & LN_K & 1000 & 0.227 & 0.458 & -0.132 & .0068 & $-0.07 n$ & -0.072 \\
\hline Wholescle Trube & $\mathrm{LB}_{2} \mathrm{~L}$ & 0.227 & 1000 & 0.115 & 0.105 & 0.019 & 0.062 & 0.017 \\
\hline Wholesule Trubt & LN_E & 0.458 & 0115 & 1000 & 0.415 & -0.288 & -0.426 & -0.420 \\
\hline Wholessle Trah & LN JPDD & -0.132 & 0.105 & 0.415 & 1000 & -0556 & -0.211 & -0.198 \\
\hline Wholessle Truse & LN_CDD & .0068 & 0.019 & -0.288 & -0556 & 1,000 & 0.122 & 0.109 \\
\hline Wholessle Trube & L.N_PSTD & $.00 n$ & 0.062 & -0.426 & -0.211 & 0.122 & 1000 & 0.975 \\
\hline Wholusis Trub & LNP.TIL & -0.072 & 0017 & -0.420 & -0198 & 0.109 & 0975 & 1.000 \\
\hline Batuil Trube & LN_XAP & 1000 & 0.701 & 0.442 & -0.154 & .0083 & $-0.07 n$ & -0.031 \\
\hline Ratail Trube & LN_L & 0.201 & 1000 & 0.221 & -0.101 & .0128 & 0.095 & 0.069 \\
\hline Ratual Trabe & LNy $x$ & 0.442 & 0.221 & 1000 & 0.415 & .0258 & -0.426 & -0.420 \\
\hline Satual Trubs & LA HDD & .0 .154 & -0.101 & 0.415 & 1000 & -0.556 & -0.211 & -0.198 \\
\hline Patul Trude & LN_CDD & -0.083 & -0.128 & -0.283 & -0.556 & 1000 & 0.122 & 0.109 \\
\hline Patail Trube & L.N_P STD & $0.0 \mathrm{~m}$ & 0.005 & -0.426 & -0.211 & 0.122 & 1000 & 0.975 \\
\hline Ratuil Trose & LNP.TTL & .0071 & 0.069 & -0.420 & -0198 & 0.109 & 0975 & 1.000 \\
\hline HRE & LH XUP & 1000 & 0.725 & 0391 & -0124 & -0.045 & 0.000 & 0.061 \\
\hline FRE & $L_{2} L$ & 0.725 & 1000 & 0.206 & -0.205 & -0.094 & 0.151 & 0.121 \\
\hline FRE & LN_E & 0.391 & 0.206 & 1000 & 0.415 & .0288 & -0.426 & .0 .420 \\
\hline FRE & LN_HDD & -0.124 & -0.2005 & 0.415 & 1000 & -0.556 & -0.211 & -0.198 \\
\hline FRE & $\mathrm{LH}_{-} C D D$ & -0.045 & -0004 & -0.288 & -0.556 & 1000 & 0.122 & 0.109 \\
\hline FRE & LN_P STD & 0.060 & 0.151 & .0 .426 & -0.211 & 0.122 & 1000 & 0.975 \\
\hline FRE & LN P TTL & 0.061 & 0.121 & .04200 & .0 .198 & 0.109 & 0975 & 1000 \\
\hline Comminizations & LNKAP & 1.000 & 0.479 & 0.463 & -0.159 & .0078 & -0.101 & .0 .091 \\
\hline Commmineationts & LN_L & 0.479 & 1000 & 0.160 & -0.191 & -0.038 & -0.114 & -0.110 \\
\hline Commanizations & LN_E & 0.463 & 0.160 & 1000 & 0.415 & -0.288 & -0.426 & -0.420 \\
\hline Communications & L__HDD & .0 .159 & -0.191 & 0.415 & 1.000 & .0556 & -0.211 & -0.198 \\
\hline Commmications & LN_CDD & .0078 & .0038 & -0.288 & .0556 & 1.000 & 0.122 & 0.109 \\
\hline Commmiestions & L.N_PSTD & -0.101 & -0.114 & -0.426 & -0.211 & 0.122 & 1000 & 0975 \\
\hline Commaniestians & LIP.TTL & -0.091 & -0.110 & -0.420 & -0.198 & 0.109 & 09975 & 1.000 \\
\hline Utilitives & LN KAP & 1000 & 0563 & 0.265 & -0.051 & -0.005 & -0.106 & -0.094 \\
\hline Utilities & $L N \perp$ & 0363 & 1000 & 0.440 & 0.122 & .0052 & -0.164 & -0.161 \\
\hline Utilitiot & $\mathrm{LN}_{2} \mathrm{E}$ & 0.265 & 0.440 & 1000 & 0.094 & 0.060 & -0.424 & -0.419 \\
\hline Utilition & LH HDD & -0.051 & 0129 & 0.094 & 1.000 & -0556 & -0.211 & -0.198 \\
\hline Dtilities & LN_CDD & .0095 & -0.052 & 0060 & -0.556 & 1000 & 0.122 & 0.109 \\
\hline Utilities & LX_PSTD & .0 .106 & .0 .164 & -0.424 & -0.211 & 0.122 & 1000 & 0975 \\
\hline Utilitss: & LSP TIL & .0 .094 & -0.161 & -0.419 & -0198 & 0.109 & 0975 & 1.000 \\
\hline Trarupertation & LN JAP & 1.000 & 0419 & 0.417 & -0.154 & -0.082 & -0.258 & -0.250 \\
\hline Trauportation & $\mathrm{LN}_{2} \mathrm{~L}$ & 0.419 & 1000 & 0.291 & -0.081 & -0.013 & -0.294 & -0.292 \\
\hline Truesportation & LN_E & 0.417 & 0.291 & 1000 & -0.164 & -0.024 & -0.486 & -0.489 \\
\hline Traupostation & $L N_{\alpha} H D D$ & -0.154 & .0001 & -0.164 & 1000 & -0.556 & -0.211 & -0.198 \\
\hline Trauportation & LN_CDD & .0 .002 & -0.013 & -0.024 & -0556 & 1.000 & 0.122 & 0.109 \\
\hline Trauportation & LN_P STD & .0 .258 & .0 .294 & -0.486 & -0211 & 0.122 & 1000 & 0.975 \\
\hline Trutuportation & LAP.TTL & .0 .250 & .0282 & -0.459 & .0198 & 0.109 & 0975 & 1.000 \\
\hline Manifktaring & LN_KAP & 1000 & 0343 & -0.123 & 0.045 & .0005 & 0.246 & 0.278 \\
\hline Mamifaterive & LN_L & 0.343 & 1000 & -0.193 & 0.284 & 0.008 & 0.440 & 0.471 \\
\hline Mamfocterive & LN_ $z$ & 0.123 & -0.193 & 1000 & 0.120 & .0061 & -0.400 & -0360 \\
\hline Mamfoctering & LN_HDD & 0.046 & 0.284 & 0.120 & 1.000 & -0.556 & -0.211 & -0198 \\
\hline Mumifotering & LA_CDD & -0.095 & 0.008 & -0.051 & -0556 & 1000 & 0.122 & 0.109 \\
\hline Munfovtaring & LNP PSTD & 0.246 & 0.440 & $-0,400$ & -0.211 & 0.122 & 1000 & 0.975 \\
\hline Mamfectorive & LN P.TTL & 0.278 & 0.471 & -0360 & -0.198 & 0.109 & 0975 & 1.000 \\
\hline Construation & LN_KAP & 1000 & 0.508 & 0.461 & 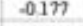 & -0.087 & -0.120 & -0.113 \\
\hline Constration & LN_L & 0508 & 1000 & 0.284 & -0.092 & -0.017 & -0.151 & -0152 \\
\hline Construstion & LN_E & 0.461 & 0.284 & 1000 & 0.415 & -0.288 & -0.426 & -0.420 \\
\hline Conutrustion & LX_HDD & .0 .17 & .0002 & 0.415 & 1.000 & -0.556 & -0.211 & -0.196 \\
\hline Conutruction & LN_CDD & .0008 & .0017 & .0288 & -0.556 & 1.000 & 0.122 & 0.109 \\
\hline Construetion & LN P STD & -0.120 & -0.151 & -0.426 & -0.211 & 0.122 & 1000 & 0.975 \\
\hline Conutruetion & LH P.TTL & -0.113 & -0.152 & $-0,420$ & -0.198 & 0.109 & 09975 & 1.000 \\
\hline Minive & LN_KAP & 1000 & 0.665 & 0.485 & -0.044 & -0.058 & -0.432 & -0.414 \\
\hline Mining & & 0.685 & 1000 & $0.59 n$ & 0.159 & 0.055 & -0.650 & -0.643 \\
\hline Mining & LNE & 0.485 & 0.597 & 1.000 & 0.120 & -0.061 & -0.400 & -0360 \\
\hline Mining & If $\mathrm{ADD}$ & -0.044 & 0.159 & 0.120 & 1000 & -0556 & -0.211 & -0.198 \\
\hline Minuse & C_CDD & .0 .058 & 0.055 & -0.061 & -0.556 & 1.000 & 0.122 & 0.109 \\
\hline Mining & , P STD & .0 .432 & .0650 & .0 .400 & .0211 & 0.122 & 1000 & 0975 \\
\hline Miring & P.TTL & -0.414 & .0643 & -0360 & -0.198 & 0.109 & 0975 & 1.000 \\
\hline Services & LNXKAP & 1.000 & 0.863 & 0.432 & -0.143 & -0.072 & -0.043 & -0.038 \\
\hline Services & & 363 & 1000 & 0.281 & -0.084 & .0 .091 & 0.100 & 0.085 \\
\hline Services & LN_E & 0.432 & 0.281 & 1000 & 0.415 & -0.288 & -0.426 & -0.420 \\
\hline Sempess & HDD & -0.143 & .0004 & 0.415 & 1000 & -0.556 & -0.211 & -0.198 \\
\hline Services & $\mathrm{CDD}$ & -0.072 & -0001 & -0.288 & -0.556 & 1000 & 0.122 & 0.109 \\
\hline Services & LN P STD & .0 .043 & 0.100 & -0426 & -0.211 & 0.122 & 1000 & 0973 \\
\hline Servicts & LNP TTL & $=0.039$ & 0.085 & -0.420 & -0.198 & 0.109 & 0975 & 1.000 \\
\hline
\end{tabular}


There is some degree of multi-collinearity between precipitation and the standard deviation in precipitation $(+0.975)$. However, both of these variables were included in the model because one or the other showed statistical significance according to sector. In addition, it is expected that the variation in rainfall increases with higher total amounts of precipitation. 


\section{CHAPTER 7}

\section{DISCUSSION OF MODEL RESULTS}

As with any rigorous modeling effort, certain caveats apply and should be discussed within the context of any relevant paper. It is important to address the removal of statistical outliers, detail the inter-annual wash-out business effect, and discuss some of the aggregation issues encountered in the development of this system of models.

\subsection{Wash-out effect}

Starr-McCluer (2000) use the term "wash out effect" to describe the statistical process by which weather-related losses in one quarter are made up in the following quarter by firms in the retail sector. In the process of building a panel data set of statelevel economic measures, some sacrifices had to be made. Given the robustness of the weather data available to NOAA/NCAR, it would have been ideal to have matching weekly, monthly, or even quarterly economic data.

Unfortunately, comprehensive (and consistent) economic measures like gross sector product are only reported at the annual level by the BEA. It is entirely plausible and even expected that businesses are able to recover weather-related losses by increasing output in subsequent weeks/months or quarters. Although it is not known to what extent, this inter-annual "wash out" effect probably represents a significant amount of sensitivity that is difficult to capture given the temporal dimension of the data. 


\subsection{Aggregation Issues}

As mentioned in the theoretical foundations of this paper, dummy variables were included in the model to capture regional variations in average weather. The marginal product of weather at the regional level can be aggregated to the national level based on actual sector economic output of the region versus the national output.

\subsection{Removing True Outliers (e.g. Alaska and Hawaii)}

\section{3a Cook’s Test}

Cook's test allows researchers to objectively identify outliers in the data. ${ }^{15}$ In this analysis, Alaska and Hawaii behave considerably different from the contiguous states in both weather and economic inputs.

\section{Historical State Output (GSP) per Capita}

Hawaii and Alaska vs. Contiguaus U.S. Average

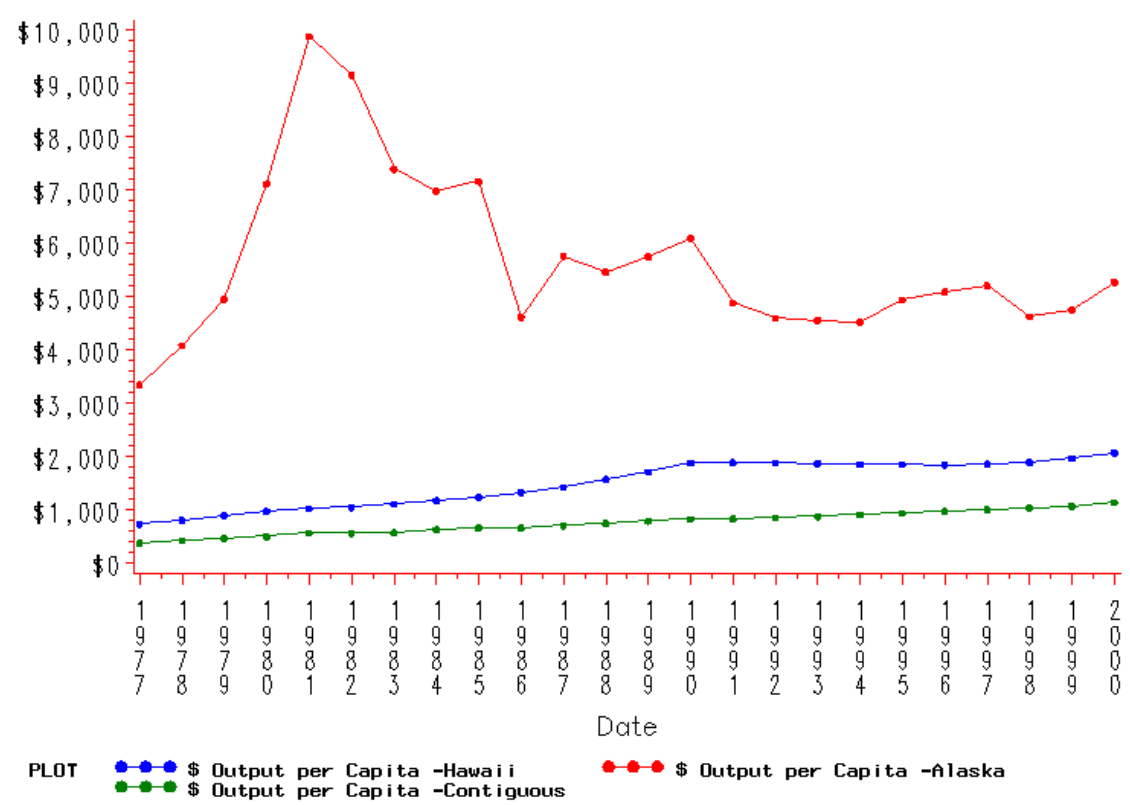

Figure 7.1 Identifying Outliers: Historical State Output per Capita

\footnotetext{
${ }^{15}$ Cook's test for distance is a statistic calculated by: 1) summing the squared differences between the estimated y-values (using all valid observations) and the estimated y-values (i.e. $y$ hats) deleting the $i^{\text {th }}$ observation (e.g. Alaska or Hawaii) and 2) normalizing this result by dividing by the estimated variance of the error term. Kennedy (2003) gives a rule of thumb suggesting a measure exceeding one suggests an influential observation.
} 
Accordingly, Alaska and Hawaii were removed prior to running the OLS regressions reported in the following section.

Modeling sector output against KAP, L, E, and W using the OLS technique described in Chapter 5 produce estimated coefficients that can be tested under various hypotheses about optimal model specification, presence of random/fixed effects, and constant returns to scale. In addition to presenting model fit statistics, simple calculus is performed on the estimated coefficients to attain sector output elasticities for all eight regions. Finally, a monte-carlo simulation is employed to rank the 88 regionalsector combinations ( 11 sectors by 8 regions) in an effort to quantify the relative weather sensitivity of each region-sector combination to one another. Figure 7.2 details annual growth rates of the 11 super-sectors estimated by the B.L.U.E. translog model.

\section{Annual Super-Sector Growth Rates}

O.L.S. Estimates from 1977-2000 Panel Dataset (i.e. coefficient of YEAR variable)

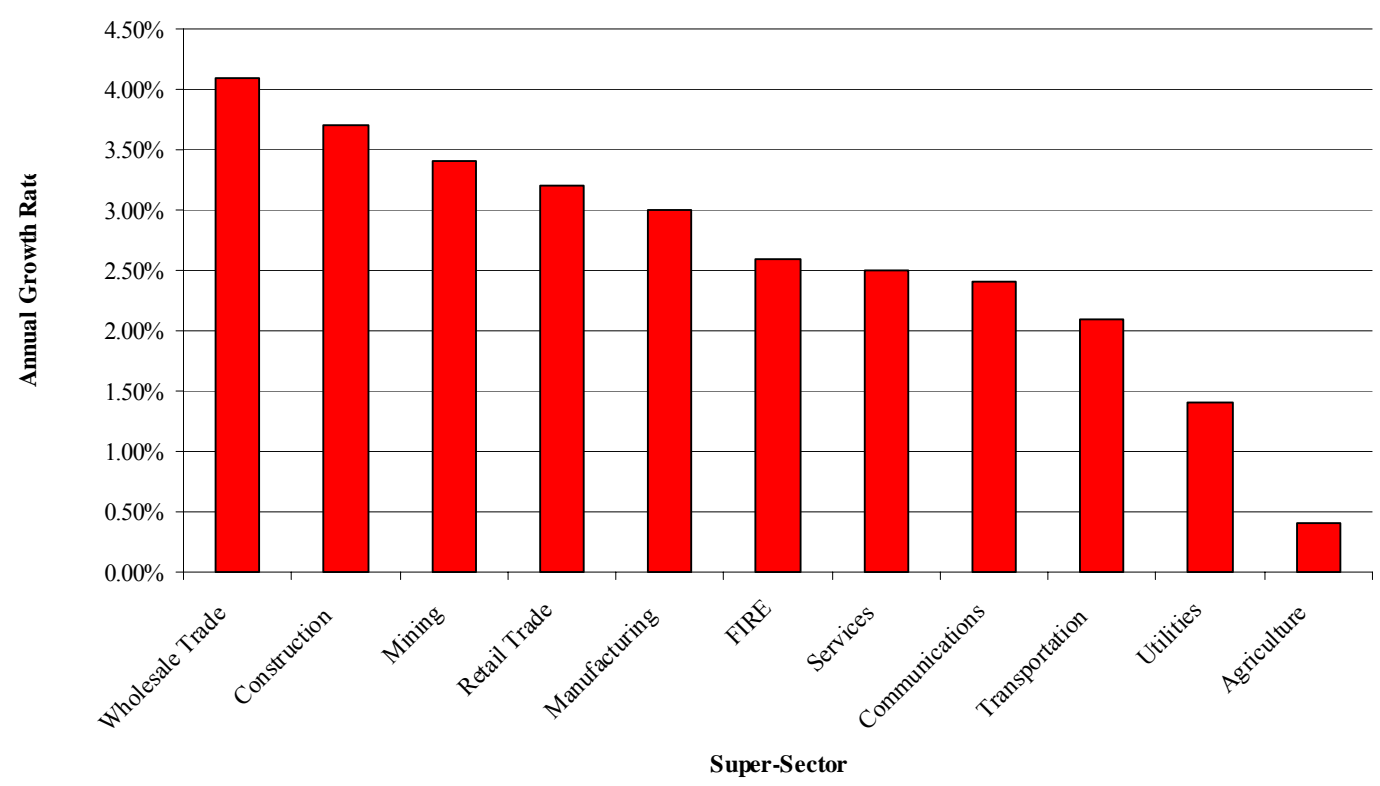

Figure 7.2 Annual Super-Sector Growth Rates 


\subsection{Hypothesis Test}

All F-tests indicate that weather variables should be included in the three models presented.

\subsection{Fit Statistics}

In general, the model fit was near unity with most sectors reporting an adjusted r-squared above $0.95 .^{16}$ In many cases, the inputs explain nearly all of the variation in this historical data. For more information, please see Appendix B which has fit statistics (pre-stationary and post-stationary) for variations of the translog model presented in this paper. Most importantly, statistical testing indicated that weather variables improve the fit of the model and should be included as independent variables. In all eleven sectors, one or more of the weather variables showed statistical significance at the $95 \%$ confidence level with many coefficients reporting 99\% confidence levels. Appendix A presents estimated coefficients for all of the variables and for all eleven supersectors.

Although the parameter estimates for weather represent the elasticity of economic output to weather, it is important to remember that a partial derivative must be taken on the entire model to properly interpret these estimates and their relationship to sector output. The following section is an interpretation of the model results in the logs. It is presented that a $1 \%$ percent change in weather yields a $\mathrm{X} \%$ change in sector economic output measured as GSP.

In addition to presenting estimated coefficients, Appendix A contains example output from the model (model fit over time by state, region, and U.S.) for the eleven sectors.

\footnotetext{
${ }^{16}$ Adjusted r-squared is a measure of model fit with 1.0 representing a perfect model fit while taking into account the number of variables in the regression.
} 


\subsection{Interpretation of Sector Results using Mixed Model}

Once the model's functional form has been solved using partial derivatives, the weather variables will be able to be interpreted correctly (see Chapter 4, Section 4). The marginal product of weather (or economic impact of weather) represents the partial derivative of all weather variables with respect to $\mathrm{Q}$ while incorporating the coefficients estimated in the Mixed Model regression. Taking the partial derivative of equation (5) yields the following function for the marginal product of HDD "in the $\operatorname{logs":}$

\section{Calculating the Elasticity of Heating Degree Days for New England's Services Sector}

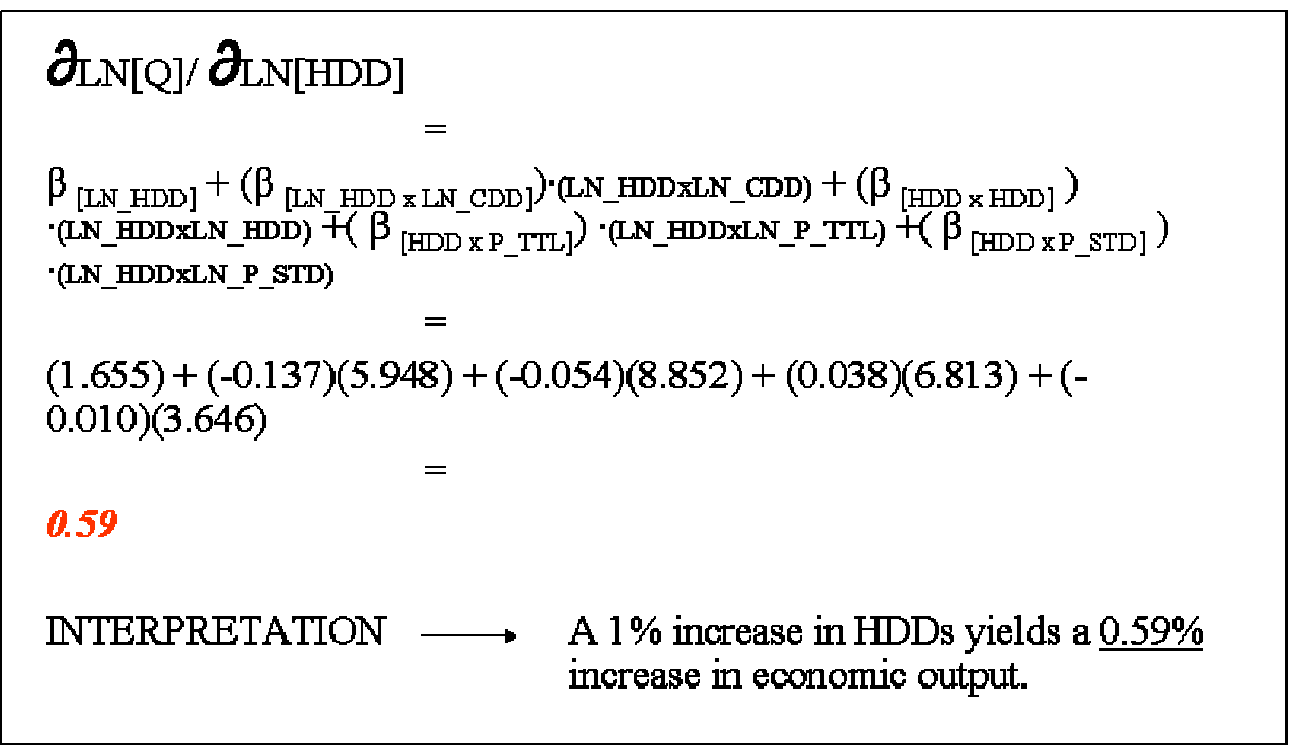

Inputting relevant parameter estimates, sector-specific values and regional averages of LN[HDD], etc. produces estimates of the economic sensitivity of sectors to weather "in the logs". Derivations were also made for the sensitivity of sectors to other weather variables including precipitation totals, cooling degree days, and precipitation variance. Tables 7.1-7.8 display preliminary results of this model detailing the sensitivity of eleven super-sectors to the four measures of weather by U.S. regions. 
This table could be used by policymakers to help identify optimal weather research opportunities at the region and sector levels.

\subsection{Sector Elasticities by Region using the Mixed Translog Model}

The model results detailed in the following tables show that some sector's output (e.g. mining) is relatively more elastic to various measures of weather than other sector outputs. The results also indicate that sector economic output is relatively more elastic to weather depending on the region. For example, the Southeast's region (including AL, AR, FL, GA, KY, LA, MS, and NC) mining sector output shows a $+2.11 \%$ elasticity to heating degree-days whereas the elasticity of the same sector output in the Southwest (AZ, NM, OK, TX) region is $+2.38 \%{ }^{17}$ It is realistic to conclude that abnormally cold weather in the Southwestern United States increases mining sector output as natural gas and other fossil fuels are extracted to meet increased home and commercial heating demand.

\section{Table 7.1 Output Elasticities (AL, AR, FL, GA, KY, LA, MS, NC)}

\begin{tabular}{lrrrr} 
& & & & \multicolumn{2}{l}{ Precip. } \\
Sector & HDD & \multicolumn{1}{l}{ CDD } & \multicolumn{1}{l}{ Precip. } & \multicolumn{1}{l}{ S.D. } \\
\hline Agriculture & $0.67 \%$ & $0.11 \%$ & $-0.19 \%$ & $0.08 \%$ \\
Wholesale Trade & $0.42 \%$ & $0.34 \%$ & $0.06 \%$ & $-0.04 \%$ \\
Retail Trade & $0.12 \%$ & $0.22 \%$ & $0.02 \%$ & $0.00 \%$ \\
FIRE & $0.04 \%$ & $0.35 \%$ & $-0.15 \%$ & $0.03 \%$ \\
Communications & $0.25 \%$ & $0.21 \%$ & $0.07 \%$ & $-0.10 \%$ \\
Utilities & $0.58 \%$ & $0.01 \%$ & $0.16 \%$ & $-0.12 \%$ \\
Transportation & $-0.34 \%$ & $-0.09 \%$ & $-0.02 \%$ & $-0.02 \%$ \\
Manufacturing & $-0.75 \%$ & $0.10 \%$ & $-0.04 \%$ & $0.03 \%$ \\
Construction & $0.03 \%$ & $0.36 \%$ & $-0.03 \%$ & $-0.02 \%$ \\
Mining & $2.11 \%$ & $1.52 \%$ & $-0.35 \%$ & $0.07 \%$ \\
Services & $0.36 \%$ & $0.44 \%$ & $0.05 \%$ & $-0.06 \%$
\end{tabular}

\footnotetext{
${ }^{17}$ In other words, if the number of heating degree-days increases by $1 \%$, economic output (i.e.
} gross product) of the sector would increase by $+2.38 \%$ for a sector with annual output exceeding $\$ 56$ billion. 
According to the model, the mining and manufacturing sectors in the Southeastern United States are relatively more elastic to weather than other super-sectors in this region. Specifically, manufacturing super-sector output is negatively affected by cooler than normal temperatures with the mining super-sector showing large increases in gross product with slight temperature changes in both directions.

\section{Converting Elasticities to Absolute Dollars}

Taking the partial derivative of equation (5) and accounting for the natural log terms yields the following function for the marginal product of HDD. $\mathrm{I}^{2}$ represents the estimated coefficient from the regression with the form:

$$
\begin{aligned}
& \frac{\partial Q}{\partial H D D}= \\
& \hat{\mathrm{I}}^{2}+\operatorname{GLAK} \hat{\mathrm{I}}^{2}+\hat{\mathrm{I}}^{2} \operatorname{MEST}+\hat{\mathrm{I}}^{2} \operatorname{NENG}+\hat{\mathrm{I}}^{2} \operatorname{PLNS}+\hat{\mathrm{I}}^{2} \mathrm{RKMT}+\hat{\mathrm{I}}^{2} \operatorname{SEST}+\frac{\mathbb{E}^{\log [\operatorname{CDD}] \log [\mathrm{HWD}]} \hat{\mathrm{I}}^{2} \log [\mathrm{CDD}]}{\mathrm{HDD}}+
\end{aligned}
$$

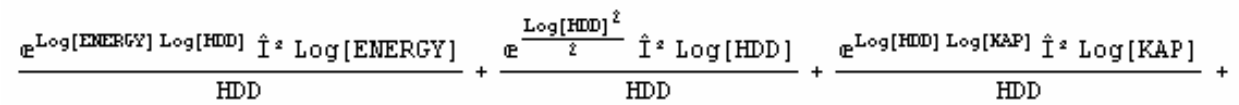

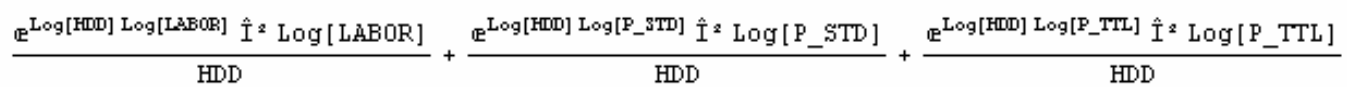




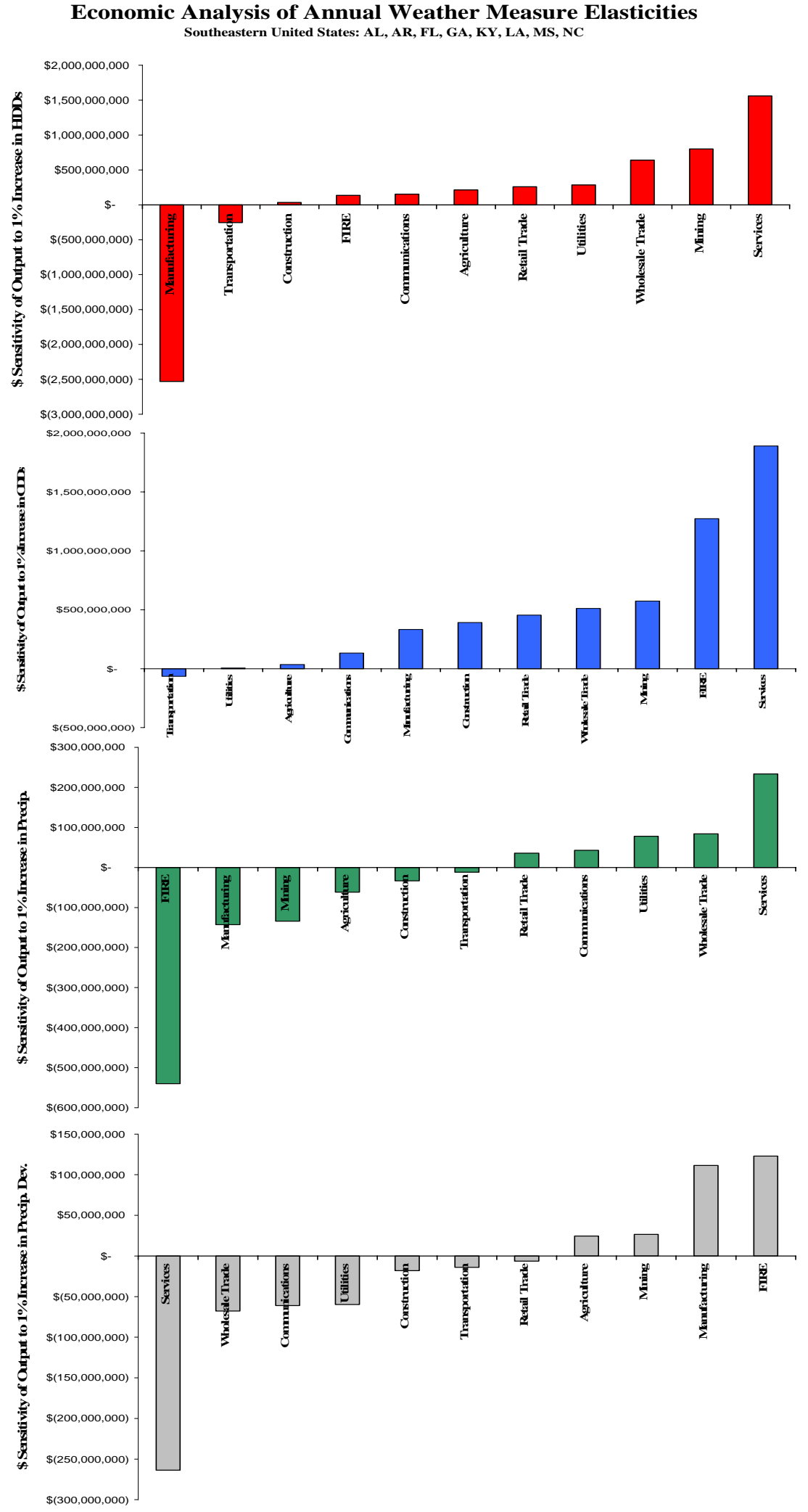

Figure 7.3 Sector Output Changes to Four Measures of Weather 
Inputting relevant parameter estimates to equation (11) above, including sectorspecific values of LN[ENERGY] and regional averages of LN[HDD], etc. produces estimates of the economic sensitivity of sectors to weather in absolute terms (i.e. dollars). Table 7.1 and Figure 7.3 present the elasticities in both relative and absolute terms for the Southeast region.

In the desert Southwest the Agriculture sector is relative more elastic to higher than average total precipitation with output dropping $-0.25 \%$ for every $1 \%$ increase in precipitation. Mining output increases significantly with warmer than average temperatures in this region of the country. Table 7.2 presents output elasticities for the Southwestern United States.

Table 7.2 Output Elasticities (AZ, NM, OK, TX)

\begin{tabular}{lrrrr} 
& & & \multicolumn{2}{l}{ Precip. } \\
Sector & HDD & CDD & Precip. & \multicolumn{1}{l}{ S.D. } \\
Agriculture & $0.72 \%$ & $0.13 \%$ & $-0.25 \%$ & $0.09 \%$ \\
Wholesale Trade & $0.29 \%$ & $0.27 \%$ & $0.07 \%$ & $-0.06 \%$ \\
Retail Trade & $0.00 \%$ & $0.22 \%$ & $0.02 \%$ & $0.00 \%$ \\
FIRE & $0.03 \%$ & $0.38 \%$ & $-0.21 \%$ & $0.06 \%$ \\
Communications & $0.09 \%$ & $0.17 \%$ & $0.08 \%$ & $-0.12 \%$ \\
Utilities & $0.59 \%$ & $0.07 \%$ & $0.17 \%$ & $-0.11 \%$ \\
Transportation & $-0.51 \%$ & $-0.12 \%$ & $-0.02 \%$ & $-0.02 \%$ \\
Manufacturing & $-0.83 \%$ & $0.08 \%$ & $-0.07 \%$ & $0.06 \%$ \\
Construction & $-0.09 \%$ & $0.36 \%$ & $-0.02 \%$ & $-0.04 \%$ \\
Mining & $2.38 \%$ & $1.48 \%$ & $-0.39 \%$ & $0.02 \%$ \\
Services & $0.29 \%$ & $0.48 \%$ & $0.07 \%$ & $-0.07 \%$
\end{tabular}

Figure 7.4 presents output elasticities in absolute terms for the Southwestern United States. In this region, gross product for the manufacturing super-sector drops significantly with cooler temperatures. Finance, insurance, and real estate (FIRE) sector product drops with increasing precipitation. 
Economic Analysis of Annual Weather Measure Elasticities Southwestern United States: AZ, NM, OK, TX
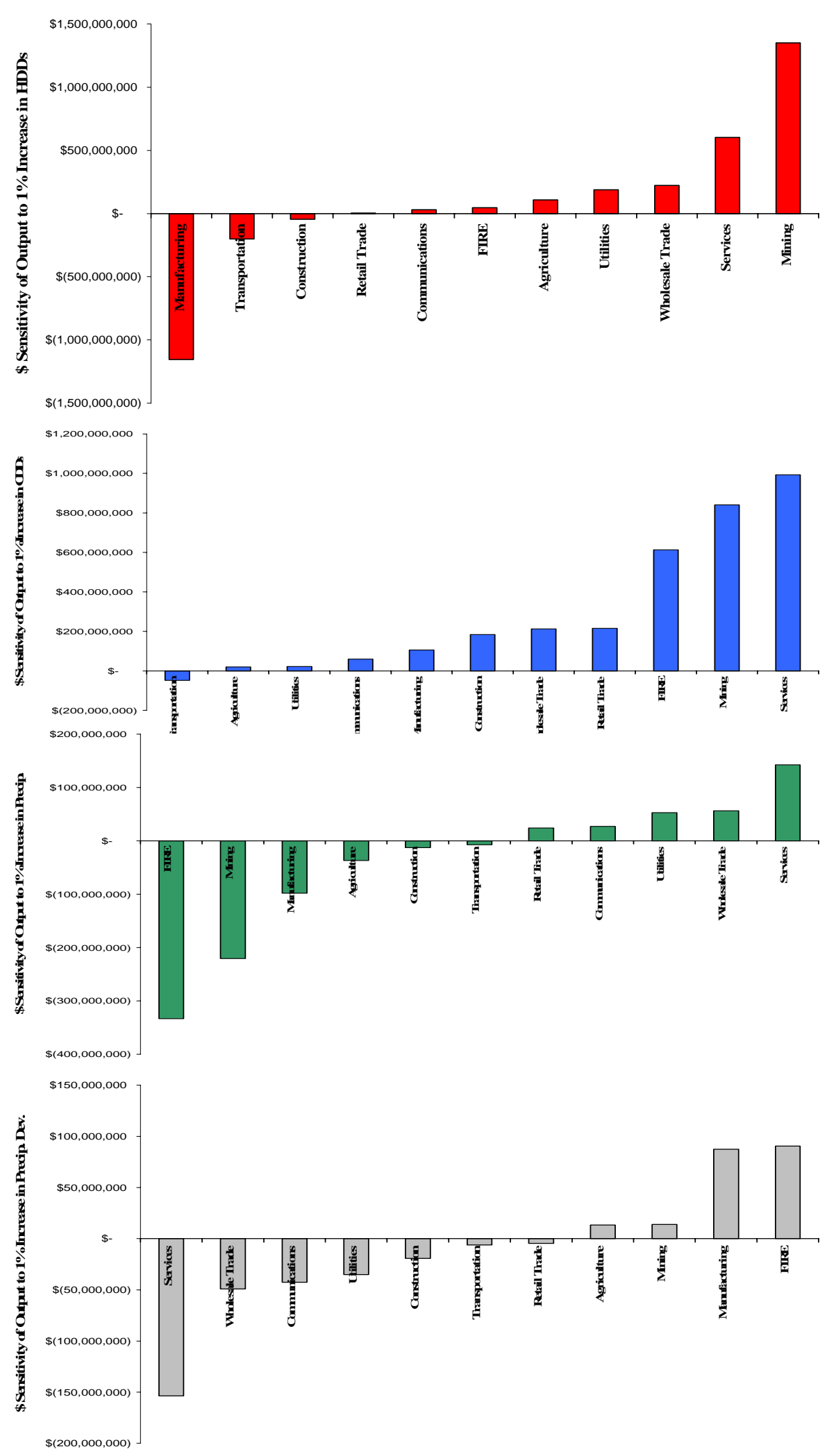

Figure 7.4 Sector Output Changes to Four Measures of Weather 
Table 7.3 and Figure 7.5 present the elasticities in both relative and absolute terms for the Far West region. Again, on absolute terms the manufacturing sector appears to impacted negatively with decreasing temperatures. Finance, insurance and real estate (FIRE) sector output is impacted negatively with higher than average precipitation in the Far Western region.

\section{Table 7.3 Output Elasticities (CA, NV, OR, WA)}

\begin{tabular}{lrrrr} 
Sector & HDD & CDD & Precip. & \multicolumn{2}{l}{ S.D. } \\
Agriculture & $0.72 \%$ & $0.07 \%$ & $-0.19 \%$ & $0.06 \%$ \\
Wholesale Trade & $0.44 \%$ & $0.30 \%$ & $0.08 \%$ & $-0.06 \%$ \\
Retail Trade & $0.17 \%$ & $0.20 \%$ & $0.05 \%$ & $-0.01 \%$ \\
FIRE & $0.11 \%$ & $0.33 \%$ & $-0.12 \%$ & $0.01 \%$ \\
Communications & $0.29 \%$ & $0.17 \%$ & $0.07 \%$ & $-0.08 \%$ \\
Utilities & $0.60 \%$ & $-0.02 \%$ & $0.15 \%$ & $-0.10 \%$ \\
Transportation & $-0.34 \%$ & $-0.07 \%$ & $0.01 \%$ & $-0.02 \%$ \\
Manufacturing & $-0.76 \%$ & $0.17 \%$ & $0.00 \%$ & $-0.01 \%$ \\
Construction & $0.06 \%$ & $0.35 \%$ & $-0.01 \%$ & $-0.01 \%$ \\
Mining & $2.14 \%$ & $1.38 \%$ & $-0.40 \%$ & $0.03 \%$ \\
Services & $0.41 \%$ & $0.42 \%$ & $0.08 \%$ & $-0.06 \%$
\end{tabular}


Economic Analysis of Annual Weather Measure Elasticities Western United States: CA, NV, OR, WA (Dummy Region)
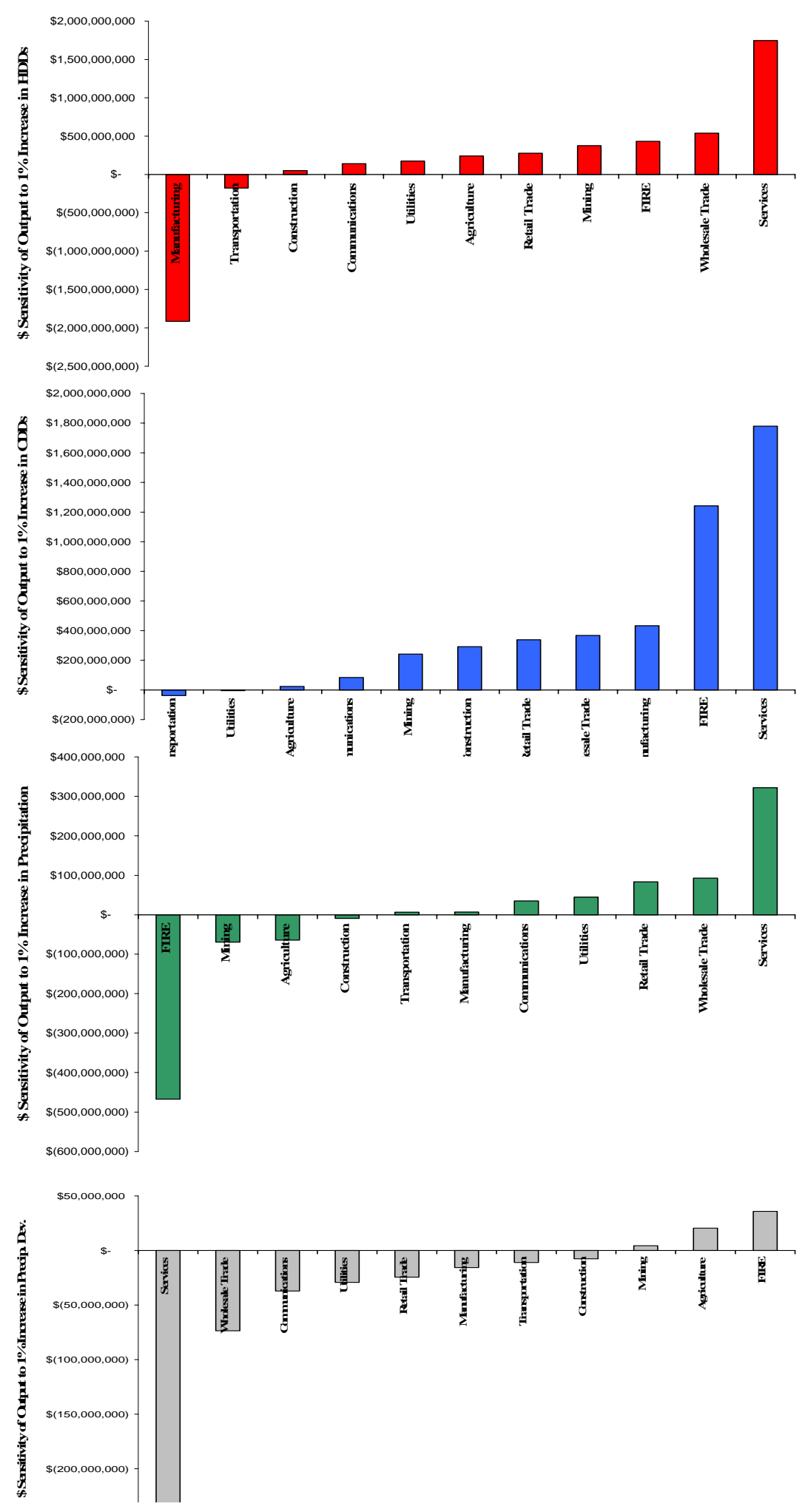

Figure 7.5 Sector Output Changes to Four Measures of Weather 
Table 7.4 and Figure 7.6 present the elasticities in both relative and absolute terms for the Rocky Mountain region. In absolute terms the manufacturing sector is impacted negatively with lower than average temperatures. However, output increases for the services sector. One significant component of the services sector for this region is winter tourism. It is plausible that cooler temperatures lead to increased tourism to mountainous places, like ski areas, where annual revenue depends heavily on reported mountain conditions (snowfall, temperature, etc.). Finance, insurance and real estate (FIRE) is impacted negatively with higher than average precipitation in the Rocky Mountain region.

\begin{tabular}{lrrrr} 
Table 7.4 Output Elasticities (CO, ID, MT, UT, WY) \\
Sector & HDD & \multicolumn{1}{c}{ CDD } & Precip. & \multicolumn{1}{l}{ Precip. } \\
Agriculture & $0.91 \%$ & $0.02 \%$ & $-0.23 \%$ & $0.03 \%$ \\
Wholesale Trade & $0.46 \%$ & $0.24 \%$ & $0.09 \%$ & $-0.09 \%$ \\
Retail Trade & $0.11 \%$ & $0.17 \%$ & $0.12 \%$ & $-0.05 \%$ \\
FIRE & $0.30 \%$ & $0.34 \%$ & $-0.14 \%$ & $-0.01 \%$ \\
Communications & $0.22 \%$ & $0.12 \%$ & $0.05 \%$ & $-0.05 \%$ \\
Utilities & $0.63 \%$ & $0.02 \%$ & $0.16 \%$ & $-0.04 \%$ \\
Transportation & $-0.59 \%$ & $-0.13 \%$ & $0.05 \%$ & $-0.03 \%$ \\
Manufacturing & $-0.94 \%$ & $0.18 \%$ & $0.07 \%$ & $-0.07 \%$ \\
Construction & $0.03 \%$ & $0.40 \%$ & $0.01 \%$ & $-0.01 \%$ \\
Mining & $3.19 \%$ & $1.51 \%$ & $-0.62 \%$ & $0.06 \%$ \\
Services & $0.47 \%$ & $0.49 \%$ & $0.13 \%$ & $-0.06 \%$
\end{tabular}


Economic Analysis of Annual Weather Measure Elasticities Rocky Mountain States : CO, ID, MT, UT, WY

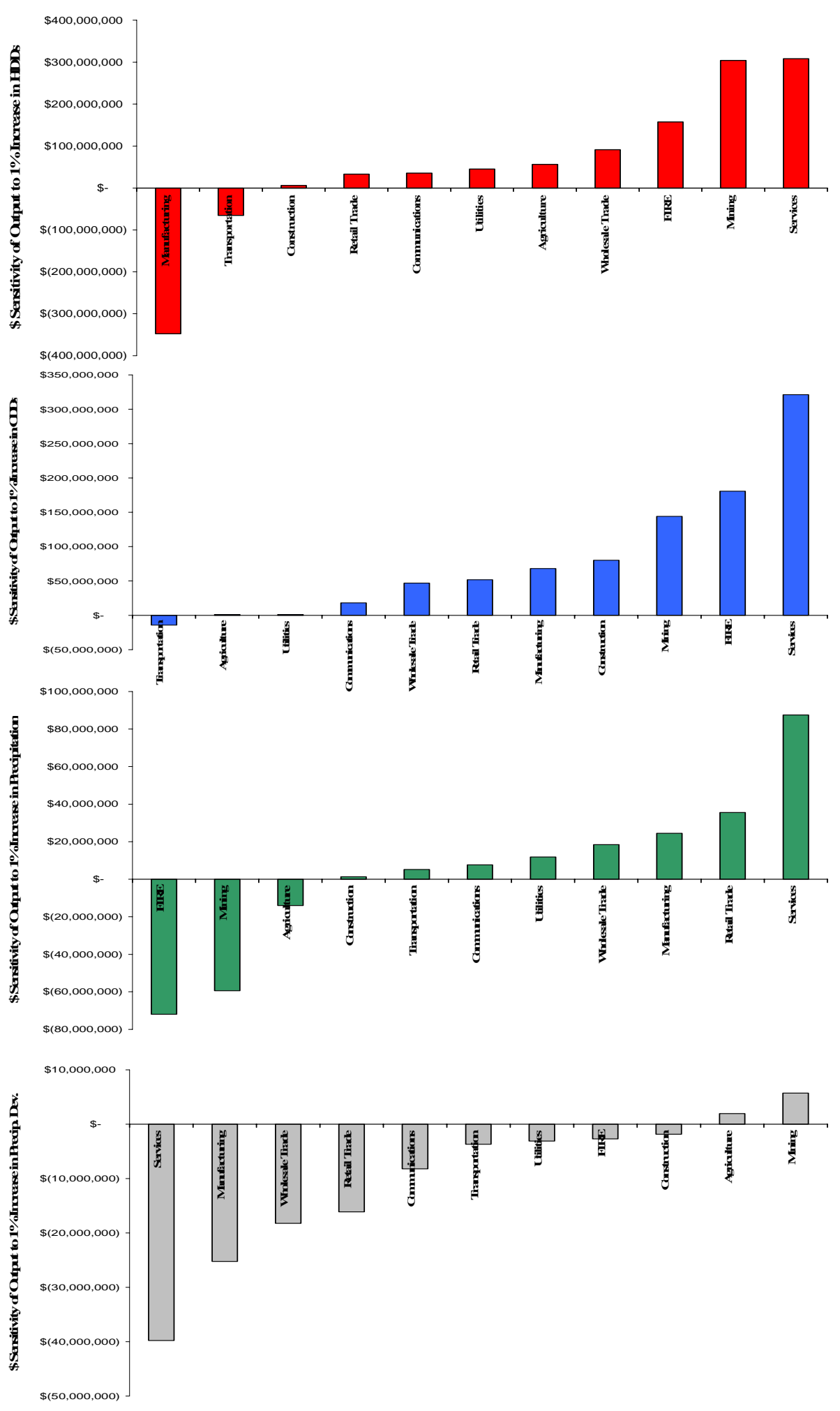

Figure 7.6 Sector Output Changes to Four Measures of Weather 
Table 7.5 and Figure 7.7 present the elasticities in both relative and absolute terms for the New England region. In absolute terms the manufacturing sector is impacted negatively with lower than average temperatures. However, output increases for three of the four measures of weather with the services sector. Although mining's relative elasticity for temperature is greater than $1 \%$, the total output of this sector in New England is negligible making the absolute amount affected by weather extremely small.

\begin{tabular}{|c|c|c|c|c|}
\hline Sector & HDD & CDD & Precip. & $\begin{array}{l}\text { Precip. } \\
\text { S.D. }\end{array}$ \\
\hline Agriculture & $0.76 \%$ & $0.02 \%$ & $-0.11 \%$ & $0.01 \%$ \\
\hline Wholesale Trade & $0.65 \%$ & $0.35 \%$ & $0.05 \%$ & $-0.04 \%$ \\
\hline Retail Trade & $0.38 \%$ & $0.20 \%$ & $0.08 \%$ & $-0.03 \%$ \\
\hline FIRE & $0.25 \%$ & $0.29 \%$ & $-0.01 \%$ & $-0.06 \%$ \\
\hline Communications & $0.55 \%$ & $0.18 \%$ & $0.04 \%$ & $0.00 \%$ \\
\hline Utilities & $0.63 \%$ & $-0.12 \%$ & $0.14 \%$ & $-0.09 \%$ \\
\hline Transportation & $-0.14 \%$ & $-0.02 \%$ & $0.04 \%$ & $-0.04 \%$ \\
\hline Manufacturing & $-0.69 \%$ & $0.30 \%$ & $0.10 \%$ & $-0.11 \%$ \\
\hline Construction & $0.25 \%$ & $0.36 \%$ & $-0.01 \%$ & $0.04 \%$ \\
\hline Mining & $1.91 \%$ & $1.32 \%$ & $-0.47 \%$ & $0.14 \%$ \\
\hline Services & $0.59 \%$ & $0.37 \%$ & $0.08 \%$ & $-0.03 \%$ \\
\hline
\end{tabular}


Economic Analysis of Annual Weather Measure Elasticities New England States : CT, ME, MA, NH, RI, VT

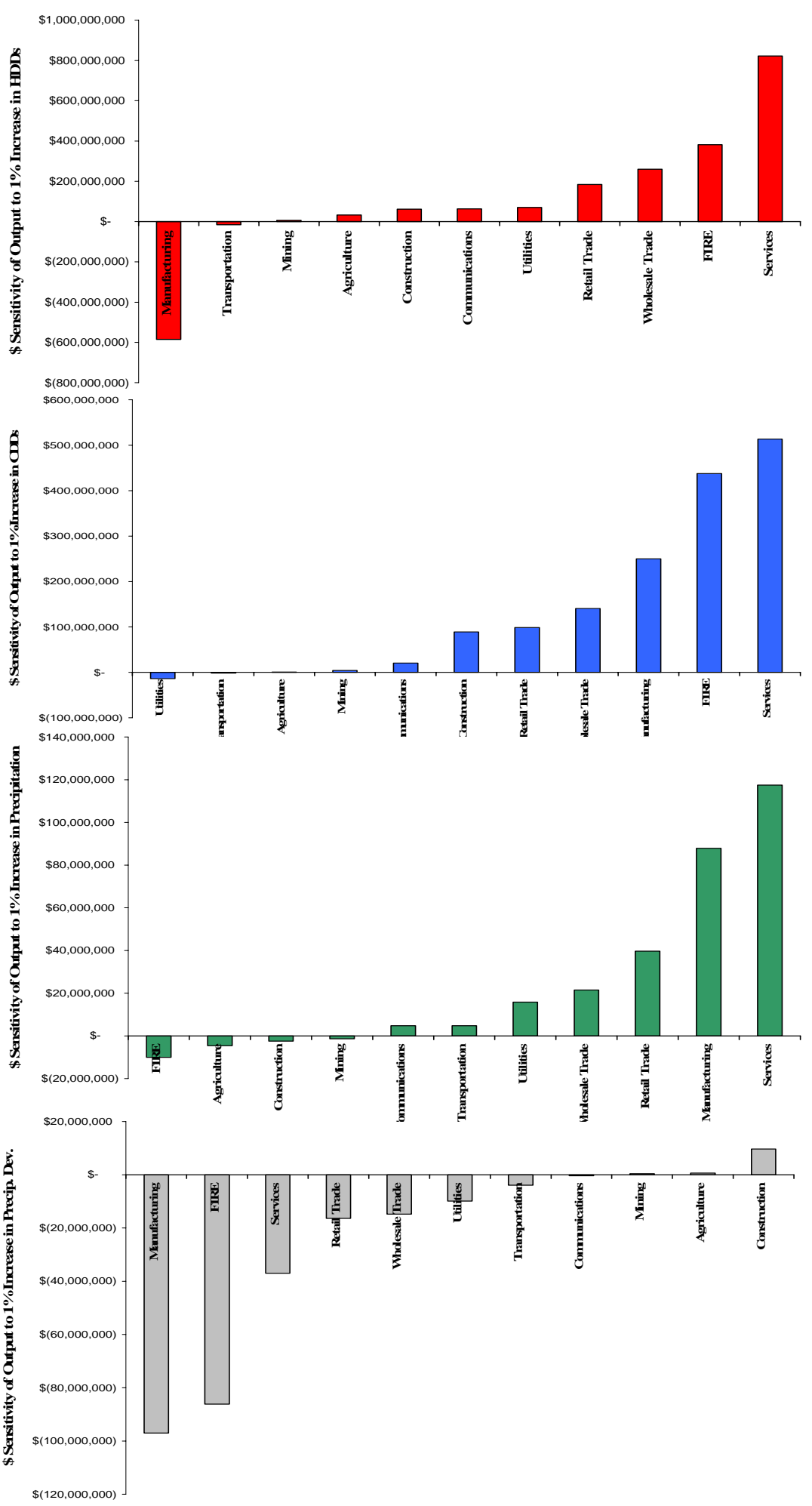

Figure 7.7 Sector Output Changes to Four Measures of Weather 
Table 7.6 and Figure 7.8 present the elasticities in both relative and absolute terms for the Middle-eastern region in the U.S. The manufacturing sector is impacted negatively (in both absolute and relative terms) with lower than average temperatures. However, similar to the other regions, output increases for the services sector.

\section{Table 7.6 Output Elasticities (DE, MD/DC, NJ, NY, PA)}

\begin{tabular}{lrrrr} 
Sector & HDD & CDD & Precip. & \multicolumn{2}{l}{ S.D. } \\
Agriculture & $0.67 \%$ & $0.04 \%$ & $-0.14 \%$ & $0.05 \%$ \\
Wholesale Trade & $0.56 \%$ & $0.34 \%$ & $0.07 \%$ & $-0.05 \%$ \\
Retail Trade & $0.29 \%$ & $0.20 \%$ & $0.05 \%$ & $-0.01 \%$ \\
FIRE & $0.13 \%$ & $0.28 \%$ & $-0.06 \%$ & $-0.02 \%$ \\
Communications & $0.44 \%$ & $0.19 \%$ & $0.07 \%$ & $-0.05 \%$ \\
Utilities & $0.59 \%$ & $-0.08 \%$ & $0.14 \%$ & $-0.10 \%$ \\
Transportation & $-0.17 \%$ & $-0.03 \%$ & $0.02 \%$ & $-0.02 \%$ \\
Manufacturing & $-0.67 \%$ & $0.22 \%$ & $0.04 \%$ & $-0.04 \%$ \\
Construction & $0.17 \%$ & $0.35 \%$ & $-0.01 \%$ & $0.01 \%$ \\
Mining & $1.80 \%$ & $1.33 \%$ & $-0.36 \%$ & $0.03 \%$ \\
Services & $0.48 \%$ & $0.37 \%$ & $0.07 \%$ & $-0.04 \%$
\end{tabular}


Economic Analysis of Annual Weather Measure Elasticities Middle-Eastern States : DE, MD/DC, NJ, NY, PA
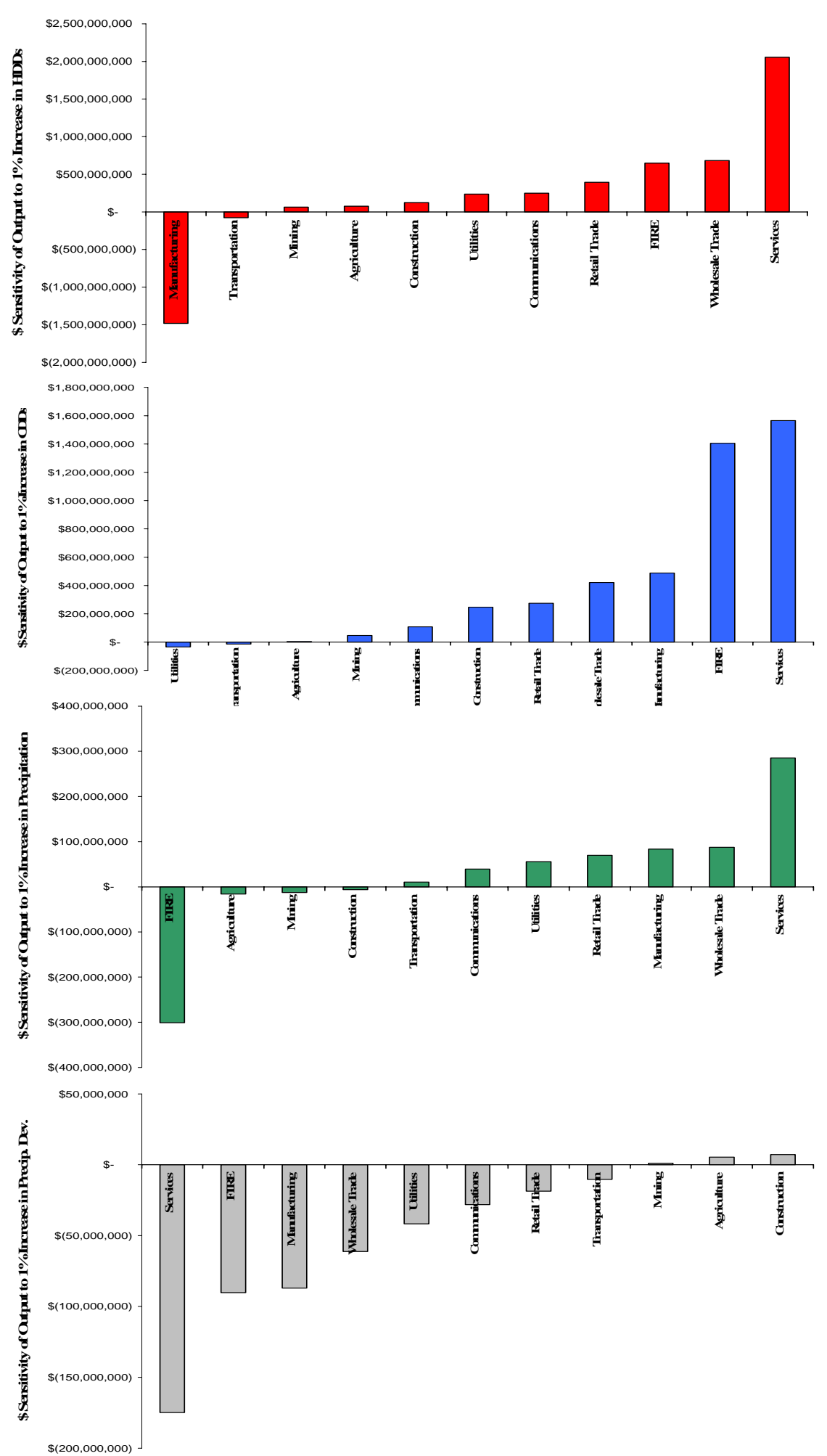

Figure 7.8 Sector Output Changes to Four Measures of Weather 
Table 7.7 and Figure 7.9 present the elasticities in both relative and absolute terms for the Great Plains region. In both absolute and relative terms the manufacturing sector is impacted negatively with lower than average temperatures. However, output increases for the services sector with lower temperatures, but decreases with strong monthly deviations in total precipitation. Like many of the other region's reported earlier, the FIRE sector is impacted negatively by higher than average precipitation levels. For example, a $1 \%$ increase in precipitation leads to a $\$ 150$ million dollar loss to sector-region output annually.

\begin{tabular}{|c|c|c|c|c|}
\hline Sector & HDD & CDD & Precip. & $\begin{array}{l}\text { Precip. } \\
\text { S.D. }\end{array}$ \\
\hline Agriculture & $0.74 \%$ & $0.02 \%$ & $-0.24 \%$ & $0.07 \%$ \\
\hline Wholesale Trade & $0.37 \%$ & $0.22 \%$ & $0.14 \%$ & $-0.11 \%$ \\
\hline Retail Trade & $0.11 \%$ & $0.17 \%$ & $0.09 \%$ & $-0.02 \%$ \\
\hline FIRE & $0.15 \%$ & $0.29 \%$ & $-0.15 \%$ & $0.01 \%$ \\
\hline Communications & $0.20 \%$ & $0.10 \%$ & $0.10 \%$ & $-0.09 \%$ \\
\hline Utilities & $0.59 \%$ & $-0.01 \%$ & $0.14 \%$ & $-0.06 \%$ \\
\hline Transportation & $-0.44 \%$ & $-0.08 \%$ & $0.04 \%$ & $-0.01 \%$ \\
\hline Manufacturing & $-0.80 \%$ & $0.21 \%$ & $0.02 \%$ & $0.00 \%$ \\
\hline Construction & $0.00 \%$ & $0.33 \%$ & $0.03 \%$ & $-0.03 \%$ \\
\hline Mining & $2.35 \%$ & $1.21 \%$ & $-0.39 \%$ & $-0.16 \%$ \\
\hline Services & $0.38 \%$ & $0.41 \%$ & $0.11 \%$ & $-0.06 \%$ \\
\hline
\end{tabular}




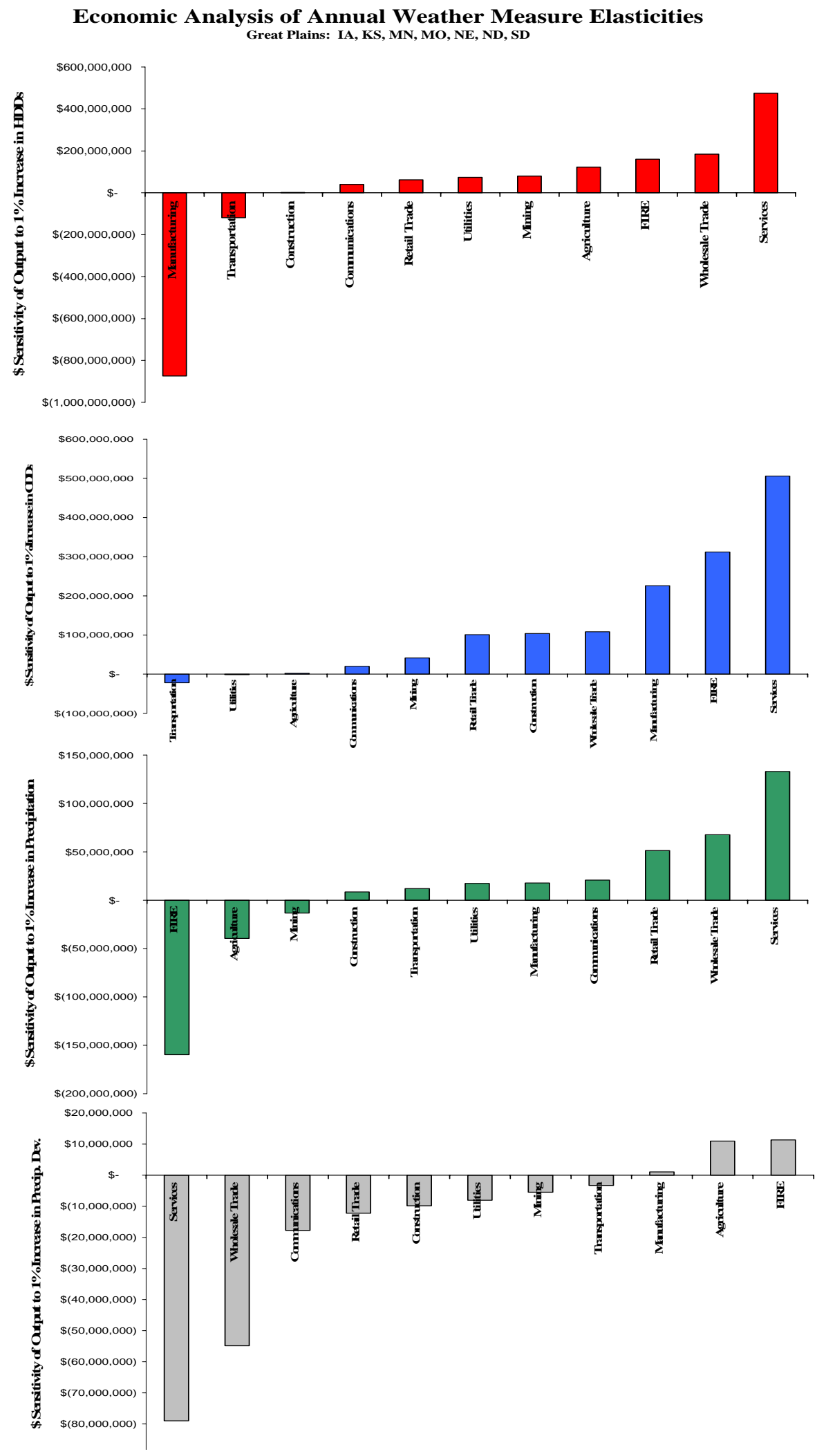

Figure 7.9 Sector Output Changes to Four Measures of Weather 
Table 7.8 and Figure 7.10 present the elasticities in both relative and absolute terms for the Great Lakes region. In both absolute and relative terms the manufacturing sector is impacted negatively with lower than average temperatures. However, output increases for the services sector with lower temperatures, but decreases with strong monthly deviations in total precipitation. Like many of the other region's reported, the FIRE sector is impacted negatively by higher than average precipitation levels. For example, a $1 \%$ increase in precipitation leads to a $\$ 300$ million dollar loss to sectorregion output annually.

\begin{tabular}{|c|c|c|c|c|}
\hline Sector & HDD & CDD & Precip. & $\begin{array}{l}\text { Precip. } \\
\text { S.D. }\end{array}$ \\
\hline Agriculture & $0.76 \%$ & $0.01 \%$ & $-0.21 \%$ & $0.05 \%$ \\
\hline Wholesale Trade & $0.47 \%$ & $0.27 \%$ & $0.11 \%$ & $-0.09 \%$ \\
\hline Retail Trade & $0.16 \%$ & $0.17 \%$ & $0.08 \%$ & $-0.03 \%$ \\
\hline FIRE & $0.18 \%$ & $0.30 \%$ & $-0.12 \%$ & $0.00 \%$ \\
\hline Communications & $0.28 \%$ & $0.14 \%$ & $0.08 \%$ & $-0.07 \%$ \\
\hline Utilities & $0.59 \%$ & $-0.03 \%$ & $0.15 \%$ & $-0.07 \%$ \\
\hline Transportation & $-0.40 \%$ & $-0.08 \%$ & $0.04 \%$ & $-0.02 \%$ \\
\hline Manufacturing & $-0.80 \%$ & $0.19 \%$ & $0.03 \%$ & $-0.03 \%$ \\
\hline Construction & $0.07 \%$ & $0.36 \%$ & $0.01 \%$ & $-0.02 \%$ \\
\hline Mining & $2.50 \%$ & $1.38 \%$ & $-0.44 \%$ & $-0.05 \%$ \\
\hline Services & $0.43 \%$ & $0.42 \%$ & $0.10 \%$ & $-0.06 \%$ \\
\hline
\end{tabular}


Economic Analysis of Annual Weather Measure Elasticities Great Lakes: IL, IN, MI, OH, WI

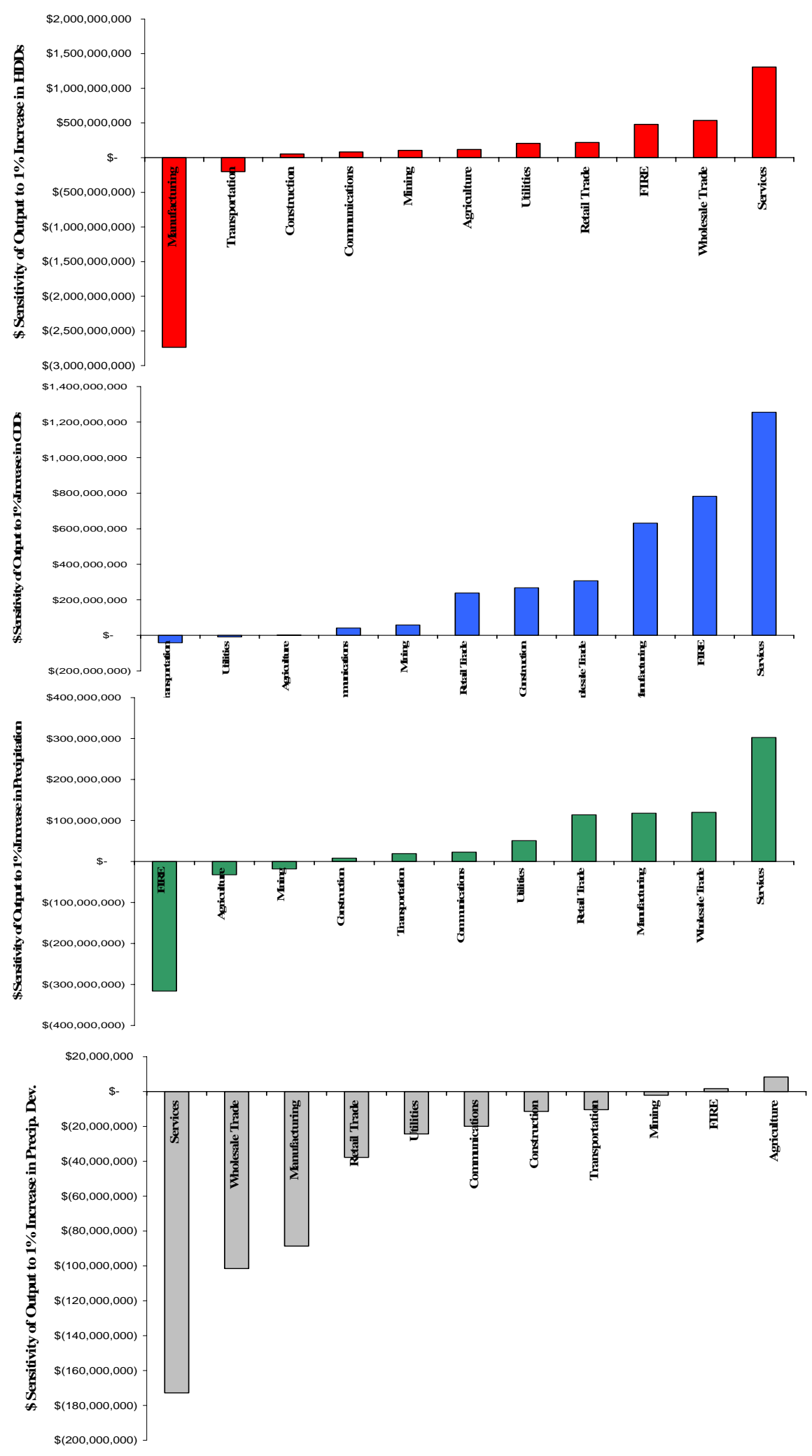

Figure 7.10 Sector Output Changes to Four Measures of Weather 


\subsection{Estimating the Relative Sensitivity of U.S. Economic Super-Sectors to Weather using a Monte-Carlo Simulation}

In order to rank the sensitivity of U.S. economic sectors to weather, a montecarlo simulation was employed on the fit equation produced from Model (3) using distributions of each of the eight region's observed weather measures (i.e. HDDs, Precipitation, etc.) from 1977-2000. Substitution of observed regional distributions of weather measures ( $\mathrm{x} \& \mathrm{z}$ in Figure 2.2) into a robustly estimated regression equation will produce observable distributions in sector output $\left(\mathrm{Y}^{* *}\right)$. Super-sector distributions with large output dispersions around the mean (i.e. average weather) indicate that a particular super-sector's economic output (measured in \$2004 dollars) is more sensitive relative to another. In other words, traditional measures of a distribution's dispersion such as variance, etc. can be used to detect the degree a sector/region is sensitive to weather.

Statistical analysis software, including SAS, allowed us to measure the dispersion of regional-sector economic output attributed to observed weather variability. Region-supersector combinations with a large dispersion of output (i.e. some measure of output variance) directly due to weather can be said to more sensitive to weather than other region-supersector combinations with less output dispersion. Accordingly, region-supersector combinations can be ranked against one another thus allowing policymakers to direct resources in an effort to mitigate this sensitivity to weather (i.e. reduce the dollar impacts of weather on a particular supersector using improved atmospheric forecasting services, etc.). For example, results from this research tell us that the Services sector in the Far West is the most weather sensitive region-supersector combination with the Mining sector in New 
England being the least sensitive to weather variability. Figure 7.11 is a flow chart depicting the process used to calculate the sensitivity of economic sectors to weather.

\section{Calculating and Ranking the Sensitivity of U.S. Economic Sectors to Weather Variability}

1. Import and process state and sector specific data including gross sector product (Q), private/public levels of capital $(\mathrm{K})$, labor hours ( $\mathrm{L}$ ), energy consumed ( $\mathrm{E})$, and four measures of weather (HDD, etc.)

2. Robustly regress model data using stationary TRANSLOG functional form by super-sector and U.S. region.

3. Monte-carlo simulation emp loyed to re estimate sector-re gio noutput ( $\mathrm{Y}$ w) due to weather variability by inserting:

A) the mean (i.e. average) values of tracitional production variables ( $K, L, E$ ) and $(Y$ w)

B) inserting repeated (e.g. 10,000 iterations), draws based on actual combinations of a region's historical weather (1977-2000) into an equation with coefficients produced from regression in step \#2 above. (Y***)

4. Calculate the impact of weather to each sector-region combination $\left(\mathrm{Q}^{*}\right)$ by sub trac ting $Y^{* * *}$ (estimated output from varying weather) from $Y^{*}$ (estimate output using average levels of weather).

5. Rank the sensitivity of sector-re gion combinations to weather by sorting sectorregions by the ir calculated standard deviation (i.e. dispersion) levels of $Q^{*}$ in descending order. For example, estimated sector output for the serwices industry in the Far West is ranked most sensitive to weather by this study, because its economic output is impacted the greatest (i.e. largest standard deviation) with regional weather variability.

\section{Figure 7.11 Process of Calculating the Relative Sensitivity of U.S. Economic}

\section{Sectors to Weather}


Prior to ranking the different region-sector combinations, the dispersion of each

modeled combination was calculated by SAS. Table 7.9 is a matrix of the estimated standard deviations of the region-sectors studied in this model.

Table 7.9 Region-Supersector Simulated Standard Deviations (\$millions of U.S. dollars) from Weather Variability

\begin{tabular}{|c|c|c|c|c|c|c|c|c|}
\hline \multirow[b]{2}{*}{ Super-sector } & \multicolumn{8}{|c|}{ Region } \\
\hline & New England & Northeast & Great Lakes & Midwest & Southeast & Southwest & Rocky Mtns & Far West \\
\hline Agriculture & $\$ \quad 131.16$ & \$ 289.94 & $\$ \quad 151.74$ & \$ 271.25 & $\$ 801.06$ & $\$ 1,206.25$ & $\$$ & $\$ \quad 5,546.30$ \\
\hline Wholesale Trade & 264.17 & $\$ \quad 624.81$ & $\$ 512$ & $\$ 337$ & $\$ 728$ & & $\$$ & \$ 18, \\
\hline Retail Trade & $\$ \quad 315.14$ & $\$ 501.99$ & $\$ 468.81$ & $\$ 359.32$ & $\$ 1,27$ & & $\$$ & $\$ 23$ \\
\hline FIRE & $\$ 2,354.82$ & $\$ 7,333.80$ & $\$ 1,407.60$ & $\$ 1,000.78$ & $\$ 2,595$ & & 455.26 & $\$ 72$, \\
\hline Comm & $\$ \quad 225.08$ & $\$ 693.26$ & \$ 109.83 & $\$ 90.54$ & $\$ 403.19$ & & 31.58 & \\
\hline Utilit & 181.85 & $\$ \quad 556.02$ & 364.95 & $\$ 218.23$ & $\$ 525.89$ & & 191.03 & \\
\hline Tran & 74.25 & $\$ 262.33$ & \$ 177.76 & $\$ 159.83$ & $\$ 221.54$ & & 77.17 & \$ $10,767.08$ \\
\hline Mant & $\$ 1,201.79$ & $\$ 2,269.26$ & $\$ 1,557.35$ & $\$ 556.08$ & $\$ 4,591.12$ & $\$ 3,316.17$ & 331.10 & $\$ 176,896.42$ \\
\hline & $\$ \quad 398.02$ & \$ 376.12 & \$ 131.25 & $\$ \quad 76.26$ & $\$ \quad 469.70$ & & 185.56 & \$ $15,899.44$ \\
\hline Mining & 19.28 & $\$ \quad 79.45$ & 242.83 & $\$ 214.83$ & $\$ \quad 646.61$ & $\$ 7,624.26$ & 878.68 & $\$ 3,562.66$ \\
\hline Services & 702.45 & $\$ 3,560.12$ & 785.24 & $\$ 504.81$ & $\$ 1,404.52$ & $\$ 8,527.28$ & 906.42 & $\$ 73,268.85$ \\
\hline
\end{tabular}


Table 7.10 presents the results of calculating and sorting the output standard deviation caused by weather variability. It is evident from both the elasticity results and the monte-carlo results that the manufacturing, services, and FIRE sectors are most sensitive to changes in weather.

Table 7.10 Region Supersectors Ranked by Output Standard Deviations due to

\begin{tabular}{|c|c|c|}
\hline$\underline{\text { Sector }}$ & $\underline{\text { Region }}$ & Sensitivity to Weather (rank) \\
\hline Services & $\mathrm{CA}, \mathrm{NV}, \mathrm{OR}, \mathrm{WA}$ & 1 \\
\hline FIRE & $\mathrm{CA}, \mathrm{NV}, \mathrm{OR}, \mathrm{WA}$ & 2 \\
\hline Retail Trade & $\mathrm{CA}, \mathrm{NV}, \mathrm{OR}, \mathrm{WA}$ & 3 \\
\hline Manufacturing & $\mathrm{CA}, \mathrm{NV}, \mathrm{OR}, \mathrm{WA}$ & 4 \\
\hline Services & AZ, NM, OK, TX & 5 \\
\hline FIRE & $\mathrm{DE}, \mathrm{MD} / \mathrm{DC}, \mathrm{NJ}, \mathrm{NY}, \mathrm{PA}$ & 6 \\
\hline Mining & AZ, NM, OK, TX & 7 \\
\hline FIRE & AZ, NM, OK, TX & 8 \\
\hline Mining & CA, NV, OR, WA & 9 \\
\hline Retail Trade & $\mathrm{AZ}, \mathrm{NM}, \mathrm{OK}, \mathrm{TX}$ & 10 \\
\hline Manufacturing & $\mathrm{AL}, \mathrm{AR}, \mathrm{FL}, \mathrm{GA}, \mathrm{KY}, \mathrm{LA}, \mathrm{MS}, \mathrm{NC}, \mathrm{SC}, \mathrm{TN}$ & 11 \\
\hline Construction & CA, NV, OR, WA & 12 \\
\hline Wholesale Trade & $\mathrm{CA}, \mathrm{NV}, \mathrm{OR}, \mathrm{WA}$ & 13 \\
\hline Services & $\mathrm{DE}, \mathrm{MD} / \mathrm{DC}, \mathrm{NJ}, \mathrm{NY}, \mathrm{PA}$ & 14 \\
\hline Transportation & CA, NV, OR, WA & 15 \\
\hline Construction & $\mathrm{AZ}, \mathrm{NM}, \mathrm{OK}, \mathrm{TX}$ & 16 \\
\hline Utilities & $\mathrm{CA}, \mathrm{NV}, \mathrm{OR}, \mathrm{WA}$ & 17 \\
\hline Manufacturing & AZ, NM, OK, TX & 18 \\
\hline Agriculture & $\mathrm{CA}, \mathrm{NV}, \mathrm{OR}, \mathrm{WA}$ & 19 \\
\hline Wholesale Trade & AZ, NM, OK, TX & 20 \\
\hline Manufacturing & DE, MD/DC, NJ, NY, PA & 21 \\
\hline FIRE & CT, ME, MA, NH, RI, VT & 22 \\
\hline FIRE & $\mathrm{AL}, \mathrm{AR}, \mathrm{FL}, \mathrm{GA}, \mathrm{KY}, \mathrm{LA}, \mathrm{MS}, \mathrm{NC}, \mathrm{SC}, \mathrm{TN}$ & 23 \\
\hline Communications & $\mathrm{CA}, \mathrm{NV}, \mathrm{OR}, \mathrm{WA}$ & 24 \\
\hline Manufacturing & IL, IN, MI, OH, WI & 25 \\
\hline Communications & AZ, NM, OK, TX & 26 \\
\hline Transportation & AZ, NM, OK, TX & 27 \\
\hline Manufacturing & CT, ME, MA, NH, RI, VT & 28 \\
\hline Utilities & AZ, NM, OK, TX & 29 \\
\hline FIRE & IL, IN, MI, OH, WI & 30 \\
\hline Services & $\mathrm{AL}, \mathrm{AR}, \mathrm{FL}, \mathrm{GA}, \mathrm{KY}, \mathrm{LA}, \mathrm{MS}, \mathrm{NC}, \mathrm{SC}, \mathrm{TN}$ & 31 \\
\hline Services & $\mathrm{CO}, \mathrm{ID}, \mathrm{MT}, \mathrm{UT}, \mathrm{WY}$ & 32 \\
\hline Agriculture & AZ, NM, OK, TX & 33 \\
\hline Services & CT, ME, MA, NH, RI, VT & 34 \\
\hline Mining & $\mathrm{CO}, \mathrm{ID}, \mathrm{MT}, \mathrm{UT}, \mathrm{WY}$ & 35 \\
\hline Retail Trade & $\mathrm{AL}, \mathrm{AR}, \mathrm{FL}, \mathrm{GA}, \mathrm{KY}, \mathrm{LA}, \mathrm{MS}, \mathrm{NC}, \mathrm{SC}, \mathrm{TN}$ & 36 \\
\hline FIRE & IA, KS, MN, MO, NE, ND, SD & 37 \\
\hline Services & IL, IN, MI, OH, WI & 38 \\
\hline
\end{tabular}


Table 7.10 (continued)

\begin{tabular}{|c|c|c|}
\hline$\underline{\text { Sector }}$ & $\underline{\text { Region }}$ & $\underline{\text { Sensitivity to Weather (rank) }}$ \\
\hline Manufacturing & IA, KS, MN, MO, NE, ND, SD & 39 \\
\hline Retail Trade & $\mathrm{DE}, \mathrm{MD} / \mathrm{DC}, \mathrm{NJ}, \mathrm{NY}, \mathrm{PA}$ & 40 \\
\hline Agriculture & $\mathrm{AL}, \mathrm{AR}, \mathrm{FL}, \mathrm{GA}, \mathrm{KY}, \mathrm{LA}, \mathrm{MS}, \mathrm{NC}, \mathrm{SC}, \mathrm{TN}$ & 41 \\
\hline Wholesale Trade & DE, MD/DC, NJ, NY, PA & 42 \\
\hline Utilities & $\mathrm{DE}, \mathrm{MD} / \mathrm{DC}, \mathrm{NJ}, \mathrm{NY}, \mathrm{PA}$ & 43 \\
\hline Communications & $\mathrm{DE}, \mathrm{MD} / \mathrm{DC}, \mathrm{NJ}, \mathrm{NY}, \mathrm{PA}$ & 44 \\
\hline Services & IA, KS, MN, MO, NE, ND, SD & 45 \\
\hline Mining & $\mathrm{AL}, \mathrm{AR}, \mathrm{FL}, \mathrm{GA}, \mathrm{KY}, \mathrm{LA}, \mathrm{MS}, \mathrm{NC}, \mathrm{SC}, \mathrm{TN}$ & 46 \\
\hline Wholesale Trade & $\mathrm{AL}, \mathrm{AR}, \mathrm{FL}, \mathrm{GA}, \mathrm{KY}, \mathrm{LA}, \mathrm{MS}, \mathrm{NC}, \mathrm{SC}, \mathrm{TN}$ & 47 \\
\hline Utilities & $\mathrm{AL}, \mathrm{AR}, \mathrm{FL}, \mathrm{GA}, \mathrm{KY}, \mathrm{LA}, \mathrm{MS}, \mathrm{NC}, \mathrm{SC}, \mathrm{TN}$ & 48 \\
\hline Wholesale Trade & IL, IN, MI, OH, WI & 49 \\
\hline FIRE & $\mathrm{CO}, \mathrm{ID}, \mathrm{MT}, \mathrm{UT}, \mathrm{WY}$ & 50 \\
\hline Retail Trade & IL, IN, MI, OH, WI & 51 \\
\hline Manufacturing & $\mathrm{CO}, \mathrm{ID}, \mathrm{MT}, \mathrm{UT}, \mathrm{WY}$ & 52 \\
\hline Construction & CT, ME, MA, NH, RI, VT & 53 \\
\hline Construction & $\mathrm{DE}, \mathrm{MD} / \mathrm{DC}, \mathrm{NJ}, \mathrm{NY}, \mathrm{PA}$ & 54 \\
\hline Retail Trade & CT, ME, MA, NH, RI, VT & 55 \\
\hline Retail Trade & IA, KS, MN, MO, NE, ND, SD & 56 \\
\hline Construction & $\mathrm{AL}, \mathrm{AR}, \mathrm{FL}, \mathrm{GA}, \mathrm{KY}, \mathrm{LA}, \mathrm{MS}, \mathrm{NC}, \mathrm{SC}, \mathrm{TN}$ & 57 \\
\hline Wholesale Trade & IA, KS, MN, MO, NE, ND, SD & 58 \\
\hline Retail Trade & $\mathrm{CO}, \mathrm{ID}, \mathrm{MT}, \mathrm{UT}, \mathrm{WY}$ & 59 \\
\hline Utilities & IL, IN, MI, OH, WI & 60 \\
\hline Wholesale Trade & CT, ME, MA, NH, RI, VT & 61 \\
\hline Agriculture & IA, KS, MN, MO, NE, ND, SD & 62 \\
\hline Construction & $\mathrm{CO}, \mathrm{ID}, \mathrm{MT}, \mathrm{UT}, \mathrm{WY}$ & 63 \\
\hline Communications & $\mathrm{AL}, \mathrm{AR}, \mathrm{FL}, \mathrm{GA}, \mathrm{KY}, \mathrm{LA}, \mathrm{MS}, \mathrm{NC}, \mathrm{SC}, \mathrm{TN}$ & 64 \\
\hline Agriculture & $\mathrm{DE}, \mathrm{MD} / \mathrm{DC}, \mathrm{NJ}, \mathrm{NY}, \mathrm{PA}$ & 65 \\
\hline Transportation & $\mathrm{DE}, \mathrm{MD} / \mathrm{DC}, \mathrm{NJ}, \mathrm{NY}, \mathrm{PA}$ & 66 \\
\hline Mining & IL, IN, MI, OH, WI & 67 \\
\hline Transportation & $\mathrm{AL}, \mathrm{AR}, \mathrm{FL}, \mathrm{GA}, \mathrm{KY}, \mathrm{LA}, \mathrm{MS}, \mathrm{NC}, \mathrm{SC}, \mathrm{TN}$ & 68 \\
\hline Communications & CT, ME, MA, NH, RI, VT & 69 \\
\hline Utilities & IA, KS, MN, MO, NE, ND, SD & 70 \\
\hline Mining & IA, KS, MN, MO, NE, ND, SD & 71 \\
\hline Utilities & CT, ME, MA, NH, RI, VT & 72 \\
\hline Utilities & $\mathrm{CO}, \mathrm{ID}, \mathrm{MT}, \mathrm{UT}, \mathrm{WY}$ & 73 \\
\hline Wholesale Trade & $\mathrm{CO}, \mathrm{ID}, \mathrm{MT}, \mathrm{UT}, \mathrm{WY}$ & 74 \\
\hline Transportation & IL, IN, MI, OH, WI & 75 \\
\hline Agriculture & IL, IN, MI, OH, WI & 76 \\
\hline Transportation & IA, KS, MN, MO, NE, ND, SD & 77 \\
\hline Agriculture & CO, ID, MT, UT, WY & 78 \\
\hline Construction & IL, IN, MI, OH, WI & 79 \\
\hline Agriculture & CT, ME, MA, NH, RI, VT & 80 \\
\hline Mining & $\mathrm{DE}, \mathrm{MD} / \mathrm{DC}, \mathrm{NJ}, \mathrm{NY}, \mathrm{PA}$ & 81 \\
\hline Communications & IL, IN, MI, OH, WI & 82 \\
\hline Communications & IA, KS, MN, MO, NE, ND, SD & 83 \\
\hline Construction & IA, KS, MN, MO, NE, ND, SD & 84 \\
\hline Transportation & CO, ID, MT, UT, WY & 85 \\
\hline
\end{tabular}


Table 7.10 (continued)

$\begin{array}{llc}\text { Sector } & \text { Region } & \text { Sensitivity to Weather (rank) } \\ \text { Transportation } & \text { CT, ME, MA, NH, RI, VT } & 86 \\ \text { Communications } & \text { CO, ID, MT, UT, WY } & 87 \\ \text { Mining } & \text { CT, ME, MA, NH, RI, VT } & 88\end{array}$

\subsection{Estimating the Net Aggregate Economic Impact of Weather Variability for} entire Regions, Sectors, and the National Economy

This research allows for easy aggregation to see the impact of weather on larger subsets of (and for) the national economy. The results of monte-carlo simulations, which produced distributions of region-sector impacts $\left(\mathrm{Q}^{*}\right)$ can be analyzed to estimate the average impact from weather variability. Figure 7.12 is the aggregated economic impacts of weather for New England (i.e. regional-level). The results of this research indicate that weather variability decreases annual output on average by $\$ 331.6$ million $(\$ 2004)$ with a low probability of losses $(<1 \%)$ at $-\$ 9.7$ billion and equally low probability $(<1 \%)$ in gains estimated at $+\$ 11.0$ billion.

Change to Economic Output from Regional Weather Variability Region: New England
11 Sector Total

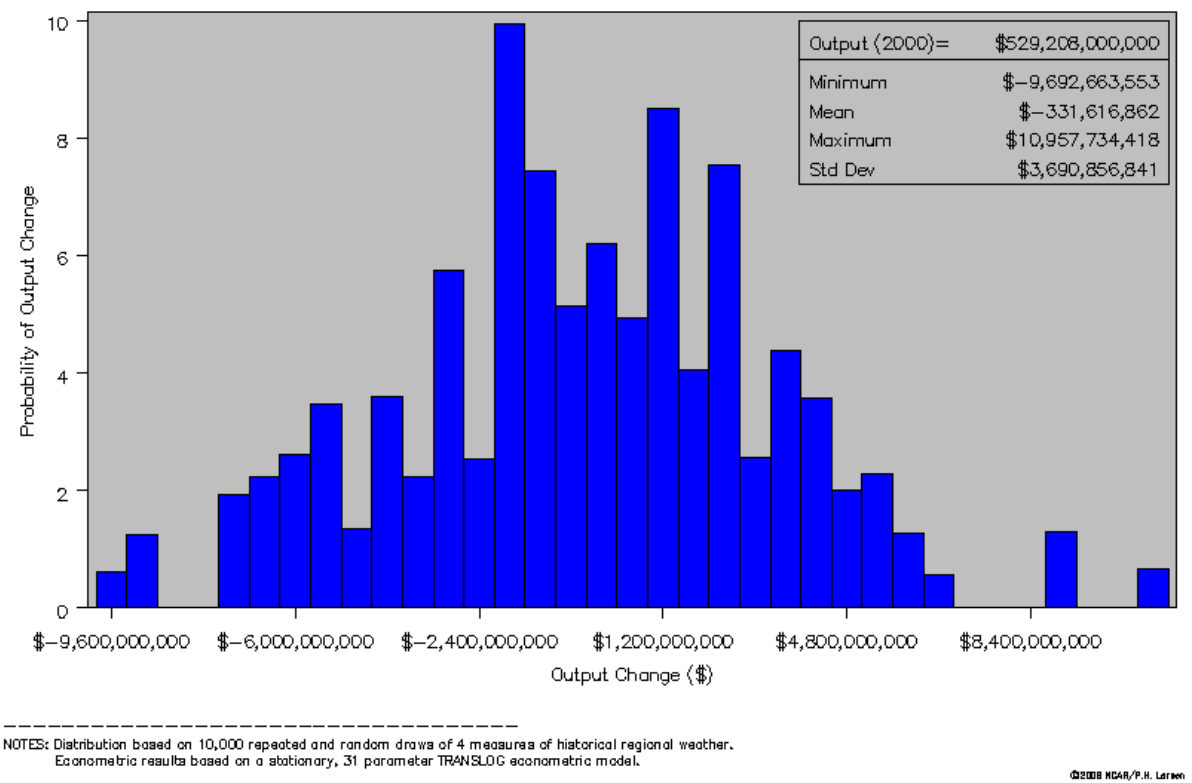

Figure 7.12 Example Output from Model Simulations (New England GSP) 
In addition to presenting the results at the regional level, it is possible to aggregate entire sectors to study the impacts of weather. Figure 7.13 is the aggregated economic impacts of weather variability for Manufacturing (i.e.national-level). The results of this research indicate that weather variability increases annual manufacturing output on average by $\$ 18.0$ billion ( $\$ 2004)$ with a low probability of losses $(<1 \%)$ at $-\$ 89.2$ billion and equally low probability $(<1 \%)$ in gains estimated at $+\$ 965.6$ billion.

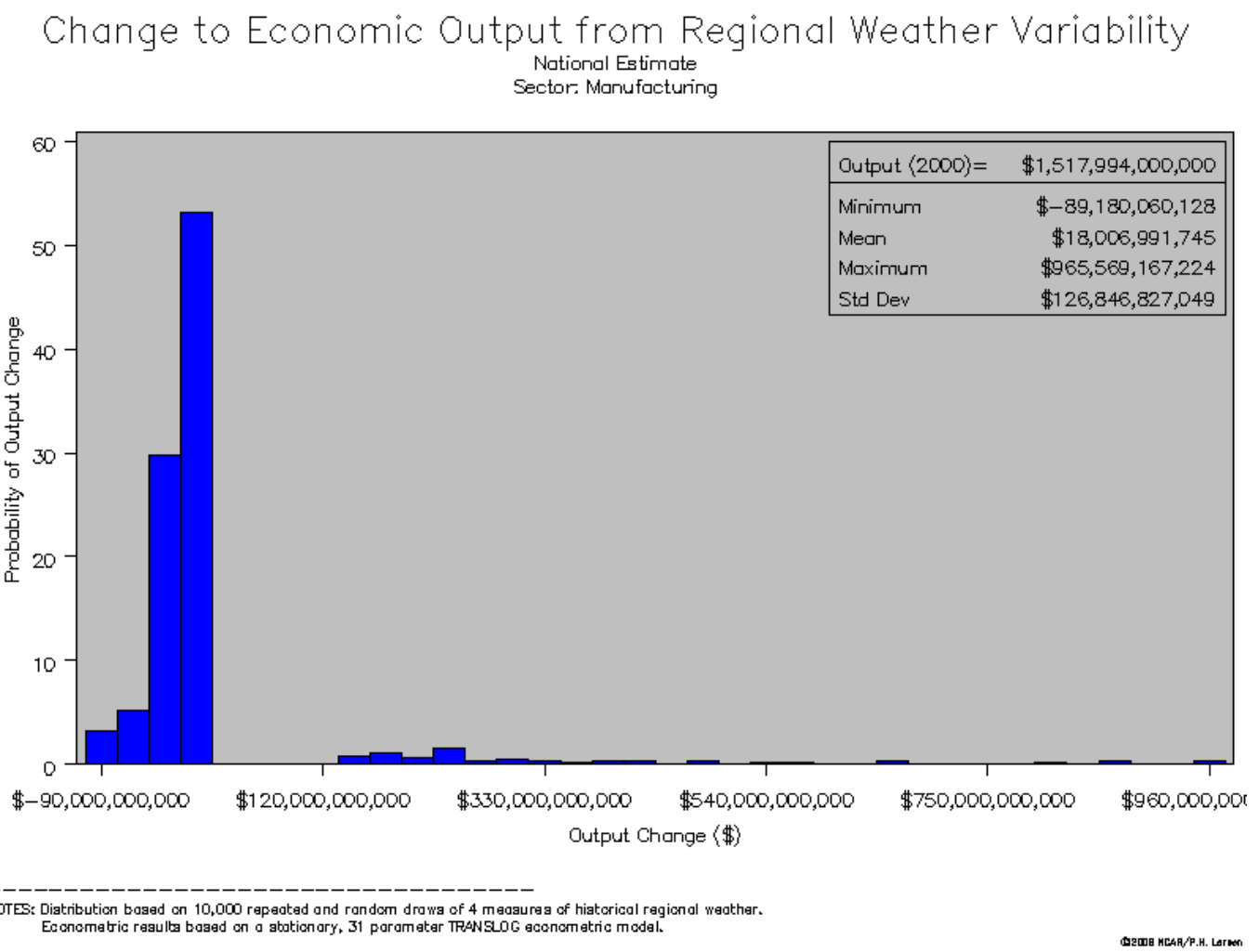

Figure 7.13 Example Output from Model Simulations (National Manufacturing GSP)

Finally, it is possible to aggregate the net economic impact of weather variability at the national level by summing all region-sector combinations. Figure 
7.14 presents research indicating that weather variability actually increases annual national output on average by about $\$ 20.8$ billion (\$2004) with a low probability of losses $(<1 \%)$ at $-\$ 476.4$ billion and equally low probability $(<1 \%)$ in gains estimated at $+\$ 932.9$ billion.

Another way of interpreting this graph is to say that U.S. Gross Domestic Product (GDP) which is the sum of all sector-state gross product estimates, increases on average by approximately $\$ 20.8$ billion annually with weather variability. ${ }^{18}$

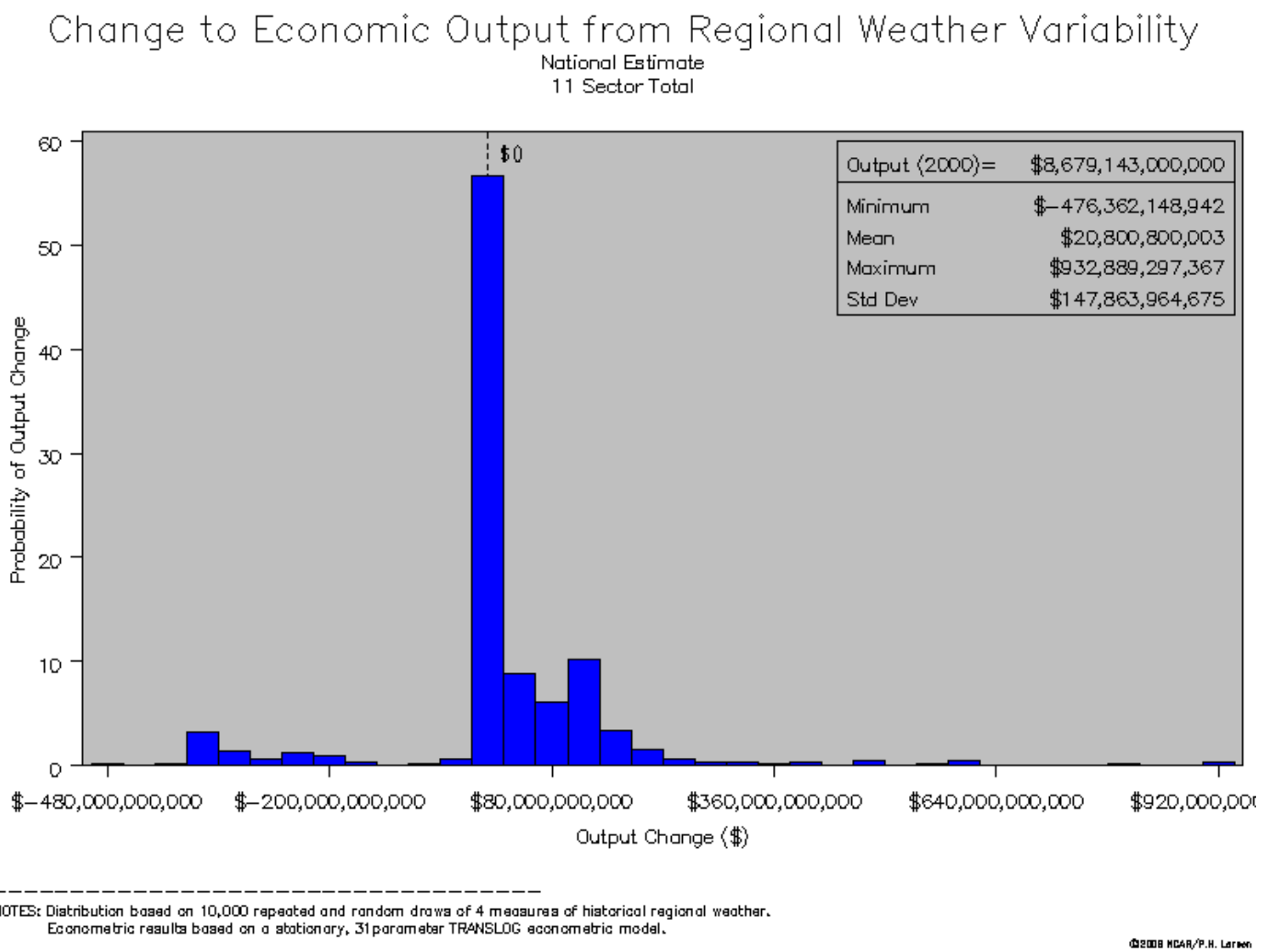

Figure 7.14 Example Output from Model Simulations (National GDP)

\footnotetext{
${ }^{18}$ Actual U.S. GDP is closer to $\$ 10$ trillion. The $\$ 8.7$ trillion estimate presented above is correct considering that the government service sector (i.e. public capital) was used as an input to the model and therefore netted out from the total presented above. Also, sector-state outputs for Alaska and Hawaii were not estimated because of an outlier concern in the fitting of the model.
} 
In general, the results of this research indicate that the Far West and Southwestern $\underline{\text { regions are more sensitive to weather variability than other regions throughout the }}$ United States. This empirical finding is evident when the region-specific histograms generated from the Monte-Carlo simulation are stacked on top of each other.

According to the sensitivity definition detailed in this thesis, regions/sectors with a large dispersion of economic output attributed to weather variability relative to other regions/sectors are said to more sensitive to weather. Figures 7.15 and 7.16 present the changes in economic output from regional weather variability with consistent scales (for comparison purposes).

\section{Change to Economic Output from Regional Weather Variability}

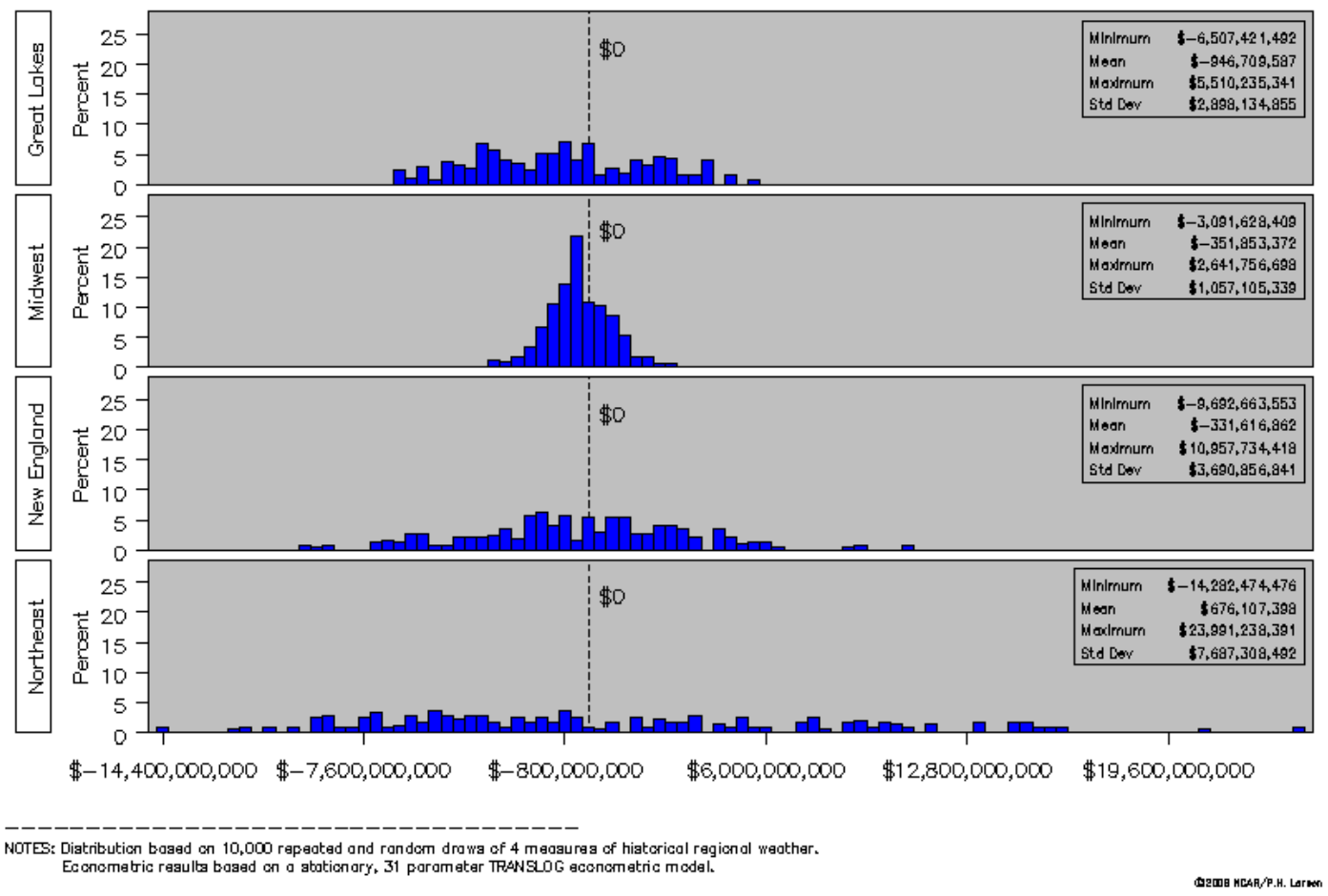

Figure 7.15 Example Output from Model Simulations (Stacked Regional

\section{Comparisons)}


Change to Economic Output from Regional Weather Variability

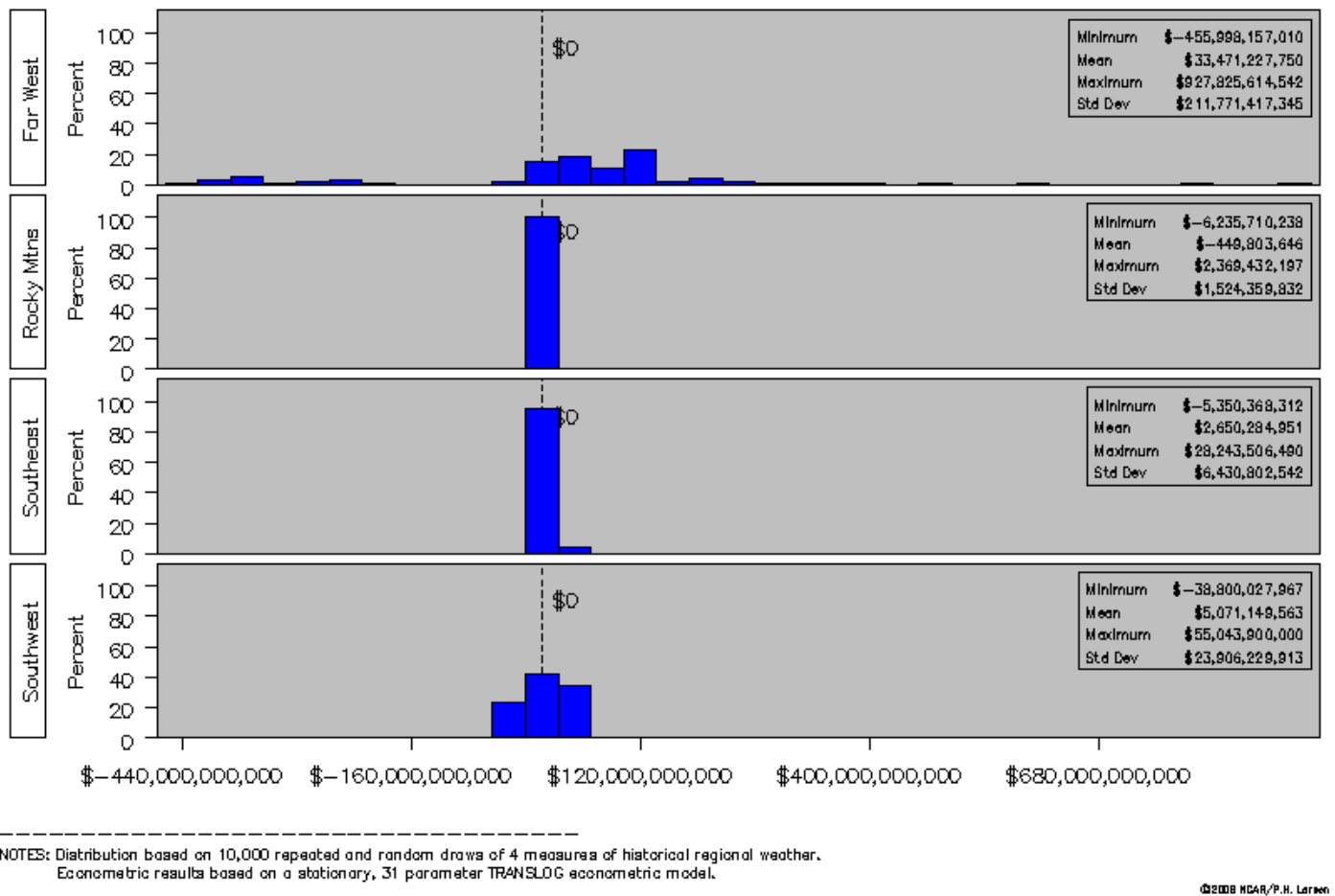

Figure 7.16 Example Output from Model Simulations (Stacked Regional

\section{Comparisons)}

Another finding of this research is that three components of the economy: FIRE, $\underline{\text { services, and manufacturing tend to be relatively more sensitive to weather variability }}$ than the other eight supersectors studied. Figures 7.17, 7.18 and 7.19 demonstrate the varied levels of dispersion in economic output due to weather variability for all 11 supersectors. 
Change to Economic Output from Regional Weather Variability Sector Estimates

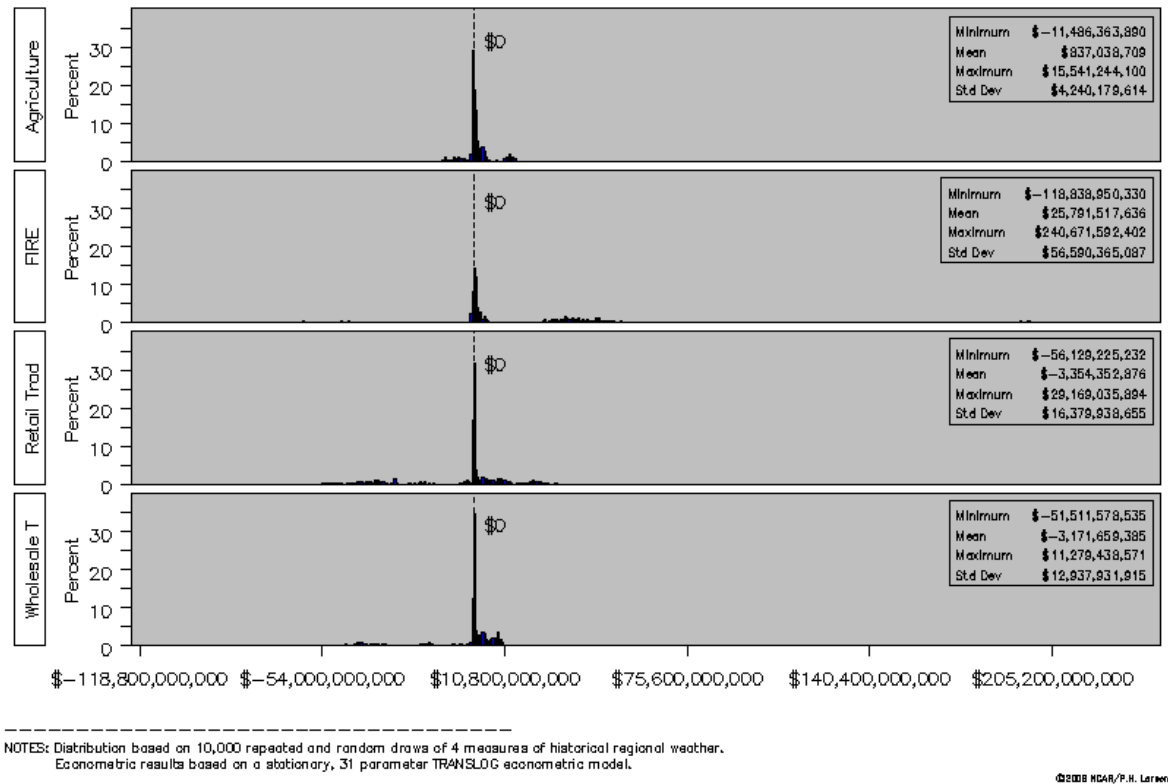

Figure 7.17 Example Output from Model Simulations (Sector Comparisons)

Change to Economic Output from Regional Weather Variability Sector Estimates

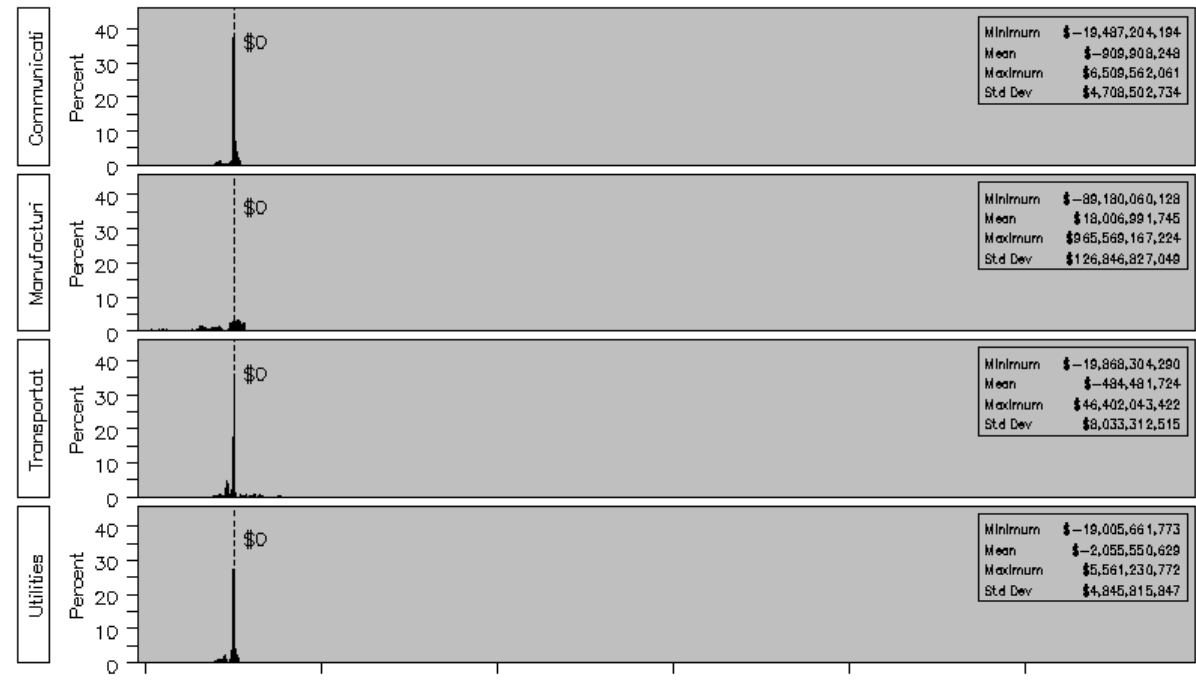

$\$-89,100,000,000 \$ 89,100,000,000 \$ 267,300,000,000 \$ 445,500,000,000 \$ 623,700,000,000 \$ 801,900,000,000$

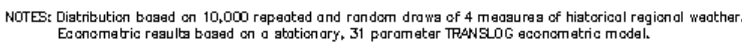

Figure 7.18 Example Output from Model Simulations (Sector Comparisons) 
Change to Economic Output from Regional Weather Variability Sector Estimates

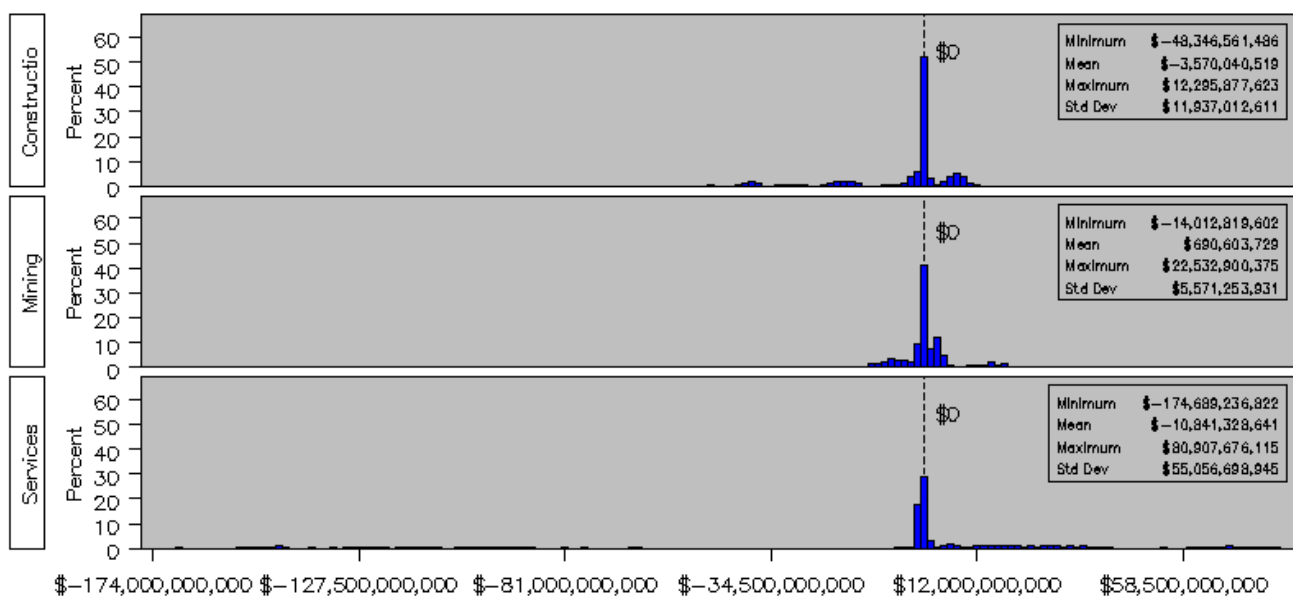

NOTES: Distribution based on 10,000 repeatad and random drawa of 4 magauras of historical regicnal wather.

Figure 7.19 Example Output from Model Simulations (Sector Comparisons) 


\section{CHAPTER 8}

\section{FUTURE DIRECTION OF RESEARCH}

\subsection{Inclusion of Historical Weather Forecast Skill Information}

Over the past thirty years the advent of Doppler radar and other sophisticated tools used by weather officials has greatly improved forecast accuracy for temperature and precipitation. Improvements in forecast capacity may lead to efficiency gains in many sectors as businesses mitigate losses related to weather using hedging techniques related to forecasting (HDD forwards, etc.). Figures 8.1 and 8.2 show the accuracy gains that have been made over the period of this model's analysis. Data provided by NOAA.

Average U.S. Temperature Forecast Errors

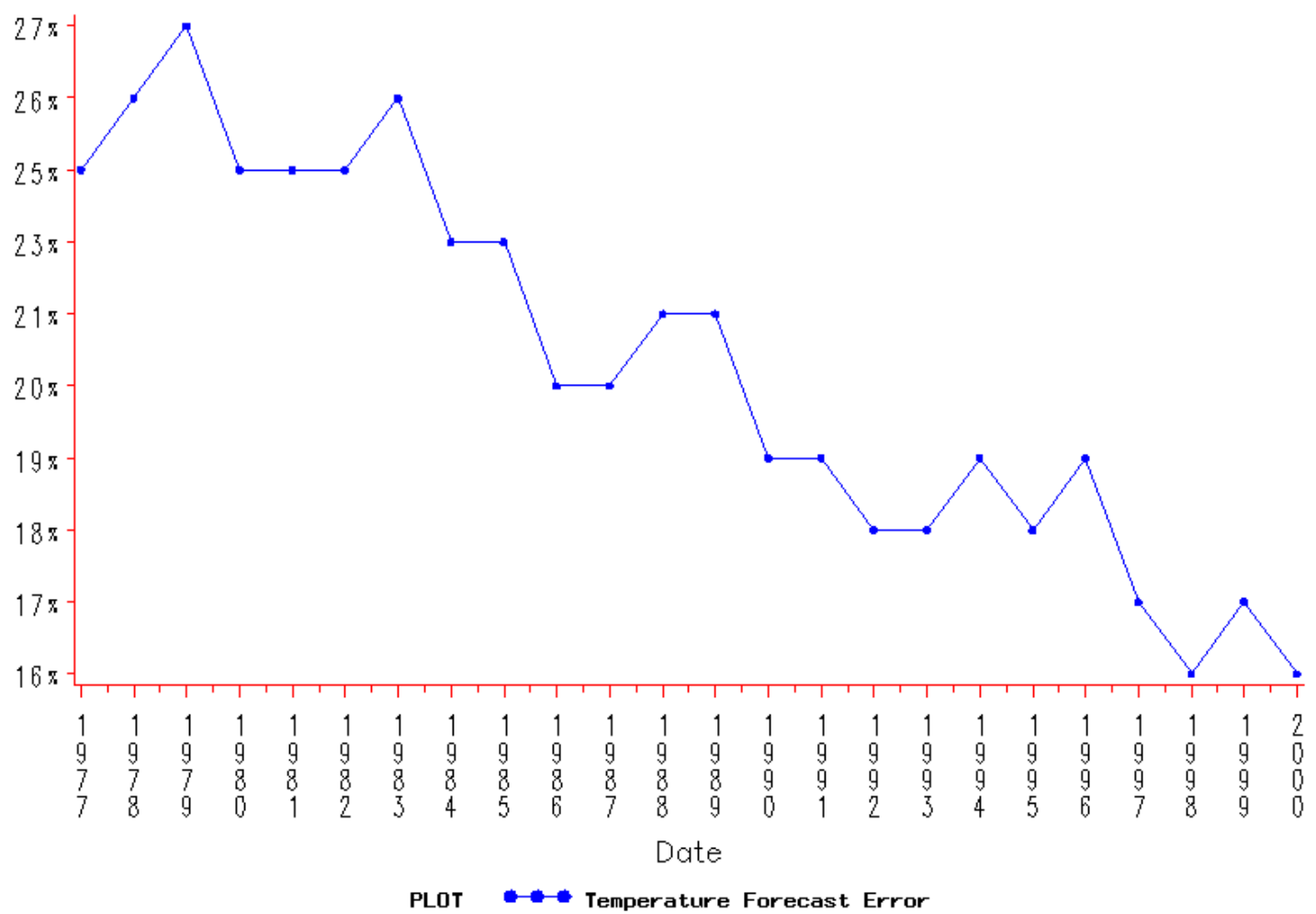

Figure 8.1 Average U.S. temperature forecast errors (1977-2000) 


\section{Average U.S. Precipitation Forecast Improvement}

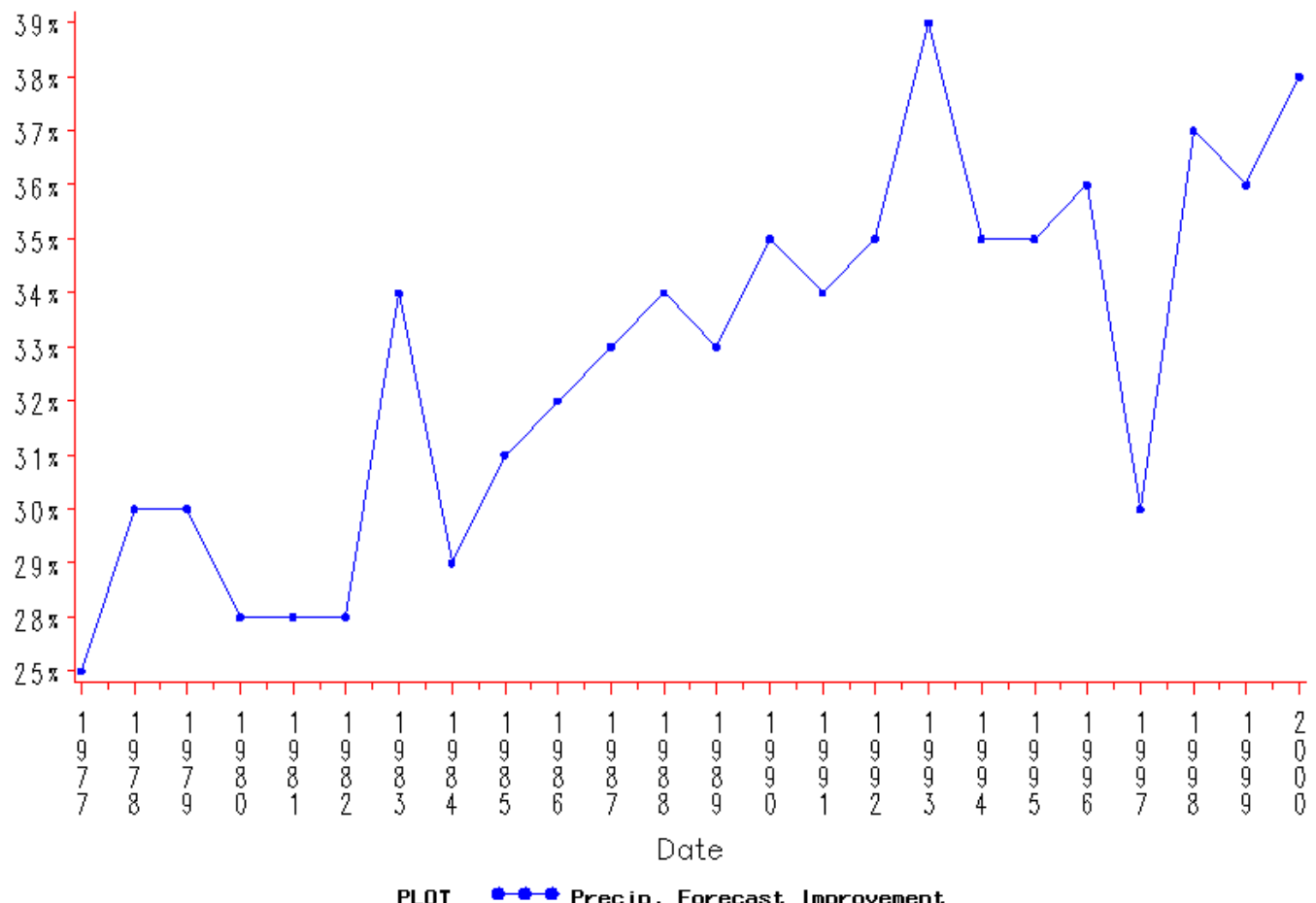

Figure 8.2 Average U.S. temperature forecast improvements (1977-2000)

Improving weather forecasts help individuals and businesses better plan for weather uncertainty. For example, a construction firm may choose to speed up a project based on short-term rainfall forecasts thus mitigating potential future losses due to inclement weather.

It is not known what impact improved weather forecasting has had on the U.S. economy. With help from the National Oceanic and Atmospheric Administration (NOAA), research is being carried out to include forecast improvements in this model and ascertain the aggregate economic impact of new technologies introduced from the NCAR. 


\section{Volume of Financial Hedging Activities}

Weather-based derivatives trading volume is growing steadily within the financial industry as more businesses construct complex strategies to hedge away financial risk associated with weather uncertainty. For example, wholesale power buyers pen contracts to HDD to offset losses from unexpected heat waves or cool spells. In addition, farmers obtain futures and forwards contacts to offset losses from drought years. In the last few years, academics have built sophisticated models of trading behavior in the financial, energy, and weather derivatives markets. Many of these models are used by consultants, power plant operators, energy traders hedging weather uncertainty, and large-scale agricultural producers to optimize revenues when faced with uncertainty in weather and relevant market information. For an excellent example, please see Mount and Yoo (2003). Specifically, the Mount and Yoo paper builds on earlier research showing how weather derivatives can be used to hedge against the price risk and volume risk of purchasing relatively large amounts of electricity on hot days when price spikes (volatile jumps in the real-time price of electricity) are likely to occur. In the Mount and Yoo model, forward contracts are specified for 1) purchasing energy at a relatively low price on cool days, and 2) purchasing energy at a relatively high price on hot days when the load is higher than normal. However, the number of hot days in a summer, when high prices are charged, is highly variable and this provides the main source of risk of the contract. Figure 8.3 is the historical trading volume of weather derivatives as recorded by the Chicago Mercantile Exchange (CME) commodities market. 


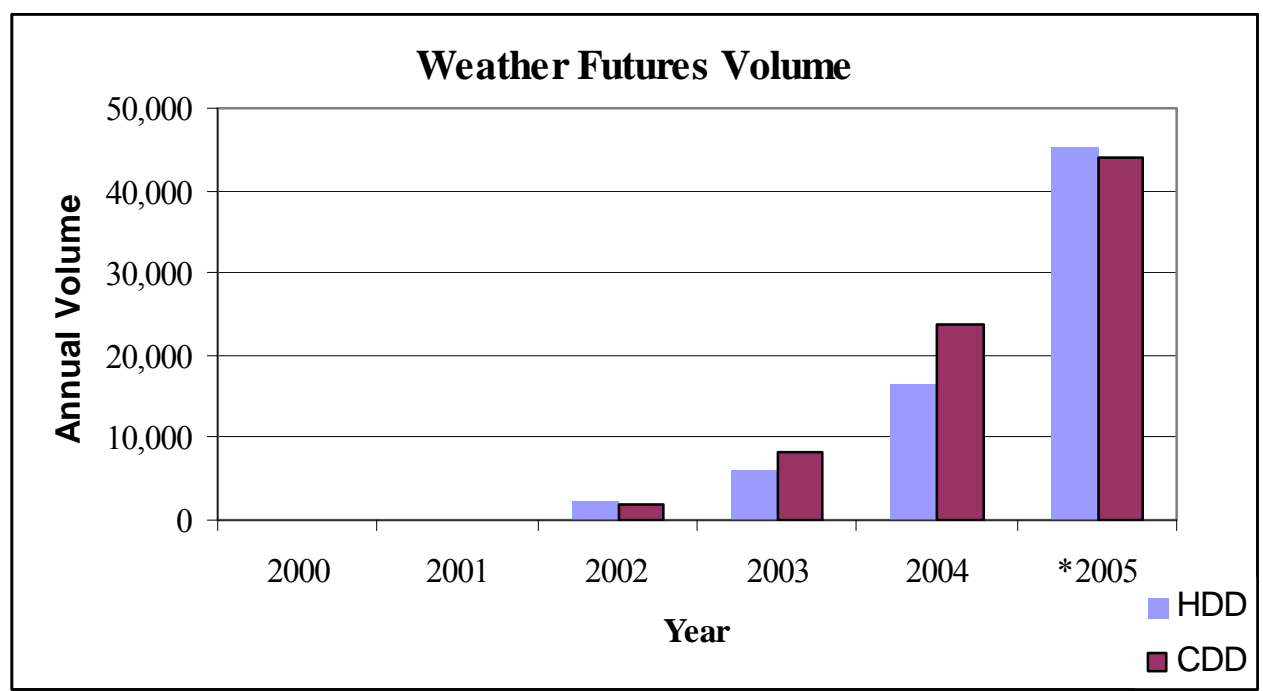

Figure 8.3 Historical Trading Volume of Weather Futures (CME, 2005) NOTE: *Covers period January through June 2005

Additional research is being planned to incorporate weather based derivatives trading volume over time as an input to the production functions discussed in this paper. In the context of this paper, weather derivatives are used as a tool to mitigate sector sensitivity to weather and may provide valuable insight into the degree of mitigation undertaken by affected sectors. 


\section{CHAPTER 9}

\section{CONCLUSION}

In the course of the core research effort, measures of weather including annual heating degree-days (HDD), cooling degree-days (CDD), precipitation ( $\mathrm{P}_{-} \mathrm{TTL}$ ), and month-to-month precipitation standard deviations (P_STD) were modeled (along with more traditional economic inputs of sector-specific capital (KAP), labor (L), and energy consumption (E)) as independent variables in a transcendental logarithmic (translog) production function. Super-sectors were modeled at the national level, corrected for time-series and state patterns, and based on historical data from 19772000. Dummy variables were also included in the model for seven regions with the FWST region (which includes California, Oregon, and Washington) left out of the regression for regional comparison purposes.

The weather and economic inputs were linearly regressed (i.e. modeled) on the natural log of sector output from the Bureau of Economic Analysis (Q) with the estimated coefficients (i.e. "betas hats") on each weather term representing the sensitivity of each weather input to output. ${ }^{19} 20$

In general, this production function takes the form:

\footnotetext{
${ }^{19}$ All variables (input and output) were subjected to a natural log transformation. Making the variables linear allows for OLS estimation techniques commonly available in many statistical software packages such as SAS.

${ }^{20}$ The partial derivative of $\mathrm{Q}$ with respect to the weather inputs (ceteris parabis) produces the sensitivity used in the results interpretation.
} 


$$
\begin{aligned}
\ln \left(Q_{i j t}\right)= & \ln \left(A_{i j t}\right)+\delta t+\beta_{L} \ln \left(L_{i j t}\right)+\beta_{K A P} \ln \left(K A P_{i j t}\right)+\beta_{E} \ln \left(E_{i j t}\right)+ \\
& \beta_{\vec{W}} \ln \left(\overrightarrow{W_{i t}}\right)+\frac{1}{2} \beta_{\vec{W} \vec{W}} \ln \left(\vec{W}_{i t}\right) \ln \left(\vec{W}_{i t}\right)+\frac{1}{2} \beta_{L L} \ln \left(L_{i j t}\right) \ln \left(L_{i j t}\right)+ \\
& \beta_{L K A P} \ln \left(L_{i j t}\right) \ln \left(K A P_{i j t}\right)+\beta_{L E} \ln \left(L_{i j t}\right) \ln \left(E_{i j t}\right)+\beta_{L \vec{W}} \ln \left(L_{i j t}\right) \ln \left(\vec{W}_{i t}\right)+ \\
& \frac{1}{2} \beta_{K A P K A P} \ln \left(K A P_{i j t}\right) \ln \left(K A P_{i j t}\right)+\beta_{K A P E} \ln \left(K A P_{i j t}\right) \ln \left(E_{i j t}\right)+ \\
& \beta_{K A P \bar{W}} \ln \left(K A P_{i j t}\right) \ln \left(\overrightarrow{W_{i t}}\right)+\frac{1}{2} \beta_{E E} \ln \left(E_{i j t}\right) \ln \left(E_{i j t}\right)+\beta_{E W} \ln \left(E_{i j t}\right) \ln \left(\overrightarrow{W_{i t}}\right)+\varepsilon_{i j t}
\end{aligned}
$$

with $i$ representing contiguous U.S. states $(\mathrm{i}=1, \ldots 48)$ and $j$ equaling sector $(\mathrm{j}=1, \ldots 11)$ both at time $t(\mathrm{t}=1, \ldots 24) . \quad \varepsilon_{i j t}$ is the error term, $\ln (A)_{i j t}$ is the intercept, and $\delta$ represents the technical change coefficient (i.e. annual technological improvement for the sector).

In order to correctly interpret the results as the total economic impact of weather on a particular sector, it was necessary to take the antilog of $\ln \left(Q_{i j t}\right)$ followed by the partial derivative of the function above: $\frac{\partial Q}{\partial \vec{W}}$ (known as the marginal product of weather).

As suspected, regional sector output shows varying degrees of sensitivity to the model's proxies for temperature and precipitation.

\section{National GDP Expands by \$20.8 billion Annually with Weather}

It was presented that, although some region-sector combinations show significant losses attributed to weather, the aggregate impact of weather variability increases

national income (measured as GDP) by approximately $\$ 20.8$ billion. However, it is important to note that economic expansion related to weather variability isn't 
necessarily a good thing for a region (or society) as a whole. For example, recent extreme weather events (including Hurricane Katrina) will often boost a state's (or region's) economic output as federal aid pours into the area and a construction boom follows. Despite this economic expansion, it is clear that weather-related catastrophic losses of life, extreme property damage, and civil unrest are not necessarily a benefit to society in the long-run.

\section{Sensitive Sectors Across Regions}

Manufacturing output across the country shows consistently negative signs for heating degree-days implying sector output drops with decreases in temperature. This research also confirms that the market for weather information may be larger in some sectors and regions relative to other sector and region combinations.

\section{Mining Output more Weather Sensitive than Previously Thought}

Another interesting result from this model shows the mining supersector sensitive (negatively) to three of the four measures of weather. This seems counterintuitive in that many mining operations existing below ground and may be immune to day-to-day weather.

One theory for this higher than expected sensitivity could be tested with interaction terms on the utilities sector (i.e. high demand for the utility sector increases mining output and mining output affects utility costs). In this case, economic sensitivity to weather could directly affect one industry (e.g. utilities) and indirectly

affect another through intra-annual shocks to demand (e.g. less than expected demand for petroleum-based minerals, decreases mining extraction output for many large industries). 
In addition to defining what it means for a sector to be economically sensitive to weather, this paper hypothesizes that weather variables have a small, but significant impact on economic production. It has been shown that the inclusion of the four measures of weather improve the fit of a BLUE translog model. It is clear that weather is indeed a measurable factor in the production process.

This paper proposes that measures of weather/climate should be considered along with the traditional factors to production when modeling economic output at the sector and region level.

Including weather as an input to a production function helps better explain risks faced in the production process of each sector. Risks in the production of goods and services lead to higher costs and uncertainty in the decision making process. From a policy standpoint, it has been very difficult to objectively prioritize sector investments in forecasting without objective methods to quantify economic sensitivity to weather conditions.

\section{Objective Method to Prioritize Weather Forecasting Research and Dissemination}

This weather-based model of production provides weather and climate policymakers with an objective method to efficiently mitigate risks by ranking each sector's degree of sensitivity.

As with many research topics, the results of this model pose more questions than provide answers. Future research is being directed in the areas of:

1) assessing the economic impact of forecast technologies,

2) including super sector/state-level price indices for both the factor inputs and in the conversion of GSP to real output (this may help control for some of the demandside impacts), 
3) including historical trading volume of weather derivatives as a model input and a method for sectors to mitigate estimated weather risks,

4) modeling the sensitivity of crop-based agricultural output versus animal-based output,

5) modeling the economic sensitivities to weather with surface transportation output compared to air transportation output and,

6) employing additional monte-carlo simulations on the weather inputs to assess future sensitivity scenarios based on climate change model predictions. 


\section{APPENDIX A: OLS RESULTS BY SECTOR}

Table A.1 OLS Results from Panel Regression Dependent Variable $=\log ($ Agriculture Gross Sector Product $)$

\begin{tabular}{|c|c|c|c|}
\hline & Model (1) & Model (2) & Model (3) \\
\hline \multirow[t]{2}{*}{ Intercept } & $-7.939 * *$ & $-93.058 * *$ & $-131.647 * *$ \\
\hline & $(2.687)$ & $(22.038)$ & $(23.746)$ \\
\hline \multirow[t]{2}{*}{ Year } & 0.002 & $0.004 * *$ & $0.004 * *$ \\
\hline & $(0.001)$ & $(0.001)$ & $(0.001)$ \\
\hline \multirow[t]{2}{*}{$\log ($ capital $)$} & $0.697 * *$ & 1.048 & -0.418 \\
\hline & $(0.026)$ & $(1.245)$ & $(1.242)$ \\
\hline \multirow[t]{2}{*}{$\log$ (labor) } & $0.843 * *$ & 1.778 & $2.636^{* *}$ \\
\hline & $(0.019)$ & $(0.995)$ & $(0.999)$ \\
\hline \multirow[t]{2}{*}{$\log$ (energy) } & 0.033 & $9.705 * *$ & $12.099 * *$ \\
\hline & $(0.037)$ & $(2.940)$ & $(2.893)$ \\
\hline \multirow[t]{2}{*}{$\log (\mathrm{hdd})$} & $-0.262 * *$ & $-0.276^{* *}$ & $3.268 * *$ \\
\hline & $(0.025)$ & $(0.025)$ & $(1.263)$ \\
\hline \multirow[t]{2}{*}{$\log (\mathrm{cdd})$} & $-0.051 * *$ & $-0.058 * *$ & $1.837 *$ \\
\hline & $(0.017)$ & $(0.017)$ & $(0.922)$ \\
\hline \multirow[t]{2}{*}{$\log ($ precip.) } & $-0.075 * *$ & $-0.068 * *$ & 0.613 \\
\hline & $(0.027)$ & $(0.026)$ & $(0.888)$ \\
\hline \multirow[t]{2}{*}{$\log \left(\right.$ precip. $\left.\sigma^{2}\right)$} & $0.079 * *$ & $0.074 * *$ & -0.519 \\
\hline & $(0.025)$ & $(0.025)$ & (1.004) \\
\hline \multirow[t]{2}{*}{$\log \left(\right.$ labor $\left.^{2}\right)$} & & $0.115^{* *}$ & $0.068 *$ \\
\hline & & $(0.041)$ & $(0.042)$ \\
\hline \multirow[t]{2}{*}{$\log \left(\right.$ energy $\left.^{2}\right)$} & & $-0.557 * *$ & $-0.739 * *$ \\
\hline & & $(0.206)$ & $(0.203)$ \\
\hline \multirow[t]{2}{*}{$\log \left(\right.$ capital $\left.^{2}\right)$} & & $-0.250^{* *}$ & $-0.254 * *$ \\
\hline & & $(0.066)$ & $(0.065)$ \\
\hline \multirow[t]{2}{*}{$\log ($ labor x energy) } & & $-0.170^{* *}$ & $-0.204 * *$ \\
\hline & & $(0.063)$ & $(0.062)$ \\
\hline \multirow[t]{2}{*}{$\log ($ labor x capital) } & & $0.111 * *$ & $0.118 * *$ \\
\hline & & $(0.030)$ & $(0.030)$ \\
\hline \multirow[t]{2}{*}{ log(capital x energy) } & & 0.051 & 0.142 \\
\hline & & $(0.090)$ & $(0.089)$ \\
\hline \multirow[t]{2}{*}{$\log \left(h d d^{2}\right)$} & & & $-0.255^{* *}$ \\
\hline & & & $(0.094)$ \\
\hline \multirow[t]{2}{*}{$\log \left(\mathrm{cdd}^{2}\right)$} & & & -0.044 \\
\hline & & & $(0.049)$ \\
\hline \multirow[t]{2}{*}{$\log \left(\right.$ precip. $\left.^{2}\right)$} & & & $0.056 * *$ \\
\hline & & & $(0.019)$ \\
\hline \multirow[t]{2}{*}{$\log \left(\right.$ precip. $\sigma^{2}$ x precip. $\left.\sigma^{2}\right)$} & & & -0.007 \\
\hline & & & $(0.020)$ \\
\hline \multirow[t]{2}{*}{$\log ($ precip $x$ hdd) } & & & -0.068 \\
\hline & & & $(0.072)$ \\
\hline \multirow[t]{2}{*}{$\log \left(\operatorname{cdd} \times\right.$ precip. $\left.\sigma^{2}\right)$} & & & 0.050 \\
\hline & & & $(0.053)$ \\
\hline $\log ($ hdd $\times$ cdd $)$ & & & $-0.171 *$ \\
\hline
\end{tabular}


Table A.1 OLS Results from Panel Regression

Dependent Variable $=\log ($ Agriculture Gross Sector Product)

\begin{tabular}{|c|c|c|c|}
\hline & Model (1) & Model (2) & Model (3) \\
\hline & & & $(0.074)$ \\
\hline \multirow[t]{2}{*}{$\log \left(\right.$ hdd $x$ precip. $\left.\sigma^{2}\right)$} & & & 0.028 \\
\hline & & & $(0.082)$ \\
\hline \multirow[t]{2}{*}{$\log$ (cdd x precip.) } & & & -0.052 \\
\hline & & & $(0.047)$ \\
\hline FIT: Adj. $\mathrm{R}^{2}$ (pre-stationary) & 0.9197 & 0.9257 & 0.9337 \\
\hline FIT: Akaike Information Criterion (stationary) & -351.5 & -400.2 & -420.6 \\
\hline Degrees of Freedom & 1,136 & 1,130 & 1,121 \\
\hline State fixed effects? & YES & YES & YES \\
\hline AR(1) time correction? & YES & YES & YES \\
\hline U.S. Regional/Geographic dummies & YES & YES & YES \\
\hline
\end{tabular}

Notes: * Significant with $95 \%$ confidence; $* *$ Significant with $99 \%$ confidence.

\section{Predicted Real $\$$ vs. Actual Real $\$$ \\ Agriculture \\ GLAK Region: $I L, I N, M I, O H, W \mid$}

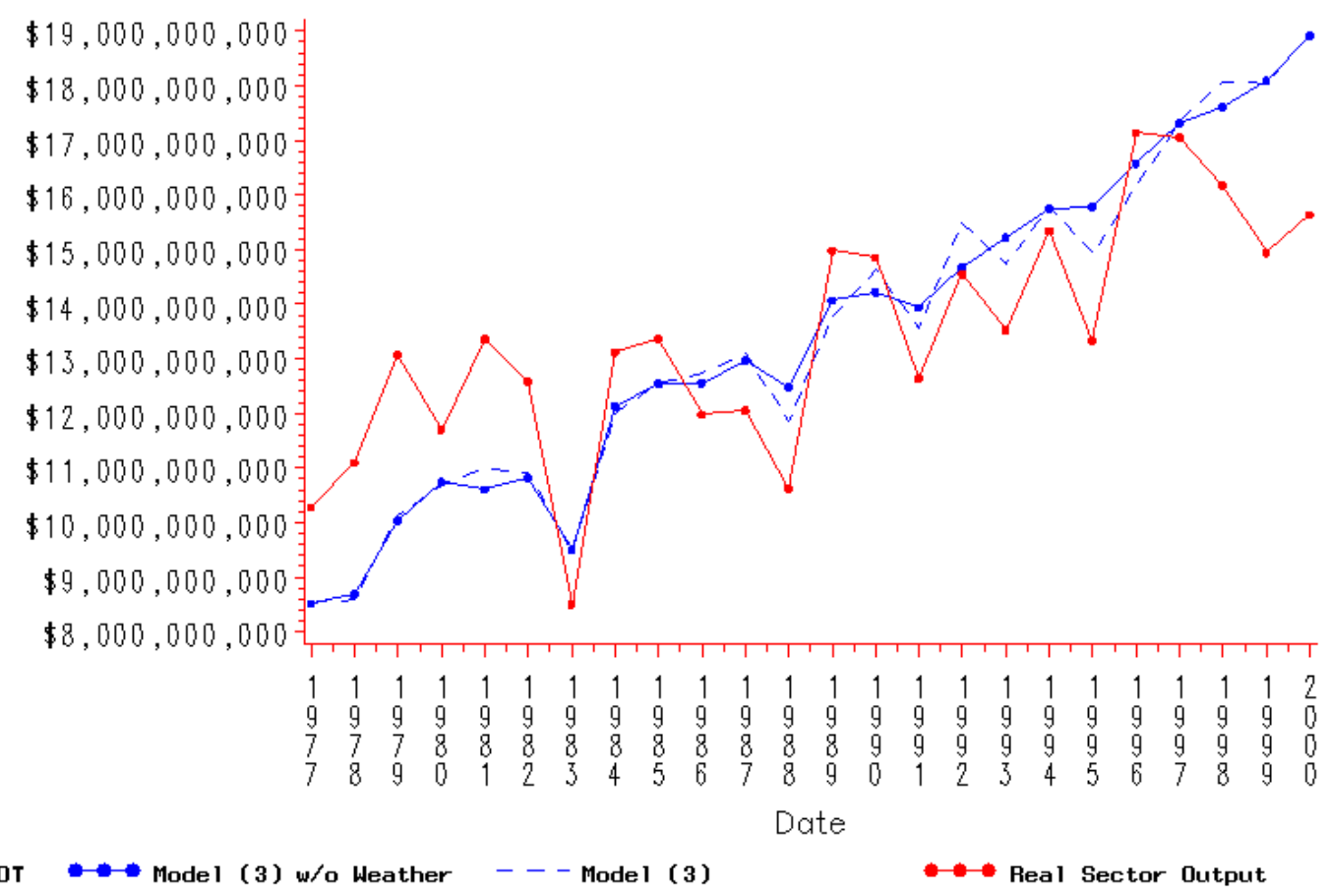


Table A.2 OLS Results from Panel Regression Dependent Variable $=\log ($ Wholesale Trade Gross Sector Product $)$

\begin{tabular}{|c|c|c|c|}
\hline & Model (1) & Model (2) & Model (3) \\
\hline \multirow{2}{*}{ Intercept } & $-80.631 * *$ & $-131.138 * *$ & $-126.271 * *$ \\
\hline & $(2.086)$ & $(14.290)$ & (14.838) \\
\hline \multirow{2}{*}{ Year } & $0.039 * *$ & $0.042 * *$ & $0.041 * *$ \\
\hline & $(0.001)$ & $(0.001)$ & $(0.001)$ \\
\hline \multirow{2}{*}{$\log ($ capital) } & $0.126^{* *}$ & -0.186 & 0.008 \\
\hline & $(0.019)$ & $(0.660)$ & $(0.654)$ \\
\hline \multirow{2}{*}{$\log$ (labor) } & $1.032 * *$ & $3.888^{*}$ & 2.803 \\
\hline & $(0.020)$ & $(1.650)$ & $(1.634)$ \\
\hline \multirow{2}{*}{$\log ($ energy $)$} & $0.080 * *$ & $4.622 * *$ & $3.533 *$ \\
\hline & $(0.019)$ & $(1.609)$ & $(1.596)$ \\
\hline \multirow[t]{2}{*}{$\log (\mathrm{hdd})$} & $-0.078 * *$ & $-0.334 * *$ & $1.300^{*}$ \\
\hline & $(0.013)$ & $(0.037)$ & $(0.619)$ \\
\hline \multirow{2}{*}{$\log (\mathrm{cdd})$} & -0.013 & -0.355 & $1.483^{* *}$ \\
\hline & $(0.008)$ & $(0.083)$ & $(0.450)$ \\
\hline \multirow{2}{*}{$\log$ (precip.) } & 0.021 & $0.124^{*}$ & $-1.727 * *$ \\
\hline & $(0.013)$ & $(0.047)$ & $(0.434)$ \\
\hline \multirow{2}{*}{$\log \left(\right.$ precip. $\left.^{2}\right)$} & $-0.024 *$ & $0.125^{*}$ & $1.221 *$ \\
\hline & $(0.012)$ & $(0.043)$ & $(0.491)$ \\
\hline \multirow{2}{*}{$\log \left(\operatorname{labor}^{2}\right)$} & & 0.233 & 0.209 \\
\hline & & $(0.161)$ & $(0.162)$ \\
\hline \multirow[t]{2}{*}{$\log \left(\right.$ energy $\left.^{2}\right)$} & & -0.071 & -0.151 \\
\hline & & $(0.012)$ & $(0.097)$ \\
\hline \multirow[t]{2}{*}{$\log \left(\right.$ capital $\left.^{2}\right)$} & & $-0.007 * *$ & $-0.334 * *$ \\
\hline & & $(0.008)$ & $(0.036)$ \\
\hline \multirow[t]{2}{*}{$\log ($ labor $\mathrm{x}$ energy) } & & $0.025^{* *}$ & $-0.262 * *$ \\
\hline & & $(0.013)$ & $(0.083)$ \\
\hline \multirow{2}{*}{$\log ($ labor x capital) } & & $-0.027 * *$ & $0.099 *$ \\
\hline & & $(0.012)$ & $(0.046)$ \\
\hline \multirow{2}{*}{$\log$ (capital x energy) } & & $-0.175^{* *}$ & $0.125 * *$ \\
\hline & & $(0.099)$ & $(0.042)$ \\
\hline \multirow[t]{2}{*}{$\log \left(\mathrm{hdd}^{2}\right)$} & & & $-0.117^{*}$ \\
\hline & & & $(0.046)$ \\
\hline \multirow[t]{2}{*}{$\log \left(\mathrm{cdd}^{2}\right)$} & & & $-0.093 * *$ \\
\hline & & & $(0.024)$ \\
\hline \multirow[t]{2}{*}{$\log \left(\right.$ precip. $\left.^{2}\right)$} & & & -0.013 \\
\hline & & & $(0.010)$ \\
\hline \multirow[t]{2}{*}{$\log \left(\right.$ precip. $\sigma^{2} \times$ precip. $\left.\sigma^{2}\right)$} & & & $0.023 *$ \\
\hline & & & $(0.010)$ \\
\hline \multirow[t]{2}{*}{$\log$ (precip x hdd) } & & & $0.158 * *$ \\
\hline & & & $(0.035)$ \\
\hline \multirow[t]{2}{*}{$\log \left(\operatorname{cdd} \times\right.$ precip. $\left.\sigma^{2}\right)$} & & & -0.046 \\
\hline & & & $(0.026)$ \\
\hline \multirow[t]{2}{*}{$\log ($ hdd $x$ cdd $)$} & & & $-0.132 * *$ \\
\hline & & & $(0.037)$ \\
\hline $\log \left(\right.$ hdd $x$ precip. $\left.\sigma^{2}\right)$ & & & $-0.116^{* *}$ \\
\hline
\end{tabular}


Table A.2 OLS Results from Panel Regression

Dependent Variable $=\log ($ Wholesale Trade Gross Sector Product $)$

\begin{tabular}{lccc} 
& Model (1) & Model (2) & Model (3) \\
\hline $\log$ (cdd x precip.) & & & $(0.040)$ \\
& & & $0.071^{* *}$ \\
FIT: Adj. R2 (pre-stationary) & & & $(0.023)$ \\
FIT: Akaike Information Criterion (stationary) & 0.9447 & 0.9525 & 0.9552 \\
Degrees of Freedom & -1937.7 & -2031.1 & -2034.3 \\
State fixed effects? & 1,136 & 1,130 & 1,121 \\
AR(1) time correction? & YES & YES & YES \\
U.S. Regional/Geographic dummies & YES & YES & YES \\
\multicolumn{2}{c}{ Notes: $=$ Significant with $95 \%$ confidence; **Significant with 99\% confidence. } \\
\hline
\end{tabular}

\section{Predicted Real $\$$ vs. Actual Real $\$$ Whalesale Trade SWST Region: AZ, NM, OK, TX}

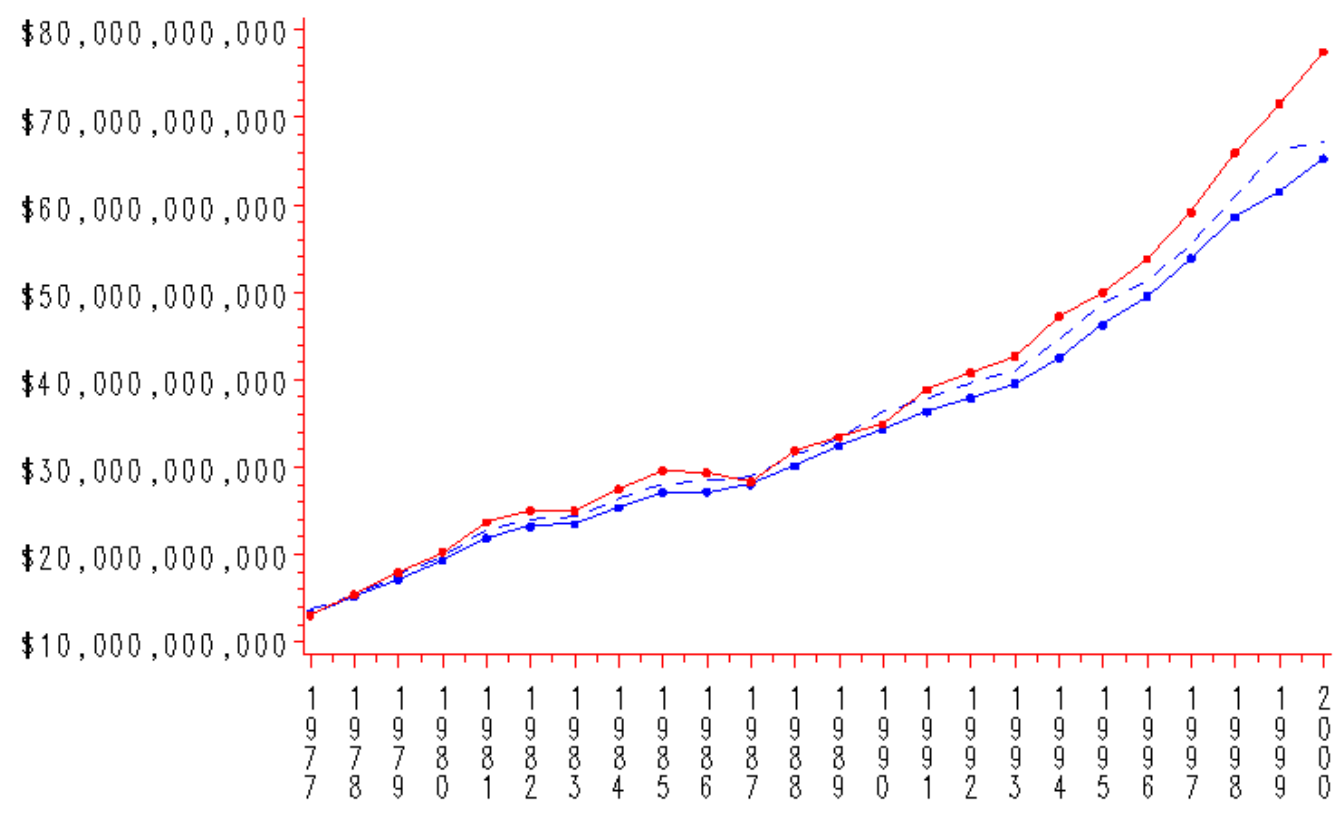

Date

PLOT - Model (3) w/o Weather --- Model (3) 
Table A.3 OLS Results from Panel Regression Dependent Variable $=\log ($ Retail Trade Gross Sector Product $)$

\begin{tabular}{|c|c|c|c|}
\hline & Model (1) & Model (2) & Model (3) \\
\hline \multirow{2}{*}{ Intercept } & $-61.087 * *$ & $-183.182 * *$ & $-181.869 * *$ \\
\hline & $(1.962)$ & $(17.271)$ & $(17.651)$ \\
\hline \multirow{2}{*}{ Year } & $0.032 * *$ & $0.034 * *$ & $0.032 * *$ \\
\hline & $(0.001)$ & $(0.001)$ & $(0.001)$ \\
\hline \multirow{2}{*}{$\log$ (capital) } & $0.318^{* *}$ & -0.905 & -0.440 \\
\hline & $(0.021)$ & (1.097) & $(1.088)$ \\
\hline \multirow{2}{*}{$\log$ (labor) } & $0.248 * *$ & $16.999 * *$ & $16.522 * *$ \\
\hline & $(0.031)$ & $(3.039)$ & $(2.996)$ \\
\hline \multirow{2}{*}{$\log$ (energy) } & -0.024 & $6.153^{* *}$ & $5.574 * *$ \\
\hline & $(0.016)$ & $(1.490)$ & $(1.475)$ \\
\hline \multirow{2}{*}{$\log (\mathrm{hdd})$} & $-0.067 * *$ & $-0.314 * *$ & 0.639 \\
\hline & $(0.011)$ & $(0.050)$ & $(0.519)$ \\
\hline \multirow[t]{2}{*}{$\log (\mathrm{cdd})$} & $0.034 * *$ & $-0.507 * *$ & $1.188^{* *}$ \\
\hline & $(0.007)$ & $(0.123)$ & $(0.377)$ \\
\hline \multirow{2}{*}{$\log$ (precip.) } & $0.027 * *$ & 0.415 & -0.170 \\
\hline & $(0.011)$ & $(0.114)$ & $(0.366)$ \\
\hline \multirow{2}{*}{$\log \left(\right.$ precip. $\left.\sigma^{2}\right)$} & $-0.037^{*}$ & $0.001 *$ & -0.369 \\
\hline & $(0.011)$ & $(0.046)$ & $(0.415)$ \\
\hline \multirow{2}{*}{$\log \left(\right.$ labor $\left.^{2}\right)$} & & $-1.344 * *$ & $-1.432 * *$ \\
\hline & & $(0.338)$ & $(0.333)$ \\
\hline \multirow[t]{2}{*}{$\log \left(\right.$ energy $\left.^{2}\right)$} & & -0.050 & -0.092 \\
\hline & & $(0.010)$ & $(0.080)$ \\
\hline \multirow[t]{2}{*}{$\log \left(\right.$ capital $\left.^{2}\right)$} & & $0.039 * *$ & $-0.307 * *$ \\
\hline & & $(0.007)$ & $(0.049)$ \\
\hline \multirow{2}{*}{$\log$ (labor $\mathrm{x}$ energy) } & & $0.015^{* *}$ & $-0.430 * *$ \\
\hline & & $(0.011)$ & $(0.123)$ \\
\hline \multirow{2}{*}{$\log ($ labor x capital $)$} & & $-0.025^{* *}$ & $0.418 * *$ \\
\hline & & $(0.010)$ & $(0.112)$ \\
\hline \multirow[t]{2}{*}{$\log$ (capital x energy) } & & -0.102 & -0.032 \\
\hline & & $(0.082)$ & $(0.047)$ \\
\hline \multirow[t]{2}{*}{$\log \left(h d d^{2}\right)$} & & & -0.033 \\
\hline & & & $(0.039)$ \\
\hline \multirow[t]{2}{*}{$\log \left(\mathrm{cdd}^{2}\right)$} & & & $-0.049^{*}$ \\
\hline & & & $(0.020)$ \\
\hline \multirow[t]{2}{*}{$\log$ (precip. $\left.{ }^{2}\right)$} & & & $-0.017^{*}$ \\
\hline & & & $(0.008)$ \\
\hline \multirow[t]{2}{*}{$\log \left(\right.$ precip. $\sigma^{2} \times$ precip. $\left.\sigma^{2}\right)$} & & & 0.011 \\
\hline & & & $(0.008)$ \\
\hline \multirow[t]{2}{*}{$\log$ (precip x hdd) } & & & 0.054 \\
\hline & & & $(0.030)$ \\
\hline \multirow[t]{2}{*}{$\log \left(\operatorname{cdd} x\right.$ precip. $\left.\sigma^{2}\right)$} & & & 0.034 \\
\hline & & & $(0.022)$ \\
\hline \multirow[t]{2}{*}{$\log ($ hdd $x$ cdd $)$} & & & $-0.088 * *$ \\
\hline & & & $(0.031)$ \\
\hline $\log \left(\right.$ hdd $\times$ precip. $\left.\sigma^{2}\right)$ & & & 0.012 \\
\hline
\end{tabular}


Table A.3 OLS Results from Panel Regression

Dependent Variable $=\log ($ Retail Trade Gross Sector Product $)$

\begin{tabular}{lcc} 
& Model (1) & Model (2) \\
\hline $\log$ (cdd x precip.) & & $(0.034)$ \\
& & -0.028 \\
& & \\
& & \\
& & $0.019)$ \\
FIT: Adj. R2 (pre-stationary) & 0.9474 & 0.9548 \\
FIT: Akaike Information Criterion (stationary) & -2256.7 & -2415.2 \\
Degrees of Freedom & 1,136 & 1,130 \\
State fixed effects? & YES & YES \\
AR(1) time correction? & YES & YES \\
U.S. Regional/Geographic dummies & YES & YES
\end{tabular}

Notes: $*=$ Significant with $95 \%$ confidence; $* *$ Significant with $99 \%$ confidence.
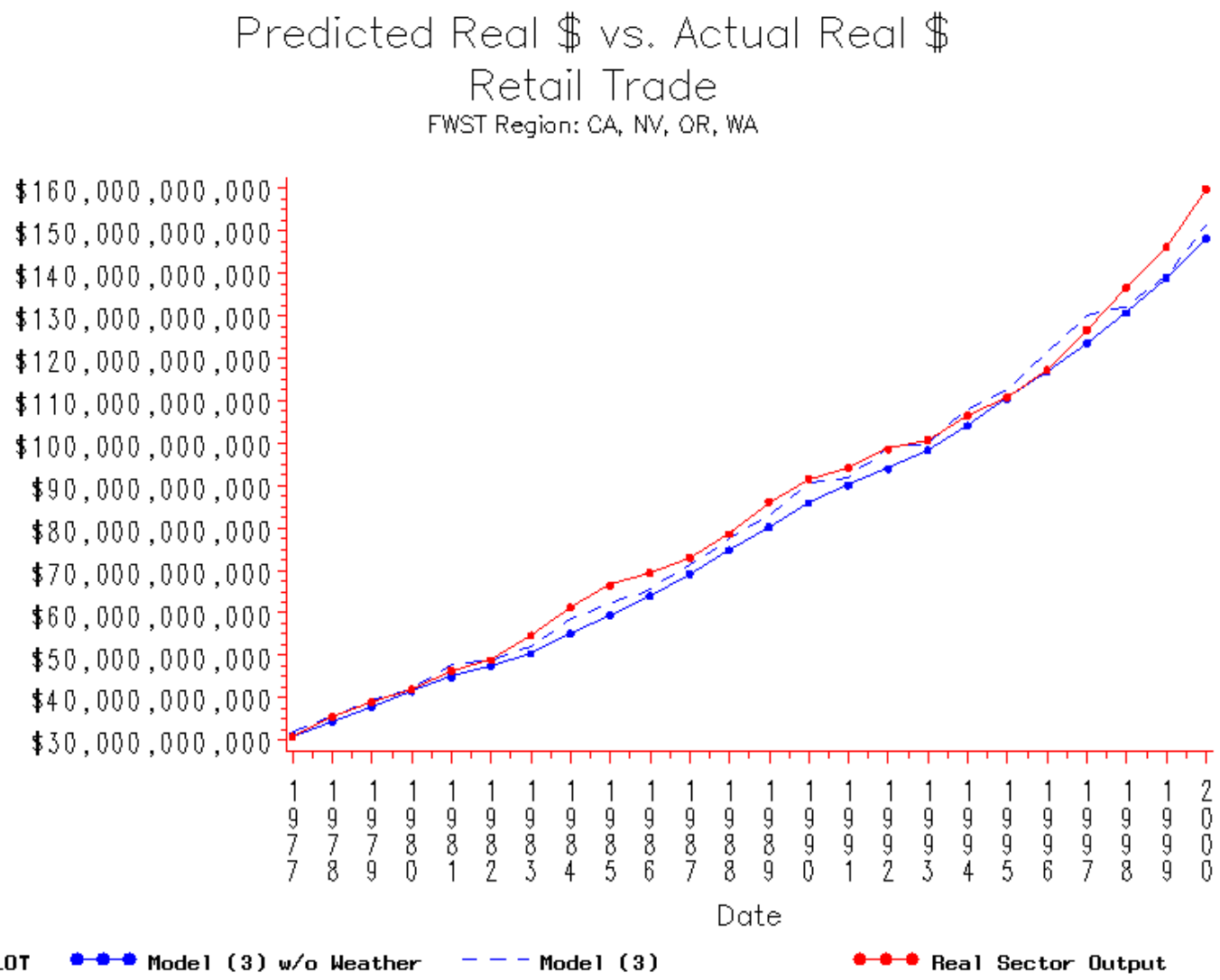
Table A.4 OLS Results from Panel Regression

Dependent Variable $=\log ($ FIRE Gross Sector Product $)$

\begin{tabular}{|c|c|c|c|}
\hline & Model (1) & Model (2) & Model (3) \\
\hline \multirow{2}{*}{ Intercept } & $-47.968^{* *}$ & $-131.821 * *$ & $-126.152 * *$ \\
\hline & $(2.940)$ & $(16.563)$ & $(16.174)$ \\
\hline \multirow{2}{*}{ Year } & $0.024 * *$ & $0.028 * *$ & $0.026 * *$ \\
\hline & $(0.001)$ & $(0.001)$ & $(0.001)$ \\
\hline \multirow{2}{*}{$\log$ (capital) } & $0.603 * *$ & -0.584 & 0.199 \\
\hline & $(0.029)$ & $(0.944)$ & $(0.881)$ \\
\hline \multirow{2}{*}{$\log$ (labor) } & $0.440 * *$ & $10.624 * *$ & $7.522 * *$ \\
\hline & $(0.037)$ & $(1.926)$ & $(1.814)$ \\
\hline \multirow{2}{*}{$\log ($ energy $)$} & -0.016 & $5.340 * *$ & $4.296^{*}$ \\
\hline & $(0.024)$ & $(1.817)$ & $(1.678)$ \\
\hline \multirow[t]{2}{*}{$\log (\mathrm{hdd})$} & $-0.079 * *$ & $-0.129 * *$ & $1.458^{*}$ \\
\hline & $(0.017)$ & $(0.056)$ & $(0.734)$ \\
\hline \multirow{2}{*}{$\log (\mathrm{cdd})$} & $-0.030 * *$ & $-0.668 * *$ & $2.344 * *$ \\
\hline & $(0.011)$ & $(0.121)$ & $(0.533)$ \\
\hline \multirow{2}{*}{$\log$ (precip.) } & -0.024 & 0.556 & 0.147 \\
\hline & $(0.017)$ & $(0.094)$ & $(0.520)$ \\
\hline \multirow{2}{*}{$\log \left(\right.$ precip. $\left.\sigma^{2}\right)$} & $0.039^{*}$ & -0.140 & -0.154 \\
\hline & $(0.015)$ & $(0.058)$ & $(0.589)$ \\
\hline \multirow[t]{2}{*}{$\log \left(\right.$ labor $\left.^{2}\right)$} & & $-0.554 * *$ & $-0.609 * *$ \\
\hline & & $(0.185)$ & $(0.173)$ \\
\hline \multirow{2}{*}{$\log \left(\right.$ energy $\left.^{2}\right)$} & & -0.090 & 0.019 \\
\hline & & $(0.016)$ & $(0.108)$ \\
\hline \multirow[t]{2}{*}{$\log \left(\right.$ capital $\left.^{2}\right)$} & & $-0.037^{*}$ & -0.092 \\
\hline & & $(0.010)$ & $(0.052)$ \\
\hline \multirow[t]{2}{*}{$\log ($ labor $\mathrm{x}$ energy) } & & $-0.013 * *$ & $-0.400 * *$ \\
\hline & & $(0.016)$ & $(0.115)$ \\
\hline \multirow{2}{*}{$\log ($ labor x capital) } & & $0.023 * *$ & $0.473 * *$ \\
\hline & & $(0.015)$ & $(0.087)$ \\
\hline \multirow{2}{*}{$\log$ (capital x energy) } & & $0.074 *$ & $-0.165^{* *}$ \\
\hline & & $(0.116)$ & $(0.054)$ \\
\hline \multirow[t]{2}{*}{$\log \left(\mathrm{hdd}^{2}\right)$} & & & -0.034 \\
\hline & & & $(0.055)$ \\
\hline \multirow[t]{2}{*}{$\log \left(\mathrm{cdd}^{2}\right)$} & & & $-0.120^{* *}$ \\
\hline & & & $(0.028)$ \\
\hline \multirow[t]{2}{*}{$\log \left(\right.$ precip. $\left.^{2}\right)$} & & & $0.063^{* *}$ \\
\hline & & & $(0.011)$ \\
\hline \multirow[t]{2}{*}{$\log \left(\right.$ precip. $\sigma^{2}$ x precip. $\left.\sigma^{2}\right)$} & & & $-0.025^{*}$ \\
\hline & & & $(0.011)$ \\
\hline \multirow[t]{2}{*}{$\log ($ precip x hdd) } & & & -0.006 \\
\hline & & & $(0.042)$ \\
\hline \multirow[t]{2}{*}{$\log \left(\operatorname{cdd} x\right.$ precip. $\left.\sigma^{2}\right)$} & & & 0.036 \\
\hline & & & $(0.031)$ \\
\hline \multirow[t]{2}{*}{$\log ($ hdd $x$ cdd $)$} & & & $-0.166^{* *}$ \\
\hline & & & $(0.043)$ \\
\hline \multirow[t]{2}{*}{$\log \left(\right.$ hdd $x$ precip. $\left.\sigma^{2}\right)$} & & & -0.008 \\
\hline & & & $(0.048)$ \\
\hline
\end{tabular}


Table A.4 OLS Results from Panel Regression

Dependent Variable $=\log ($ FIRE Gross Sector Product $)$

\begin{tabular}{lccc} 
& Model (1) & Model (2) & Model (3) \\
\hline $\log$ (cdd x precip.) & & & -0.053 \\
& & & $(0.028)$ \\
& & & 0.9627 \\
FIT: Adj. R2 (pre-stationary) & 0.9502 & 0.9545 & -1645.9 \\
FIT: Akaike Information Criterion (stationary) & -1408.5 & -1499.1 & 1,121 \\
Degrees of Freedom & 1,136 & 1,130 & YES \\
State fixed effects? & YES & YES & YES \\
AR(1) time correction? & YES & YES & YES \\
U.S. Regional/Geographic dummies & YES & YES &
\end{tabular}

Notes: $*=$ Significant with $95 \%$ confidence; $* *$ Significant with $99 \%$ confidence.

\section{Predicted Real \$vs. Actual Real \$ \\ FIRE \\ SEST Region: AL, AR, FL, GA, KY, LA, MS, NC}

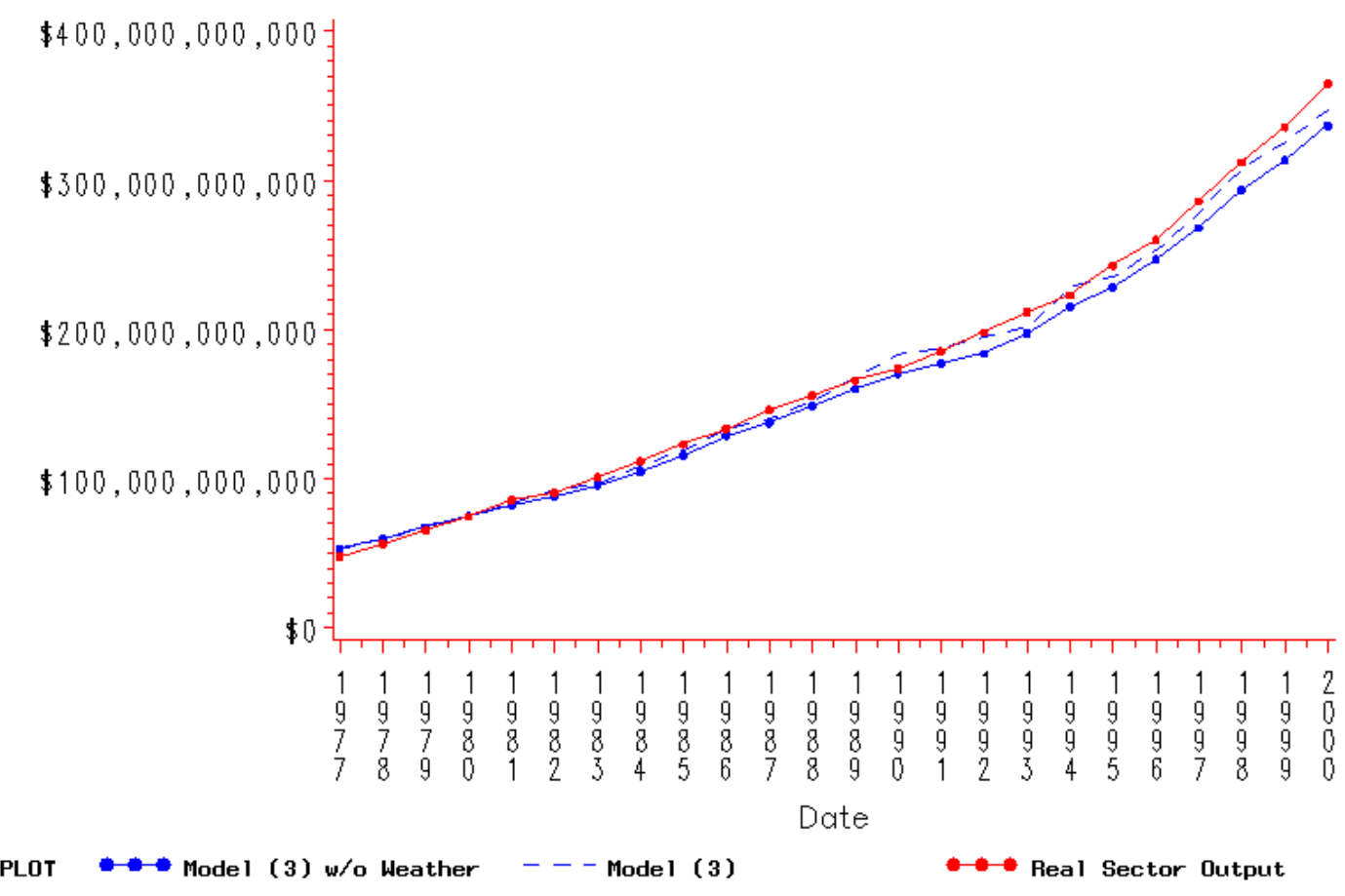


Table A.5 OLS Results from Panel Regression Dependent Variable $=\log ($ Communications Gross Sector Product $)$

\begin{tabular}{|c|c|c|c|}
\hline & Model (1) & Model (2) & Model (3) \\
\hline \multirow{2}{*}{ Intercept } & $-43.743 * *$ & -0.168 & -0.905 \\
\hline & $(2.424)$ & (14.129) & $(14.468)$ \\
\hline \multirow{2}{*}{ Year } & $0.022 * *$ & $0.024 * *$ & $0.024 * *$ \\
\hline & $(0.001)$ & $(0.001)$ & $(0.001)$ \\
\hline \multirow{2}{*}{$\log$ (capital) } & $0.606 * *$ & $-1.415^{*}$ & -1.089 \\
\hline & $(0.024)$ & $(0.722)$ & $(0.698)$ \\
\hline \multirow{2}{*}{$\log$ (labor) } & $0.491 * *$ & $-3.070 * *$ & $-3.424 * *$ \\
\hline & $(0.018)$ & $(1.072)$ & $(1.056)$ \\
\hline \multirow{2}{*}{$\log ($ energy $)$} & $-0.063 * *$ & $-3.731 * *$ & $-4.255^{* *}$ \\
\hline & $(0.022)$ & $(1.690)$ & $(1.628)$ \\
\hline \multirow{2}{*}{$\log (\mathrm{hdd})$} & $-0.104 * *$ & $-0.590 * *$ & 0.921 \\
\hline & $(0.015)$ & $(0.047)$ & $(0.640)$ \\
\hline \multirow{2}{*}{$\log (\mathrm{cdd})$} & -0.001 & -0.088 & 1.067 \\
\hline & $(0.010)$ & $(0.071)$ & $(0.466)$ \\
\hline \multirow{2}{*}{$\log$ (precip.) } & $0.070 * *$ & $0.534 * *$ & $-1.392 * *$ \\
\hline & $(0.015)$ & $(0.046)$ & $(0.455)$ \\
\hline \multirow{2}{*}{$\log \left(\right.$ precip. $\left.\sigma^{2}\right)$} & $-0.045^{* *}$ & $0.203^{* *}$ & 0.632 \\
\hline & $(0.014)$ & $(0.051)$ & $(0.515)$ \\
\hline \multirow[t]{2}{*}{$\log \left(\right.$ labor $\left.^{2}\right)$} & & 0.083 & 0.045 \\
\hline & & $(0.071)$ & $(0.070)$ \\
\hline \multirow{2}{*}{$\log \left(\right.$ energy $\left.^{2}\right)$} & & -0.103 & 0.188 \\
\hline & & $(0.013)$ & $(0.104)$ \\
\hline \multirow[t]{2}{*}{$\log \left(\right.$ capital $\left.^{2}\right)$} & & $0.011 * *$ & $-0.566 * *$ \\
\hline & & $(0.009)$ & $(0.045)$ \\
\hline \multirow{2}{*}{$\log$ (labor $\mathrm{x}$ energy) } & & 0.056 & -0.030 \\
\hline & & $(0.014)$ & $(0.069)$ \\
\hline \multirow[t]{2}{*}{$\log ($ labor x capital) } & & $-0.040 * *$ & $0.497 * *$ \\
\hline & & $(0.013)$ & $(0.044)$ \\
\hline \multirow{2}{*}{$\log$ (capital x energy) } & & $0.169^{* *}$ & $0.187 * *$ \\
\hline & & $(0.108)$ & $(0.049)$ \\
\hline \multirow[t]{2}{*}{$\log \left(\mathrm{hdd}^{2}\right)$} & & & -0.072 \\
\hline & & & $(0.048)$ \\
\hline \multirow[t]{2}{*}{$\log \left(\mathrm{cdd}^{2}\right)$} & & & $-0.048^{*}$ \\
\hline & & & $(0.025)$ \\
\hline \multirow[t]{2}{*}{$\log \left(\right.$ precip. $\left.{ }^{2}\right)$} & & & 0.001 \\
\hline & & & $(0.010)$ \\
\hline \multirow[t]{2}{*}{$\log \left(\right.$ precip. $\sigma^{2} \times$ precip. $\left.\sigma^{2}\right)$} & & & $0.022 *$ \\
\hline & & & $(0.010)$ \\
\hline \multirow[t]{2}{*}{$\log$ (precip x hdd) } & & & $0.112 * *$ \\
\hline & & & $(0.037)$ \\
\hline \multirow[t]{2}{*}{$\log \left(\operatorname{cdd} x\right.$ precip. $\left.\sigma^{2}\right)$} & & & $-0.062 *$ \\
\hline & & & $(0.027)$ \\
\hline \multirow[t]{2}{*}{$\log ($ hdd $x$ cdd $)$} & & & $-0.116^{* *}$ \\
\hline & & & $(0.038)$ \\
\hline \multirow[t]{2}{*}{$\log \left(\right.$ hdd $x$ precip. $\left.\sigma^{2}\right)$} & & & -0.034 \\
\hline & & & $(0.042)$ \\
\hline
\end{tabular}


Table A.5 OLS Results from Panel Regression

Dependent Variable $=\log ($ Communications Gross Sector Product $)$

\begin{tabular}{lcc} 
& Model (1) & Model (2) \\
\hline $\log$ (cdd x precip.) & & $0.074 * *$ \\
& & \\
& & \\
& & $0.024)$ \\
FIT: Adj. R2 (pre-stationary) & 0.9357 & 0.9481 \\
FIT: Akaike Information Criterion (stationary) & -1619.5 & -1870.3 \\
Degrees of Freedom & 1,136 & 1,130 \\
State fixed effects? & YES & YES \\
AR(1) time correction? & YES & YES \\
U.S. Regional/Geographic dummies & YES & YES
\end{tabular}

Notes: * = Significant with $95 \%$ confidence; **Significant with $99 \%$ confidence.
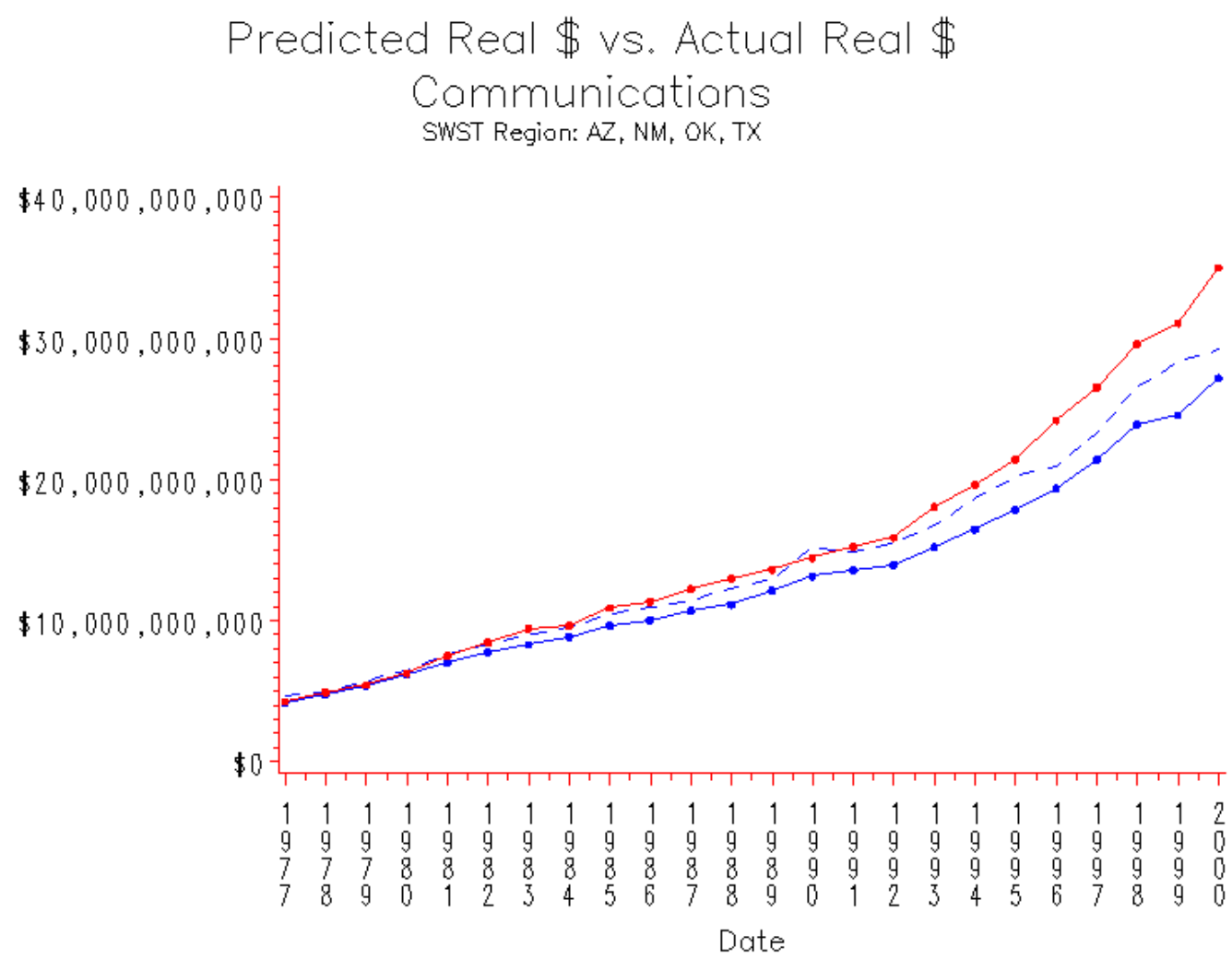

PLOT - Model (3) w/o Weather --- Model (3)

$\because$ Real Sector Output 
Table A.6 OLS Results from Panel Regression Dependent Variable $=\log ($ Utilities Gross Sector Product $)$

\begin{tabular}{|c|c|c|c|}
\hline & Model (1) & Model (2) & Model (3) \\
\hline \multirow{2}{*}{ Intercept } & $-33.370^{* *}$ & $-40.270^{* *}$ & $-45.871 * *$ \\
\hline & $(3.730)$ & $(5.674)$ & $(10.362)$ \\
\hline \multirow{2}{*}{ Year } & $0.015^{* *}$ & $0.014^{* *}$ & $0.014 * *$ \\
\hline & $(0.002)$ & $(0.002)$ & $(0.002)$ \\
\hline \multirow{2}{*}{$\log ($ capital) } & $0.718^{* *}$ & $4.859^{* *}$ & $5.666^{* *}$ \\
\hline & $(0.043)$ & $(0.862)$ & $(0.871)$ \\
\hline \multirow{2}{*}{$\log$ (labor) } & $0.567 * *$ & $2.918^{*}$ & 0.925 \\
\hline & $(0.036)$ & $(1.434)$ & $(1.501)$ \\
\hline \multirow{2}{*}{$\log ($ energy) } & $0.063 * *$ & $-1.878^{* *}$ & $-2.126^{* *}$ \\
\hline & $(0.016)$ & $(0.274)$ & $(0.303)$ \\
\hline \multirow[t]{2}{*}{$\log (\mathrm{hdd})$} & $-0.151^{* *}$ & $-0.902 * *$ & 2.046 \\
\hline & $(0.028)$ & $(0.092)$ & $(1.274)$ \\
\hline \multirow[t]{2}{*}{$\log (\mathrm{cdd})$} & -0.023 & 0.209 & 0.714 \\
\hline & $(0.019)$ & $(0.074)$ & $(0.930)$ \\
\hline \multirow{2}{*}{$\log$ (precip.) } & $0.090 * *$ & $0.329 * *$ & 0.888 \\
\hline & $(0.029)$ & $(0.108)$ & $(0.889)$ \\
\hline \multirow{2}{*}{$\log \left(\right.$ precip. $\left.\sigma^{2}\right)$} & $-0.125^{* *}$ & $0.072 * *$ & -0.524 \\
\hline & $(0.027)$ & $(0.039)$ & $(1.010)$ \\
\hline \multirow[t]{2}{*}{$\log \left(\right.$ labor $\left.^{2}\right)$} & & $-1.395^{* *}$ & $-1.327 * *$ \\
\hline & & $(0.158)$ & $(0.159)$ \\
\hline \multirow[t]{2}{*}{$\log \left(\right.$ energy $\left.^{2}\right)$} & & -0.089 & 0.000 \\
\hline & & $(0.025)$ & $(0.034)$ \\
\hline \multirow[t]{2}{*}{$\log \left(\right.$ capital $\left.^{2}\right)$} & & $0.031 * *$ & $-0.923^{* *}$ \\
\hline & & $(0.017)$ & $(0.092)$ \\
\hline \multirow{2}{*}{$\log ($ labor $\mathrm{x}$ energy) } & & $0.130^{* *}$ & $0.291 * *$ \\
\hline & & $(0.026)$ & $(0.077)$ \\
\hline \multirow{2}{*}{$\log$ (labor x capital) } & & $-0.132 * *$ & $0.331 * *$ \\
\hline & & $(0.024)$ & $(0.107)$ \\
\hline \multirow[t]{2}{*}{$\log$ (capital x energy) } & & 0.002 & 0.038 \\
\hline & & $(0.033)$ & $(0.039)$ \\
\hline \multirow[t]{2}{*}{$\log \left(h d d^{2}\right)$} & & & -0.179 \\
\hline & & & $(0.094)$ \\
\hline \multirow[t]{2}{*}{$\log \left(\operatorname{cdd}^{2}\right)$} & & & 0.007 \\
\hline & & & $(0.049)$ \\
\hline \multirow[t]{2}{*}{$\log \left(\right.$ precip. $\left.^{2}\right)$} & & & -0.014 \\
\hline & & & $(0.020)$ \\
\hline \multirow[t]{2}{*}{$\log \left(\right.$ precip. $\sigma^{2} \times$ precip. $\left.\sigma^{2}\right)$} & & & -0.021 \\
\hline & & & $(0.020)$ \\
\hline \multirow[t]{2}{*}{$\log$ (precip $\mathrm{x}$ hdd) } & & & -0.060 \\
\hline & & & $(0.072)$ \\
\hline \multirow[t]{2}{*}{$\log \left(\operatorname{cdd} \times\right.$ precip. $\left.\sigma^{2}\right)$} & & & -0.008 \\
\hline & & & $(0.053)$ \\
\hline \multirow[t]{2}{*}{$\log ($ hdd $x$ cdd $)$} & & & -0.072 \\
\hline & & & $(0.076)$ \\
\hline \multirow[t]{2}{*}{$\log \left(\right.$ hdd $\mathrm{x}$ precip. $\left.\sigma^{2}\right)$} & & & 0.059 \\
\hline & & & $(0.082)$ \\
\hline
\end{tabular}


Table A.6 OLS Results from Panel Regression

Dependent Variable $=\log ($ Utilities Gross Sector Product $)$

\begin{tabular}{lccc} 
& Model (1) & Model (2) & Model (3) \\
\hline $\log$ (cdd x precip.) & & & -0.028 \\
& & & $(0.047)$ \\
& & & 0.8659 \\
FIT: Adj. R2 (pre-stationary) & 0.8135 & 0.8568 & -424.0 \\
FIT: Akaike Information Criterion (stationary) & -147.7 & -438.0 & 1,121 \\
Degrees of Freedom & 1,136 & 1,130 & YES \\
State fixed effects? & YES & YES & YES \\
AR(1) time correction? & YES & YES & YES \\
U.S. Regional/Geographic dummies $\quad$ Yetes: * Significant with 95\% confidence; **Significant with 99\% confidence. & YES
\end{tabular}

\section{Predicted Real $\$$ vs. Actual Real $\$$ \\ Utilities \\ MEST Region: DE, MD/DC, NJ, NY, PA}

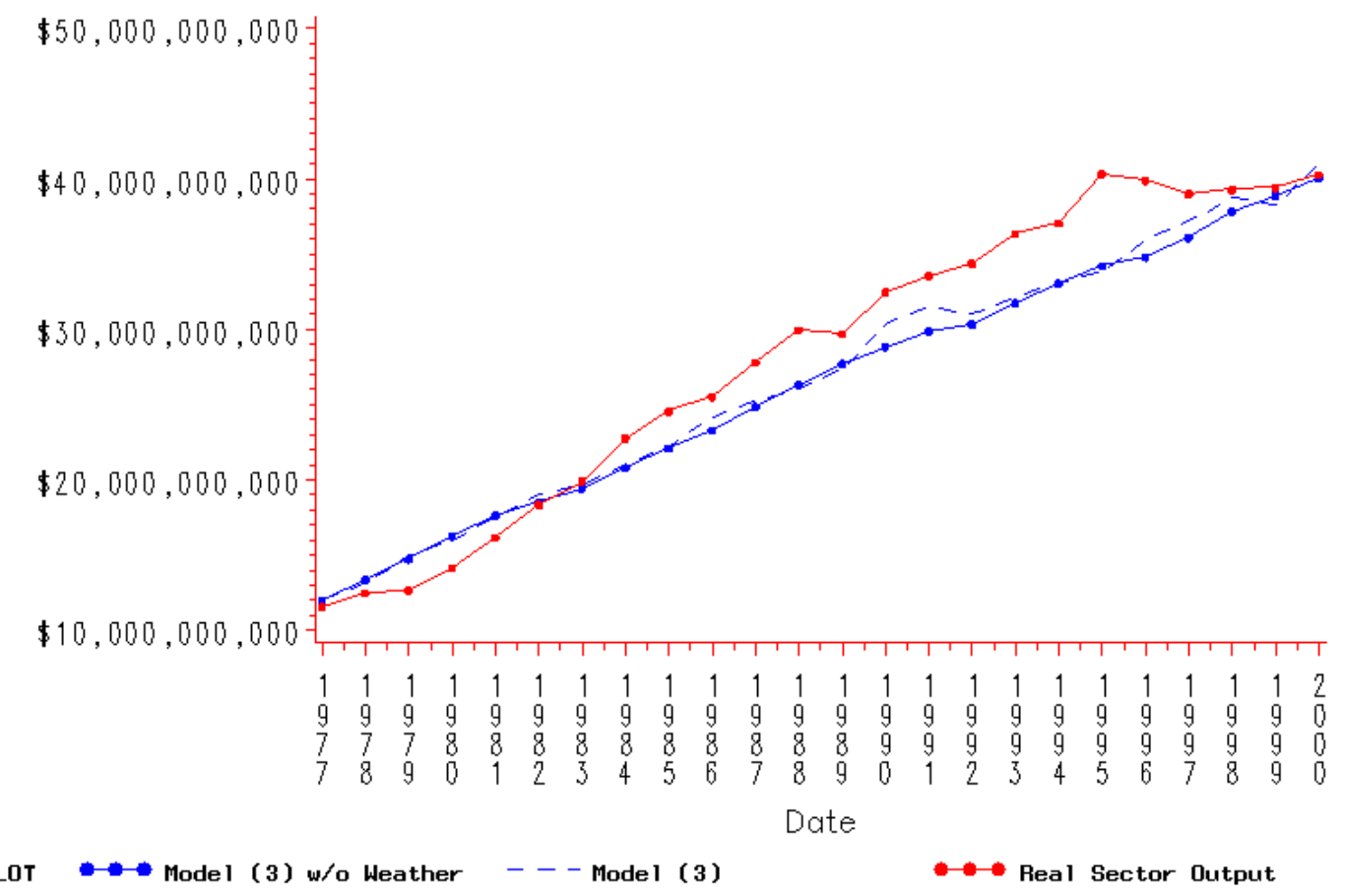


Table A.7 OLS Results from Panel Regression Dependent Variable $=\log ($ Transportation Gross Sector Product $)$

\begin{tabular}{|c|c|c|c|}
\hline & Model (1) & Model (2) & Model (3) \\
\hline \multirow{2}{*}{ Intercept } & $-41.425^{* *}$ & 24.311 & $55.007^{* *}$ \\
\hline & $(2.612)$ & (13.580) & $(15.353)$ \\
\hline \multirow{2}{*}{ Year } & $0.016^{* *}$ & $0.021 * *$ & $0.020 * *$ \\
\hline & $(0.001)$ & $(0.001)$ & $(0.001)$ \\
\hline \multirow{2}{*}{$\log$ (capital) } & $0.732 * *$ & $4.576^{* *}$ & $5.056^{* *}$ \\
\hline & $(0.031)$ & $(1.010)$ & $(1.019)$ \\
\hline \multirow{2}{*}{$\log$ (labor) } & $0.028 * *$ & 0.200 & 1.216 \\
\hline & $(0.008)$ & $(1.253)$ & $(1.300)$ \\
\hline \multirow{2}{*}{$\log$ (energy) } & $0.496^{* *}$ & $-9.317 * *$ & $-12.066^{* *}$ \\
\hline & $(0.027)$ & $(1.580)$ & (1.628) \\
\hline \multirow{2}{*}{$\log (\mathrm{hdd})$} & -0.007 & -0.445 & $-1.589^{*}$ \\
\hline & $(0.021)$ & $(0.054)$ & $(0.773)$ \\
\hline \multirow{2}{*}{$\log (\mathrm{cdd})$} & $0.038 * *$ & $-0.237 * *$ & -0.712 \\
\hline & $(0.014)$ & $(0.067)$ & $(0.549)$ \\
\hline \multirow{2}{*}{$\log$ (precip.) } & -0.005 & 0.569 & -0.673 \\
\hline & $(0.022)$ & $(0.029)$ & $(0.523)$ \\
\hline \multirow{2}{*}{$\log \left(\right.$ precip. $\left.\sigma^{2}\right)$} & $-0.041 * *$ & -0.226 & -0.493 \\
\hline & $(0.020)$ & $(0.054)$ & $(0.593)$ \\
\hline \multirow[t]{2}{*}{$\log \left(\operatorname{labor}^{2}\right)$} & & $-0.020 * *$ & $-0.022 * *$ \\
\hline & & $(0.004)$ & $(0.004)$ \\
\hline \multirow[t]{2}{*}{$\log \left(\right.$ energy $\left.^{2}\right)$} & & $-0.012 * *$ & $0.889 * *$ \\
\hline & & $(0.014)$ & $(0.102)$ \\
\hline \multirow[t]{2}{*}{$\log \left(\right.$ capital $\left.^{2}\right)$} & & $0.038 * *$ & $-0.468 * *$ \\
\hline & & $(0.010)$ & $(0.054)$ \\
\hline \multirow{2}{*}{$\log ($ labor $x$ energy) } & & $0.009 * *$ & $-0.291 * *$ \\
\hline & & $(0.015)$ & $(0.070)$ \\
\hline \multirow{2}{*}{$\log ($ labor x capital $)$} & & $-0.026^{* *}$ & $0.563 * *$ \\
\hline & & $(0.014)$ & $(0.029)$ \\
\hline \multirow{2}{*}{$\log$ (capital x energy) } & & $0.713^{* *}$ & $-0.238 * *$ \\
\hline & & $(0.100)$ & $(0.055)$ \\
\hline \multirow[t]{2}{*}{$\log \left(\mathrm{hdd}^{2}\right)$} & & & 0.109 \\
\hline & & & $(0.057)$ \\
\hline \multirow[t]{2}{*}{$\log \left(\mathrm{cdd}^{2}\right)$} & & & 0.044 \\
\hline & & & $(0.029)$ \\
\hline \multirow[t]{2}{*}{$\log \left(\right.$ precip. $\left.^{2}\right)$} & & & 0.000 \\
\hline & & & $(0.012)$ \\
\hline \multirow[t]{2}{*}{$\log \left(\right.$ precip. $\sigma^{2} \times$ precip. $\left.\sigma^{2}\right)$} & & & 0.000 \\
\hline & & & $(0.012)$ \\
\hline \multirow[t]{2}{*}{$\log$ (precip x hdd) } & & & 0.079 \\
\hline & & & $(0.043)$ \\
\hline \multirow[t]{2}{*}{$\log \left(\operatorname{cdd} \mathrm{x}\right.$ precip. $\left.\sigma^{2}\right)$} & & & 0.028 \\
\hline & & & $(0.031)$ \\
\hline \multirow[t]{2}{*}{$\log ($ hdd $x$ cdd $)$} & & & 0.051 \\
\hline & & & $(0.045)$ \\
\hline \multirow[t]{2}{*}{$\log \left(\right.$ hdd $x$ precip. $\left.\sigma^{2}\right)$} & & & 0.033 \\
\hline & & & $(0.048)$ \\
\hline
\end{tabular}


Table A.7 OLS Results from Panel Regression

Dependent Variable $=\log ($ Transportation Gross Sector Product $)$

\begin{tabular}{|c|c|c|c|}
\hline & Model (1) & Model (2) & Model (3) \\
\hline $\log ($ cdd x precip. $)$ & & & $\begin{array}{c}0.002 \\
(0.028)\end{array}$ \\
\hline FIT: Adj. R2 (pre-stationary) & 0.8913 & 0.9355 & 0.9491 \\
\hline FIT: Akaike Information Criterion (stationary) & -768.6 & -1613.9 & -1604.1 \\
\hline Degrees of Freedom & 1,136 & 1,130 & 1,121 \\
\hline State fixed effects? & YES & YES & YES \\
\hline AR(1) time correction? & YES & YES & YES \\
\hline U.S. Regional/Geographic dummies & YES & YES & YES \\
\hline
\end{tabular}

Notes: * $=$ Significant with $95 \%$ confidence; $* *$ Significant with $99 \%$ confidence.

\section{Predicted Real $\$$ vs. Actual Real $\$$ \\ Transportation \\ SWST Region: AZ, NM, OK, TX}

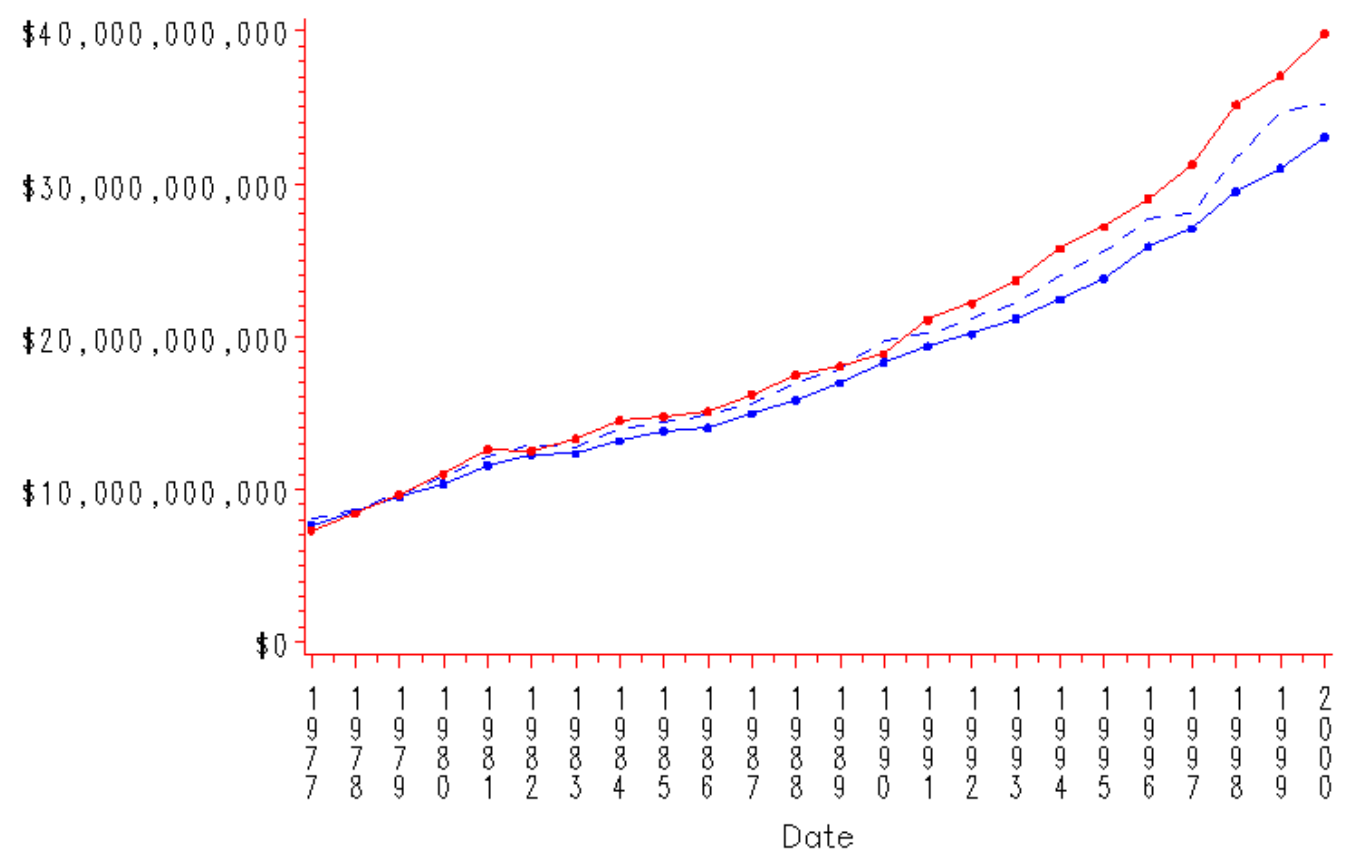


Table A.8 OLS Results from Panel Regression Dependent Variable = log(Manufacturing Gross Sector Product)

\begin{tabular}{|c|c|c|c|}
\hline & Model (1) & Model (2) & Model (3) \\
\hline \multirow{2}{*}{ Intercept } & $-52.809^{* *}$ & $-42.763^{* *}$ & $-28.517 *$ \\
\hline & $(3.838)$ & $(11.047)$ & (13.459) \\
\hline \multirow{2}{*}{ Year } & $0.024 * *$ & $0.030^{* *}$ & $0.031 * *$ \\
\hline & $(0.002)$ & $(0.002)$ & $(0.002)$ \\
\hline \multirow{2}{*}{$\log ($ capital) } & $0.579 * *$ & $1.939^{* *}$ & $1.798 * *$ \\
\hline & $(0.038)$ & $(0.632)$ & $(0.629)$ \\
\hline \multirow{2}{*}{$\log$ (labor) } & $0.698 * *$ & $2.338^{* *}$ & $1.883^{* *}$ \\
\hline & $(0.022)$ & $(0.685)$ & $(0.727)$ \\
\hline \multirow[t]{2}{*}{$\log ($ energy) } & $0.071 * *$ & $-3.782 * *$ & $-4.030^{* *}$ \\
\hline & $(0.010)$ & $(0.772)$ & $(0.778)$ \\
\hline \multirow{2}{*}{$\log (\mathrm{hdd})$} & -0.023 & $-0.249 * *$ & $-2.564^{*}$ \\
\hline & $(0.020)$ & $(0.062)$ & $(1.039)$ \\
\hline \multirow{2}{*}{$\log (\mathrm{cdd})$} & -0.012 & -0.019 & -0.350 \\
\hline & $(0.013)$ & $(0.025)$ & $(0.740)$ \\
\hline \multirow{2}{*}{$\log$ (precip.) } & $0.047^{*}$ & 0.126 & 0.243 \\
\hline & $(0.021)$ & $(0.039)$ & $(0.699)$ \\
\hline \multirow[t]{2}{*}{$\log \left(\right.$ precip. $\left.\sigma^{2}\right)$} & -0.032 & -0.024 & -1.038 \\
\hline & $(0.020)$ & $(0.023)$ & $(0.786)$ \\
\hline \multirow[t]{2}{*}{$\log \left(\right.$ labor $\left.^{2}\right)$} & & $-0.262 * *$ & $-0.227 * *$ \\
\hline & & $(0.049)$ & $(0.052)$ \\
\hline \multirow[t]{2}{*}{$\log \left(\right.$ energy $\left.^{2}\right)$} & & $0.083^{* *}$ & $0.248^{* *}$ \\
\hline & & $(0.023)$ & $(0.032)$ \\
\hline \multirow[t]{2}{*}{$\log \left(\right.$ capital $\left.^{2}\right)$} & & $0.009 * *$ & $-0.264 * *$ \\
\hline & & $(0.013)$ & $(0.062)$ \\
\hline \multirow[t]{2}{*}{$\log ($ labor $\mathrm{x}$ energy) } & & 0.035 & -0.019 \\
\hline & & $(0.021)$ & $(0.025)$ \\
\hline \multirow[t]{2}{*}{$\log ($ labor x capital $)$} & & $-0.019 * *$ & $0.145^{* *}$ \\
\hline & & $(0.019)$ & $(0.039)$ \\
\hline \multirow[t]{2}{*}{$\log$ (capital x energy) } & & 0.235 & -0.020 \\
\hline & & $(0.032)$ & $(0.023)$ \\
\hline \multirow[t]{2}{*}{$\log \left(h d d^{2}\right)$} & & & $0.212 * *$ \\
\hline & & & $(0.078)$ \\
\hline \multirow[t]{2}{*}{$\log \left(\operatorname{cdd}^{2}\right)$} & & & -0.053 \\
\hline & & & $(0.038)$ \\
\hline \multirow[t]{2}{*}{$\log \left(\right.$ precip. $\left.^{2}\right)$} & & & 0.018 \\
\hline & & & $(0.016)$ \\
\hline \multirow[t]{2}{*}{$\log \left(\right.$ precip. $\sigma^{2} \times$ precip. $\left.\sigma^{2}\right)$} & & & -0.020 \\
\hline & & & $(0.015)$ \\
\hline \multirow[t]{2}{*}{$\log$ (precip $x$ hdd) } & & & 0.025 \\
\hline & & & $(0.057)$ \\
\hline \multirow[t]{2}{*}{$\log \left(\operatorname{cdd} \times\right.$ precip. $\left.\sigma^{2}\right)$} & & & $0.102 *$ \\
\hline & & & $(0.042)$ \\
\hline \multirow[t]{2}{*}{$\log ($ hdd $x$ cdd $)$} & & & 0.103 \\
\hline & & & $(0.061)$ \\
\hline \multirow[t]{2}{*}{$\log \left(\right.$ hdd $\mathrm{x}$ precip. $\left.\sigma^{2}\right)$} & & & 0.040 \\
\hline & & & $(0.064)$ \\
\hline
\end{tabular}


Table A.8 OLS Results from Panel Regression

Dependent Variable $=\log ($ Manufacturing Gross Sector Product $)$

\begin{tabular}{lccc} 
& Model (1) & Model (2) & Model (3) \\
\hline $\log$ (cdd x precip.) & & & -0.071 \\
& & & $(0.038)$ \\
& & & 0.9373 \\
FIT: Adj. R2 (pre-stationary) & 0.9252 & 0.9351 & -971.7 \\
FIT: Akaike Information Criterion (stationary) & -867.9 & -973.1 & 1,121 \\
Degrees of Freedom & 1,136 & 1,130 & YES \\
State fixed effects? & YES & YES & YES \\
AR(1) time correction? & YES & YES & YES \\
U.S. Regional/Geographic dummies $\quad$ YES & YES
\end{tabular}

\section{Predicted Real \$vs. Actual Real \$ Manufacturing \\ NENG Region: CT, ME, MA, NH, RI, VT}

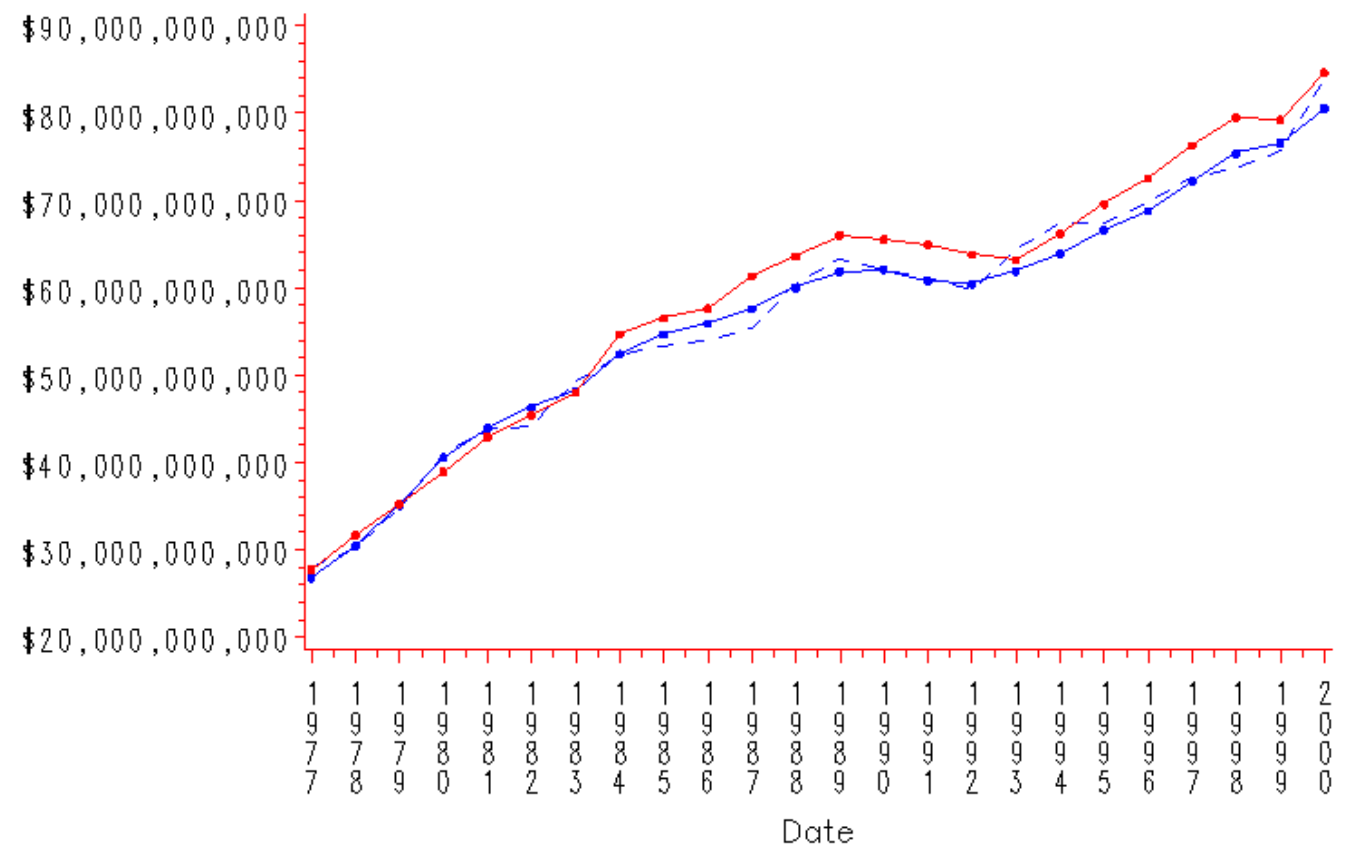

PLOT - Model (3) w/o Weather -- Model (3) 
Table A.9 OLS Results from Panel Regression

Dependent Variable $=\log ($ Construction Gross Sector Product $)$

\begin{tabular}{|c|c|c|c|}
\hline & Model (1) & Model (2) & Model (3) \\
\hline \multirow{2}{*}{ Intercept } & $-80.832^{* *}$ & $-129.844 * *$ & $-138.931 * *$ \\
\hline & $(2.529)$ & $(16.361)$ & $(17.503)$ \\
\hline \multirow{2}{*}{ Year } & $0.039 * *$ & $0.038^{* *}$ & $0.037 * *$ \\
\hline & $(0.001)$ & $(0.001)$ & $(0.001)$ \\
\hline \multirow{2}{*}{$\log$ (capital) } & -0.032 & $4.528 * *$ & $4.326^{* *}$ \\
\hline & $(0.026)$ & $(0.923)$ & $(0.910)$ \\
\hline \multirow{2}{*}{$\log$ (labor) } & $0.899 * *$ & $-3.840 * *$ & -1.682 \\
\hline & $(0.021)$ & $(1.504)$ & $(1.525)$ \\
\hline \multirow{2}{*}{$\log$ (energy) } & $0.175^{* *}$ & $6.748^{* *}$ & $6.590 * *$ \\
\hline & $(0.026)$ & $(1.985)$ & $(1.935)$ \\
\hline \multirow{2}{*}{$\log (\mathrm{hdd})$} & $-0.050 * *$ & -0.242 & 0.292 \\
\hline & $(0.018)$ & $(0.064)$ & $(0.845)$ \\
\hline \multirow{2}{*}{$\log (\mathrm{cdd})$} & $0.028^{*}$ & $0.211^{* *}$ & $1.370^{*}$ \\
\hline & $(0.012)$ & $(0.095)$ & $(0.613)$ \\
\hline \multirow{2}{*}{$\log$ (precip.) } & -0.026 & -0.447 & -1.115 \\
\hline & $(0.018)$ & $(0.064)$ & $(0.586)$ \\
\hline \multirow{2}{*}{$\log \left(\right.$ precip. $\left.\sigma^{2}\right)$} & 0.015 & 0.055 & 0.717 \\
\hline & $(0.017)$ & $(0.065)$ & $(0.664)$ \\
\hline \multirow[t]{2}{*}{$\log \left(\right.$ labor $\left.^{2}\right)$} & & $0.637^{* *}$ & $0.572 * *$ \\
\hline & & $(0.115)$ & $(0.114)$ \\
\hline \multirow[t]{2}{*}{$\log \left(\right.$ energy $\left.^{2}\right)$} & & $-0.024 * *$ & $-0.465 * *$ \\
\hline & & $(0.016)$ & $(0.134)$ \\
\hline \multirow{2}{*}{$\log \left(\right.$ capital $\left.^{2}\right)$} & & $0.030 * *$ & $-0.244 * *$ \\
\hline & & $(0.011)$ & $(0.063)$ \\
\hline \multirow[t]{2}{*}{$\log ($ labor $\mathrm{x}$ energy) } & & $-0.026^{*}$ & 0.081 \\
\hline & & $(0.017)$ & $(0.096)$ \\
\hline \multirow{2}{*}{$\log ($ labor x capital) } & & $0.020^{* *}$ & $-0.394 * *$ \\
\hline & & $(0.016)$ & $(0.063)$ \\
\hline \multirow{2}{*}{$\log$ (capital x energy) } & & -0.548 & 0.043 \\
\hline & & $(0.137)$ & $(0.064)$ \\
\hline \multirow{2}{*}{$\log \left(h d d^{2}\right)$} & & & -0.016 \\
\hline & & & $(0.062)$ \\
\hline \multirow[t]{2}{*}{$\log \left(\mathrm{cdd}^{2}\right)$} & & & $-0.119 * *$ \\
\hline & & & $(0.032)$ \\
\hline \multirow[t]{2}{*}{$\log \left(\right.$ precip. $\left.^{2}\right)$} & & & -0.004 \\
\hline & & & $(0.013)$ \\
\hline \multirow[t]{2}{*}{$\log \left(\right.$ precip. $\sigma^{2} \times$ precip. $\left.\sigma^{2}\right)$} & & & 0.022 \\
\hline & & & $(0.013)$ \\
\hline \multirow[t]{2}{*}{$\log$ (precip x hdd) } & & & $0.103 *$ \\
\hline & & & $(0.048)$ \\
\hline \multirow[t]{2}{*}{$\log \left(\operatorname{cdd} \times\right.$ precip. $\left.\sigma^{2}\right)$} & & & -0.046 \\
\hline & & & $(0.035)$ \\
\hline \multirow[t]{2}{*}{$\log ($ hdd $x$ cdd $)$} & & & -0.082 \\
\hline & & & $(0.050)$ \\
\hline \multirow[t]{2}{*}{$\log \left(\right.$ hdd x precip. $\left.\sigma^{2}\right)$} & & & -0.050 \\
\hline & & & $(0.054)$ \\
\hline
\end{tabular}


Table A.9 OLS Results from Panel Regression

Dependent Variable $=\log ($ Construction Gross Sector Product $)$

\begin{tabular}{lccc} 
& Model (1) & Model (2) & Model (3) \\
\hline $\log$ (cdd x precip.) & & & 0.035 \\
& & & $(0.031)$ \\
& & & 0.9195 \\
FIT: Adj. R2 (pre-stationary) & 0.8982 & 0.9130 & -1374.3 \\
FIT: Akaike Information Criterion (stationary) & -1164.1 & -1345.7 & 1,121 \\
Degrees of Freedom & 1,136 & 1,130 & YES \\
State fixed effects? & YES & YES & YES \\
AR(1) time correction? & YES & YES & YES \\
U.S. Regional/Geographic dummies & YES & YES &
\end{tabular}

Notes: * = Significant with $95 \%$ confidence; ${ }^{*}$ Significant with $99 \%$ confidence.

\section{Predicted Real $\$$ vs. Actual Real $\$$ Construction \\ SEST Region: AL, AR, FL, GA, KY, LA, MS, NC}

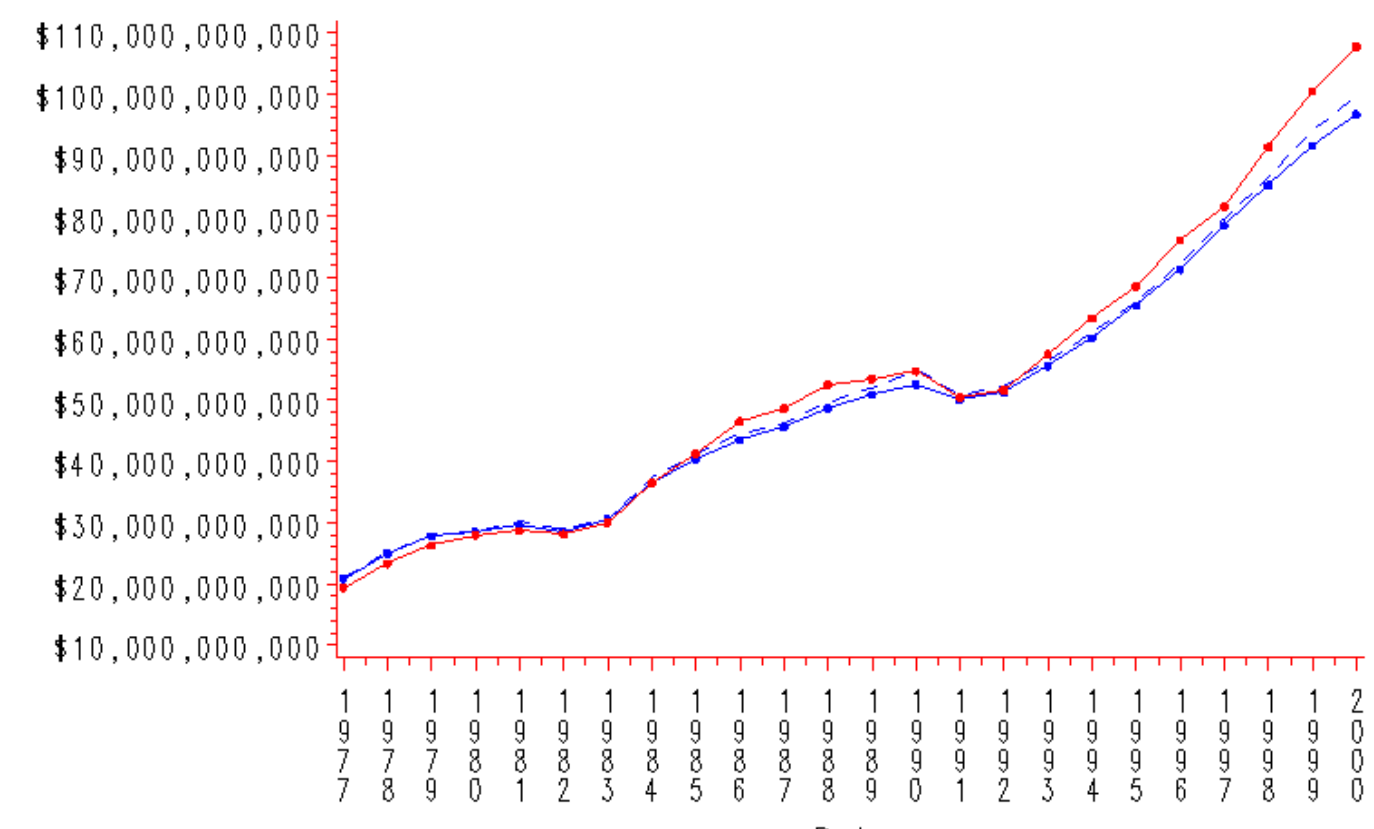

Date

PLOT - Model (3) w/o Weather - - Model (3)

$\because$ Real Sector Output 
Table A.10 OLS Results from Panel Regression Dependent Variable $=\log ($ Mining Gross Sector Product $)$

\begin{tabular}{|c|c|c|c|}
\hline & Model (1) & Model (2) & Model (3) \\
\hline \multirow{2}{*}{ Intercept } & $-74.704 * *$ & -19.555 & $-78.961 * *$ \\
\hline & $(5.030)$ & (13.778) & (20.563) \\
\hline \multirow{2}{*}{ Year } & $0.038 * *$ & $0.035^{* *}$ & $0.034 * *$ \\
\hline & $(0.003)$ & $(0.003)$ & $(0.003)$ \\
\hline \multirow{2}{*}{$\log$ (capital) } & $0.096^{*}$ & -0.547 & -0.572 \\
\hline & $(0.042)$ & $(0.936)$ & $(0.870)$ \\
\hline \multirow{2}{*}{$\log$ (labor) } & $1.222 * *$ & -0.286 & 0.139 \\
\hline & $(0.021)$ & $(0.517)$ & $(0.503)$ \\
\hline \multirow{2}{*}{$\log ($ energy $)$} & $0.049 *$ & $-4.914 * *$ & $-4.208 * *$ \\
\hline & $(0.023)$ & $(1.440)$ & (1.398) \\
\hline \multirow{2}{*}{$\log (\mathrm{hdd})$} & $-0.351 * *$ & $-0.176^{*}$ & $8.530 * *$ \\
\hline & $(0.044)$ & $(0.073)$ & $(2.060)$ \\
\hline \multirow{2}{*}{$\log (\mathrm{cdd})$} & $-0.078 * *$ & 0.121 & $7.000 * *$ \\
\hline & $(0.030)$ & $(0.025)$ & $(1.460)$ \\
\hline \multirow{2}{*}{$\log$ (precip.) } & $-0.316^{* *}$ & $-0.055^{* *}$ & $-4.336 * *$ \\
\hline & $(0.045)$ & $(0.032)$ & $(1.382)$ \\
\hline \multirow{2}{*}{$\log \left(\right.$ precip. $\left.\sigma^{2}\right)$} & $0.210^{* *}$ & $0.133^{* *}$ & $7.043 * *$ \\
\hline & $(0.042)$ & $(0.051)$ & $(1.568)$ \\
\hline \multirow{2}{*}{$\log \left(\right.$ labor $\left.^{2}\right)$} & & $-0.048^{*}$ & $-0.085^{* *}$ \\
\hline & & $(0.022)$ & $(0.022)$ \\
\hline \multirow{2}{*}{$\log \left(\right.$ energy $\left.^{2}\right)$} & & $-0.099^{*}$ & $0.171 *$ \\
\hline & & $(0.050)$ & $(0.081)$ \\
\hline \multirow[t]{2}{*}{$\log \left(\right.$ capital $\left.^{2}\right)$} & & $-0.034 *$ & -0.039 \\
\hline & & $(0.028)$ & $(0.069)$ \\
\hline \multirow[t]{2}{*}{$\log$ (labor $\mathrm{x}$ energy) } & & $-0.320 * *$ & $0.115^{* *}$ \\
\hline & & $(0.042)$ & $(0.025)$ \\
\hline \multirow{2}{*}{$\log ($ labor x capital) } & & 0.211 & -0.068 \\
\hline & & $(0.039)$ & $(0.030)$ \\
\hline \multirow[t]{2}{*}{$\log$ (capital x energy) } & & $0.179 * *$ & 0.076 \\
\hline & & $(0.083)$ & $(0.048)$ \\
\hline \multirow{2}{*}{$\log \left(h d d^{2}\right)$} & & & $-0.666^{* *}$ \\
\hline & & & $(0.153)$ \\
\hline \multirow[t]{2}{*}{$\log \left(\operatorname{cdd}^{2}\right)$} & & & $-0.503 * *$ \\
\hline & & & $(0.076)$ \\
\hline \multirow[t]{2}{*}{$\log \left(\right.$ precip. $\left.^{2}\right)$} & & & $0.086^{* *}$ \\
\hline & & & $(0.030)$ \\
\hline \multirow[t]{2}{*}{$\log \left(\right.$ precip. $\sigma^{2} \times$ precip. $\left.\sigma^{2}\right)$} & & & 0.015 \\
\hline & & & $(0.030)$ \\
\hline \multirow[t]{2}{*}{$\log$ (precip x hdd) } & & & $0.235^{*}$ \\
\hline & & & $(0.112)$ \\
\hline \multirow[t]{2}{*}{$\log \left(\operatorname{cdd} x\right.$ precip. $\left.\sigma^{2}\right)$} & & & $-0.316^{* *}$ \\
\hline & & & $(0.084)$ \\
\hline \multirow[t]{2}{*}{$\log ($ hdd $x$ cdd $)$} & & & $-0.536^{* *}$ \\
\hline & & & $(0.121)$ \\
\hline \multirow[t]{2}{*}{$\log \left(\right.$ hdd x precip. $\left.\sigma^{2}\right)$} & & & $-0.571 * *$ \\
\hline & & & $(0.127)$ \\
\hline
\end{tabular}


Table A.10 OLS Results from Panel Regression

Dependent Variable $=\log ($ Mining Gross Sector Product $)$

\begin{tabular}{lccc} 
& Model (1) & Model (2) & Model (3) \\
\hline $\log$ (cdd x precip.) & & & $0.251^{* *}$ \\
& & & $(0.075)$ \\
& & & 0.9709 \\
FIT: Adj. R2 (pre-stationary) & 0.9603 & 0.9665 & 586.7 \\
FIT: Akaike Information Criterion (stationary) & 860.4 & 738.9 & 1,120 \\
Degrees of Freedom & 1,135 & 1,129 & YES \\
State fixed effects? & YES & YES & YES \\
AR(1) time correction? & YES & YES & YES \\
U.S. Regional/Geographic dummies & YES & YES &
\end{tabular}

Notes: * = Significant with $95 \%$ confidence; ${ }^{*}$ Significant with $99 \%$ confidence.

\section{Predicted Real $\$$ vs. Actual Real $\$$ Mining \\ FWST Region: CA, NV, OR, WA}

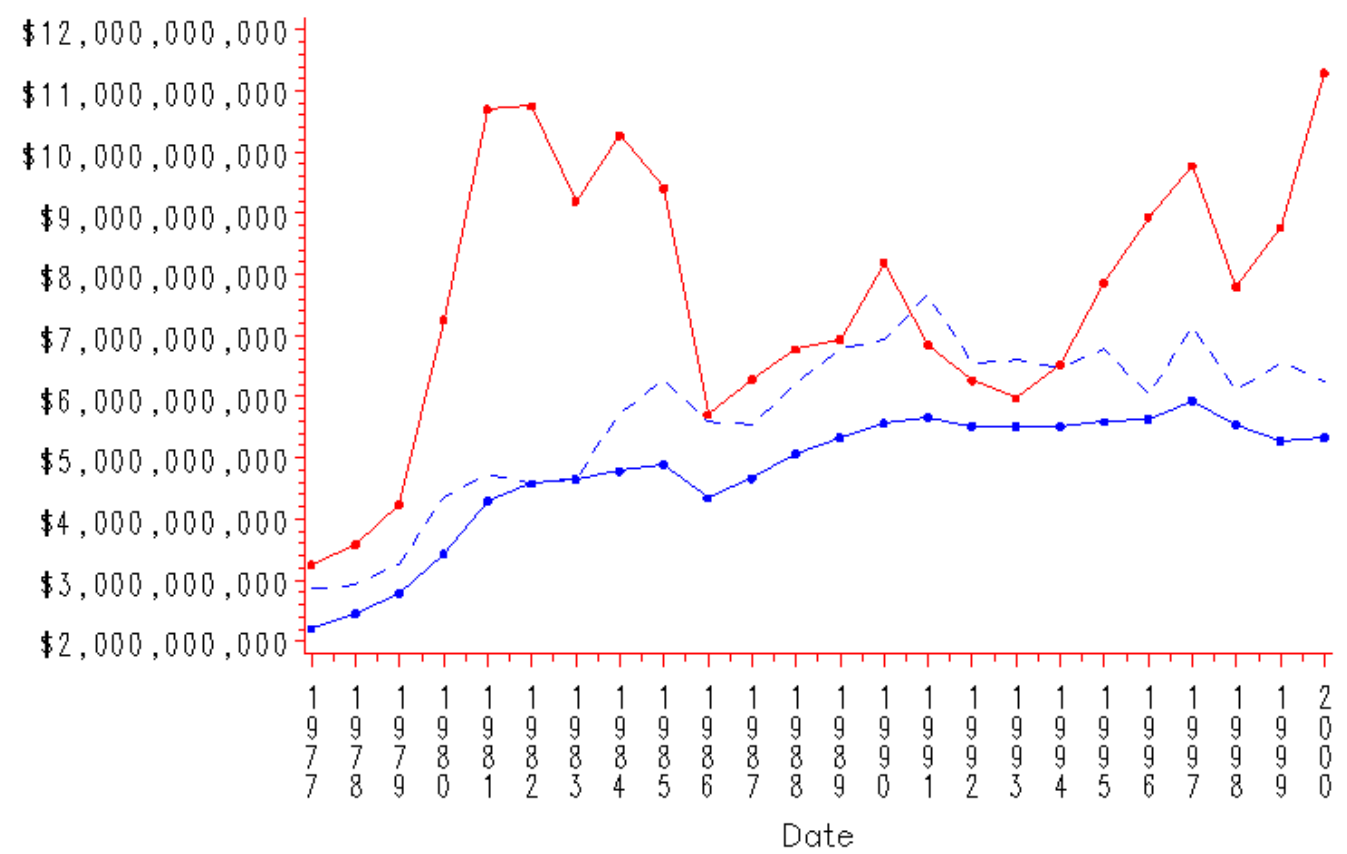

PLOT - Model (3) w/o Weather --- Model (3) 
Table A.11 OLS Results from Panel Regression Dependent Variable $=\log ($ Services Gross Sector Product $)$

\begin{tabular}{|c|c|c|c|}
\hline & Model (1) & Model (2) & Model (3) \\
\hline \multirow{2}{*}{ Intercept } & $-57.172 * *$ & -84.620 & $-87.274 * *$ \\
\hline & $(2.184)$ & (14.954) & 15.177 \\
\hline \multirow{2}{*}{ Year } & $0.028 * *$ & $0.025 * *$ & $0.025 * *$ \\
\hline & $(0.001)$ & $(0.001)$ & $(0.001)$ \\
\hline \multirow{2}{*}{$\log$ (capital) } & $0.549 *$ & 1.781 & 3.021 \\
\hline & $(0.028)$ & $(1.205)$ & (1.192) \\
\hline \multirow{2}{*}{$\log$ (labor) } & $0.653 * *$ & 3.302 & 1.369 \\
\hline & $(0.032)$ & $(1.680)$ & $(1.667)$ \\
\hline \multirow{2}{*}{$\log ($ energy $)$} & $-0.005^{*}$ & $1.659 * *$ & $0.837 * *$ \\
\hline & $(0.020)$ & $(1.707)$ & $(1.662)$ \\
\hline \multirow{2}{*}{$\log (\mathrm{hdd})$} & $-0.068 * *$ & $-0.547^{*}$ & $1.655^{* *}$ \\
\hline & $(0.013)$ & $(0.099)$ & $(0.665)$ \\
\hline \multirow{2}{*}{$\log (\mathrm{cdd})$} & $0.040 * *$ & 0.402 & $2.129 * *$ \\
\hline & $(0.009)$ & $(0.110)$ & $(0.479)$ \\
\hline \multirow{2}{*}{$\log$ (precip.) } & $0.038 * *$ & $0.763 * *$ & $-0.075^{* *}$ \\
\hline & $(0.014)$ & $(0.127)$ & $(0.454)$ \\
\hline \multirow{2}{*}{$\log \left(\right.$ precip. $\left.\sigma^{2}\right)$} & $-0.059 * *$ & $-0.247 * *$ & $0.125^{* *}$ \\
\hline & $(0.013)$ & $(0.075)$ & $(0.508)$ \\
\hline \multirow{2}{*}{$\log \left(\right.$ labor $\left.^{2}\right)$} & & $-1.621^{*}$ & $-1.563 * *$ \\
\hline & & $(0.208)$ & $(0.220)$ \\
\hline \multirow{2}{*}{$\log \left(\right.$ energy $\left.^{2}\right)$} & & $-0.016^{*}$ & $-0.171^{*}$ \\
\hline & & $(0.013)$ & $(0.100)$ \\
\hline \multirow[t]{2}{*}{$\log \left(\right.$ capital $\left.^{2}\right)$} & & $0.066^{*}$ & -0.546 \\
\hline & & $(0.009)$ & $(0.098)$ \\
\hline \multirow{2}{*}{$\log$ (labor $\mathrm{x}$ energy) } & & $0.036^{* *}$ & $0.488 * *$ \\
\hline & & $(0.013)$ & $(0.110)$ \\
\hline \multirow{2}{*}{$\log ($ labor x capital) } & & -0.058 & 0.761 \\
\hline & & $(0.012)$ & $(0.129)$ \\
\hline \multirow[t]{2}{*}{$\log$ (capital x energy) } & & $-0.214 * *$ & -0.323 \\
\hline & & $(0.102)$ & $(0.075)$ \\
\hline \multirow{2}{*}{$\log \left(h d d^{2}\right)$} & & & $-0.107 * *$ \\
\hline & & & $(0.049)$ \\
\hline \multirow[t]{2}{*}{$\log \left(\operatorname{cdd}^{2}\right)$} & & & $-0.129 * *$ \\
\hline & & & $(0.025)$ \\
\hline \multirow[t]{2}{*}{$\log \left(\right.$ precip. $\left.^{2}\right)$} & & & $-0.023 * *$ \\
\hline & & & $(0.010)$ \\
\hline \multirow[t]{2}{*}{$\log \left(\right.$ precip. $\sigma^{2} \times$ precip. $\left.\sigma^{2}\right)$} & & & 0.016 \\
\hline & & & $(0.010)$ \\
\hline \multirow[t]{2}{*}{$\log$ (precip x hdd) } & & & $0.038^{*}$ \\
\hline & & & $(0.037)$ \\
\hline \multirow[t]{2}{*}{$\log \left(\operatorname{cdd} x\right.$ precip. $\left.\sigma^{2}\right)$} & & & $-0.016^{* *}$ \\
\hline & & & $(0.027)$ \\
\hline \multirow[t]{2}{*}{$\log ($ hdd $x$ cdd $)$} & & & $-0.137 * *$ \\
\hline & & & $(0.039)$ \\
\hline \multirow[t]{2}{*}{$\log \left(\right.$ hdd x precip. $\left.\sigma^{2}\right)$} & & & $-0.010^{* *}$ \\
\hline & & & $(0.041)$ \\
\hline
\end{tabular}


Table A.11 OLS Results from Panel Regression

Dependent Variable $=\log ($ Services Gross Sector Product $)$

\begin{tabular}{lccc} 
& Model (1) & Model (2) & Model (3) \\
\hline $\log$ (cdd x precip.) & & & $-0.016^{* *}$ \\
& & & $(0.024)$ \\
& & & 0.9748 \\
FIT: Adj. R2 (pre-stationary) & 0.9680 & 0.9731 & -1964.2 \\
FIT: Akaike Information Criterion (stationary) & -1795.3 & -1932.3 & 1,121 \\
Degrees of Freedom & 1,136 & 1,130 & YES \\
State fixed effects? & YES & YES & YES \\
AR(1) time correction? & YES & YES & YES \\
U.S. Regional/Geographic dummies & YES & YES &
\end{tabular}

Notes: * $=$ Significant with $95 \%$ confidence; $* *$ Significant with $99 \%$ confidence.

\section{Predicted Real \$vs. Actual Real \$ \\ Services \\ SWST Region: AZ, NM, OK, TX}

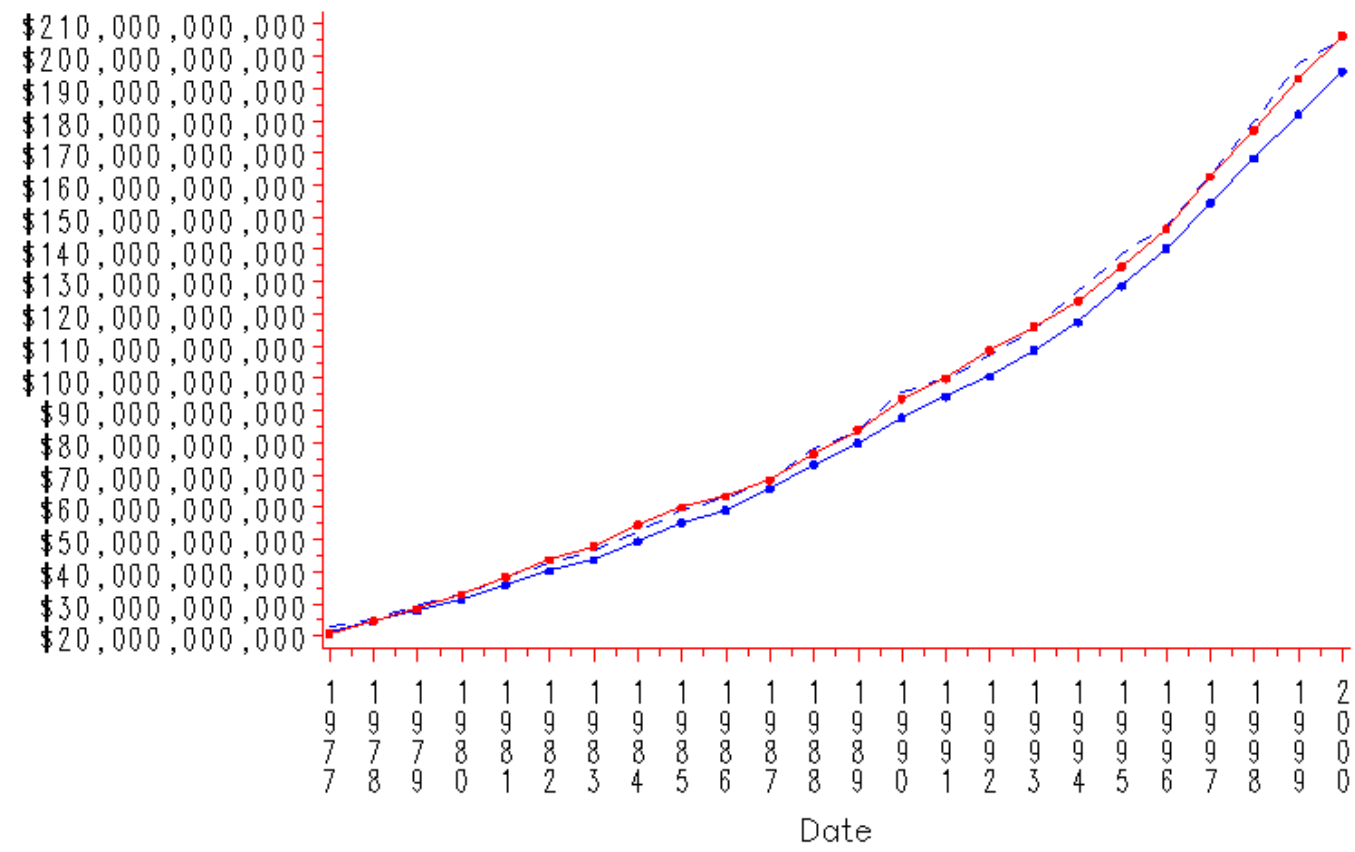

PLOT Model (3) w/o Weather - - Model (3)

$\because$ Real Sector Output 
APPENDIX B: SELECTED SECTOR/REGIONAL-LEVEL PLOTS FROM MONTE-CARLO SIMULATION
Change to Economic Output from Regional Weather Variability
Region: West Coost
11 Sector Total

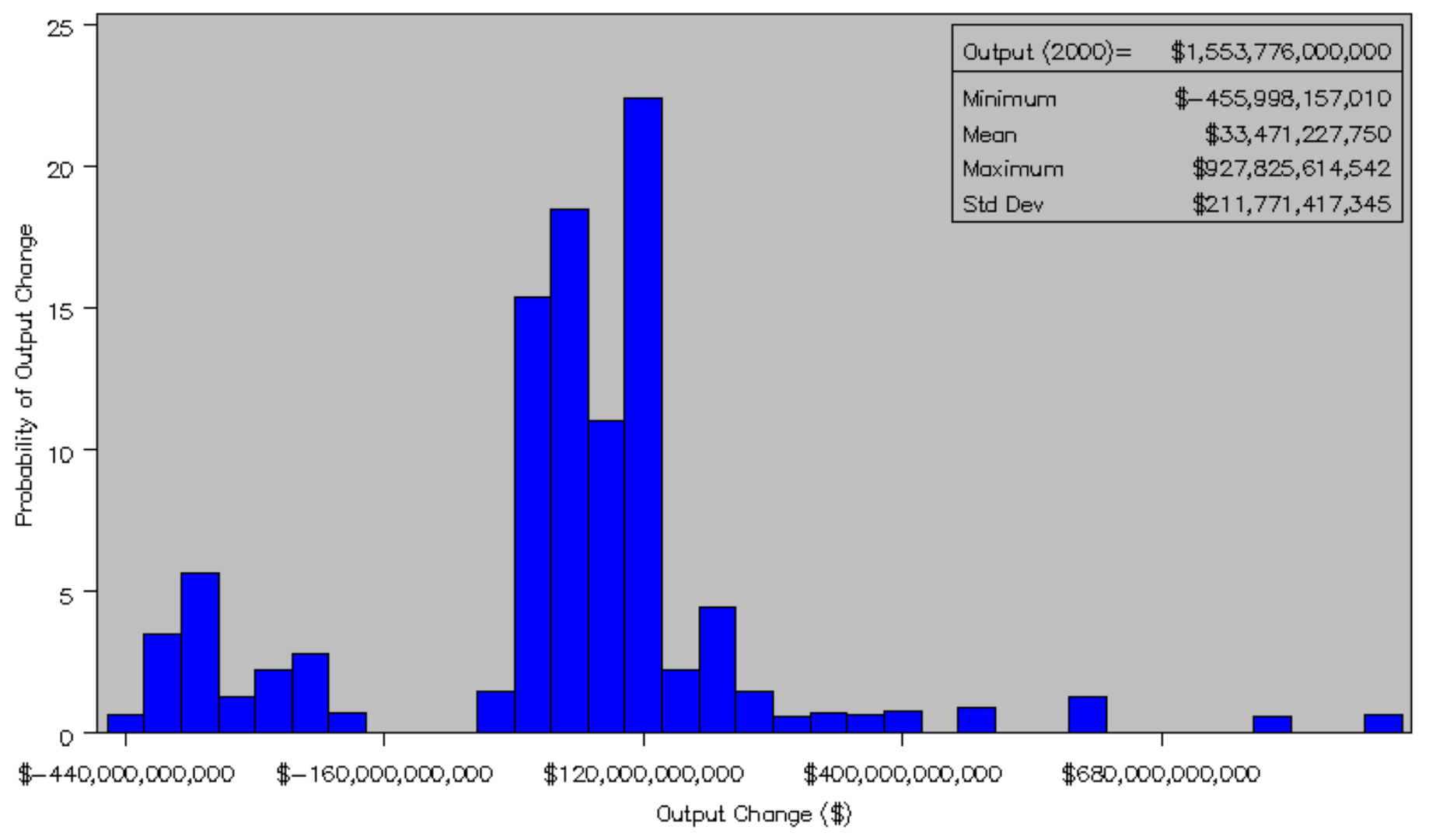

NOTES: Diatribution based on 10,000 rapeated and random drawa of 4 measuras of historical regicnal waather. 


\section{Change to Economic Output from Regional Weather Variability Region: Rocky Mountains 11 Sector Total}

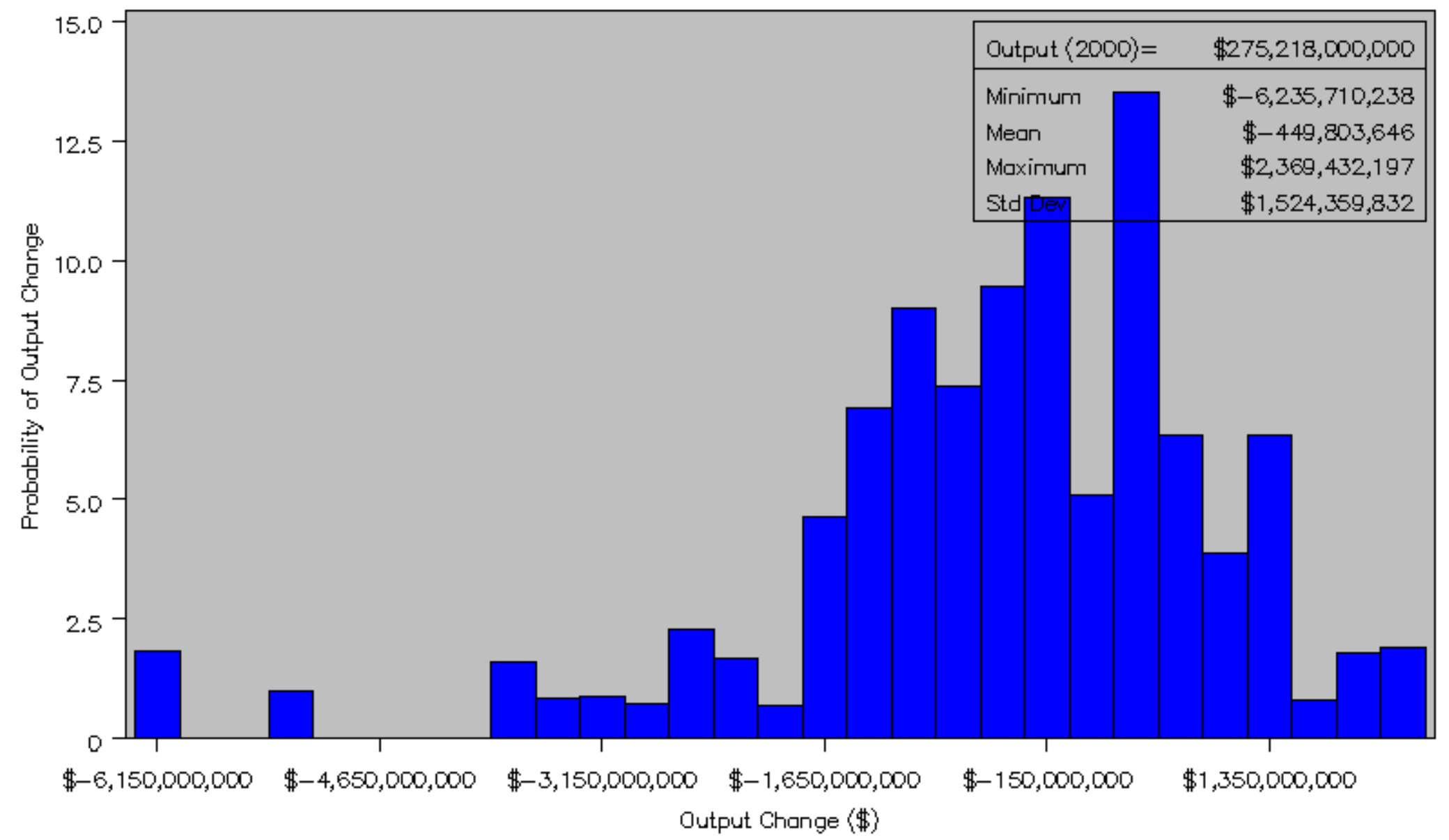




\section{Change to Economic Output from Regional Weather Variability Region: Middle East 11 Sector Total}

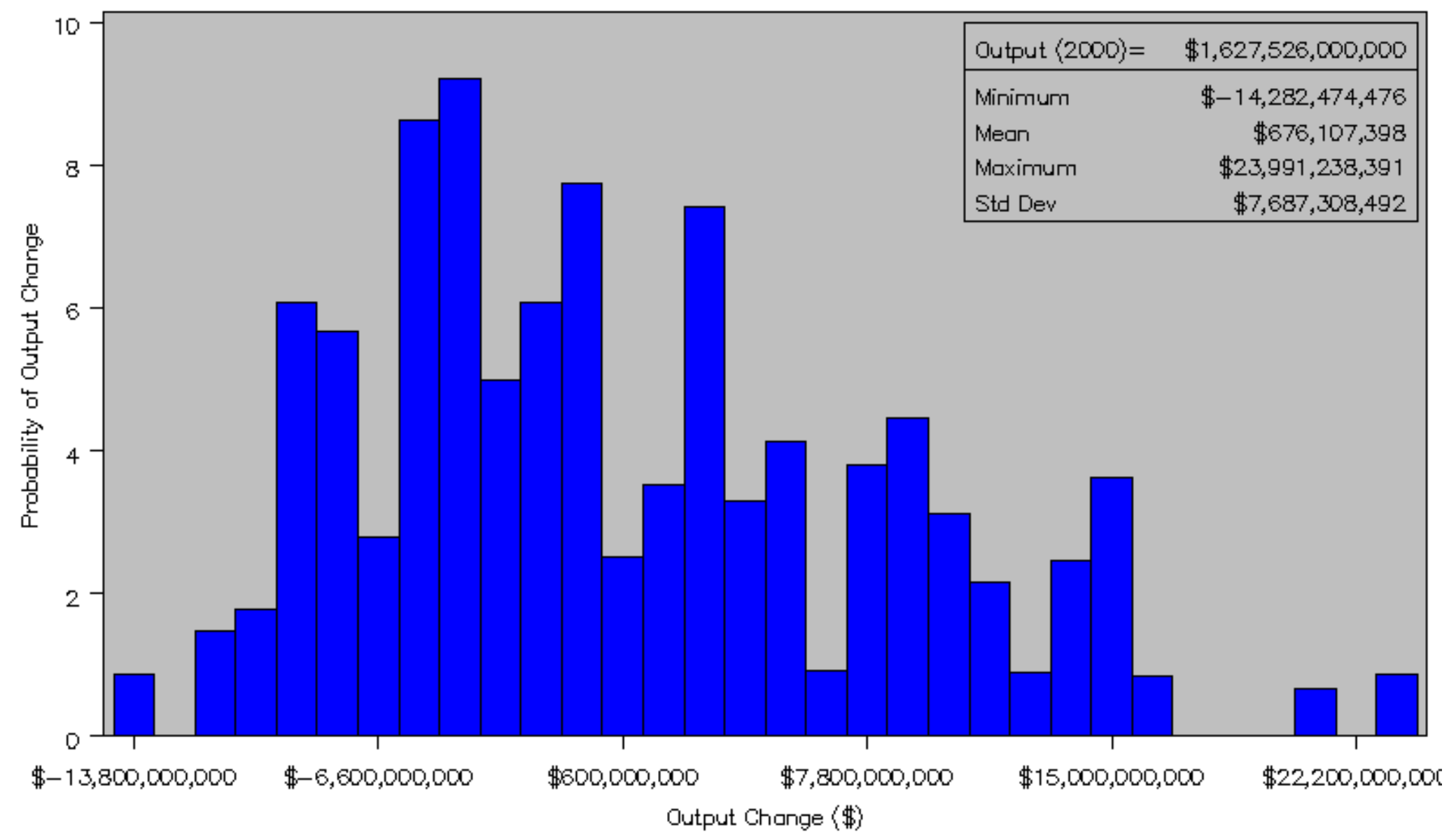

NOTES: Diatribution based on 10,000 rapeated and randan drawa of 4 maasuras of historical regional weather. Eccnomatric rasulta based on a abationary, 31 paramater TRANSLOG aconomatric model. 


\section{Change to Economic Output from Regional Weather Variability \\ Region: Southwest \\ 11 Sector Total}

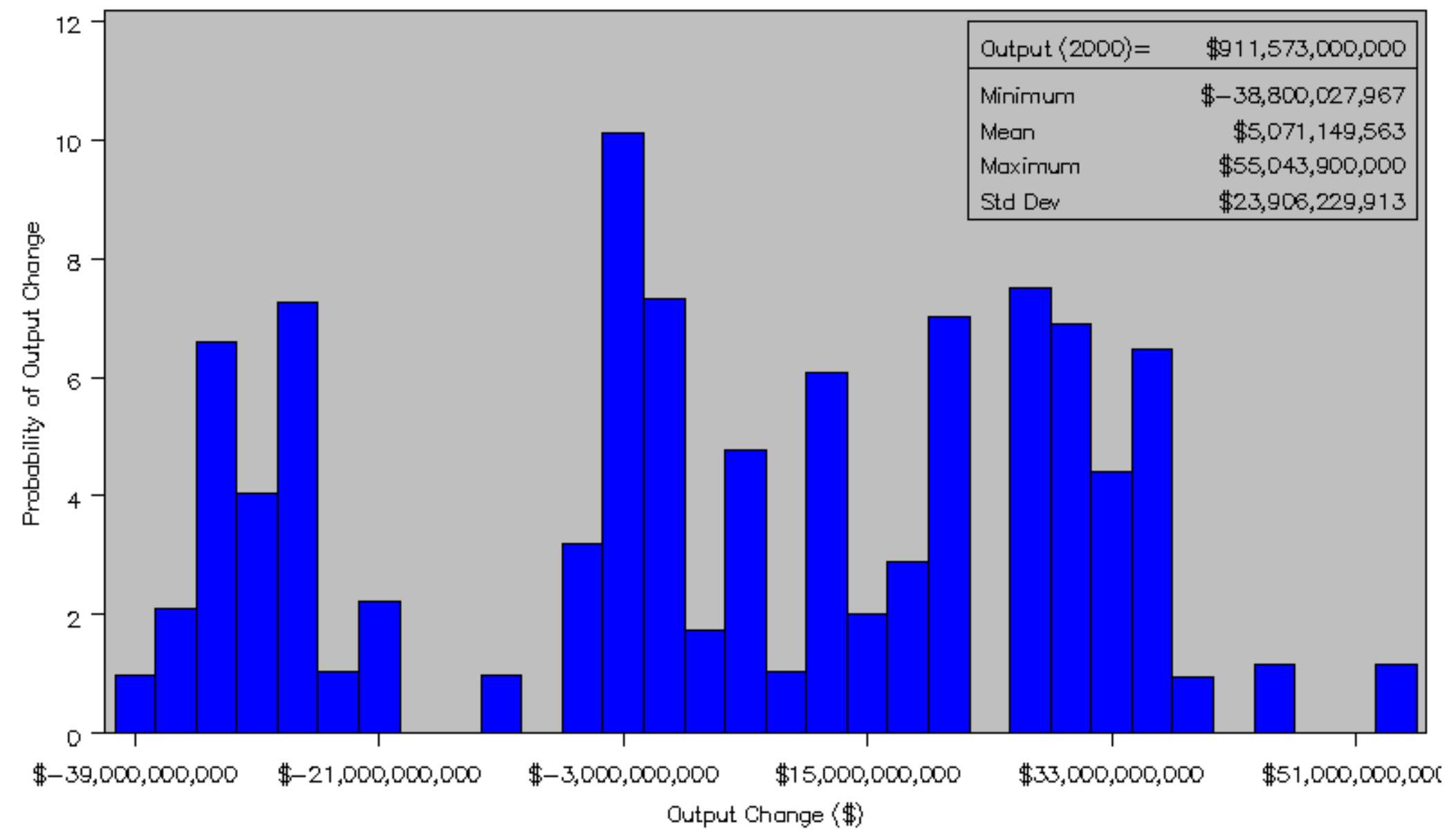




\section{Change to Economic Output from Regional Weather Variability National Estimate Sector: Agriculture}

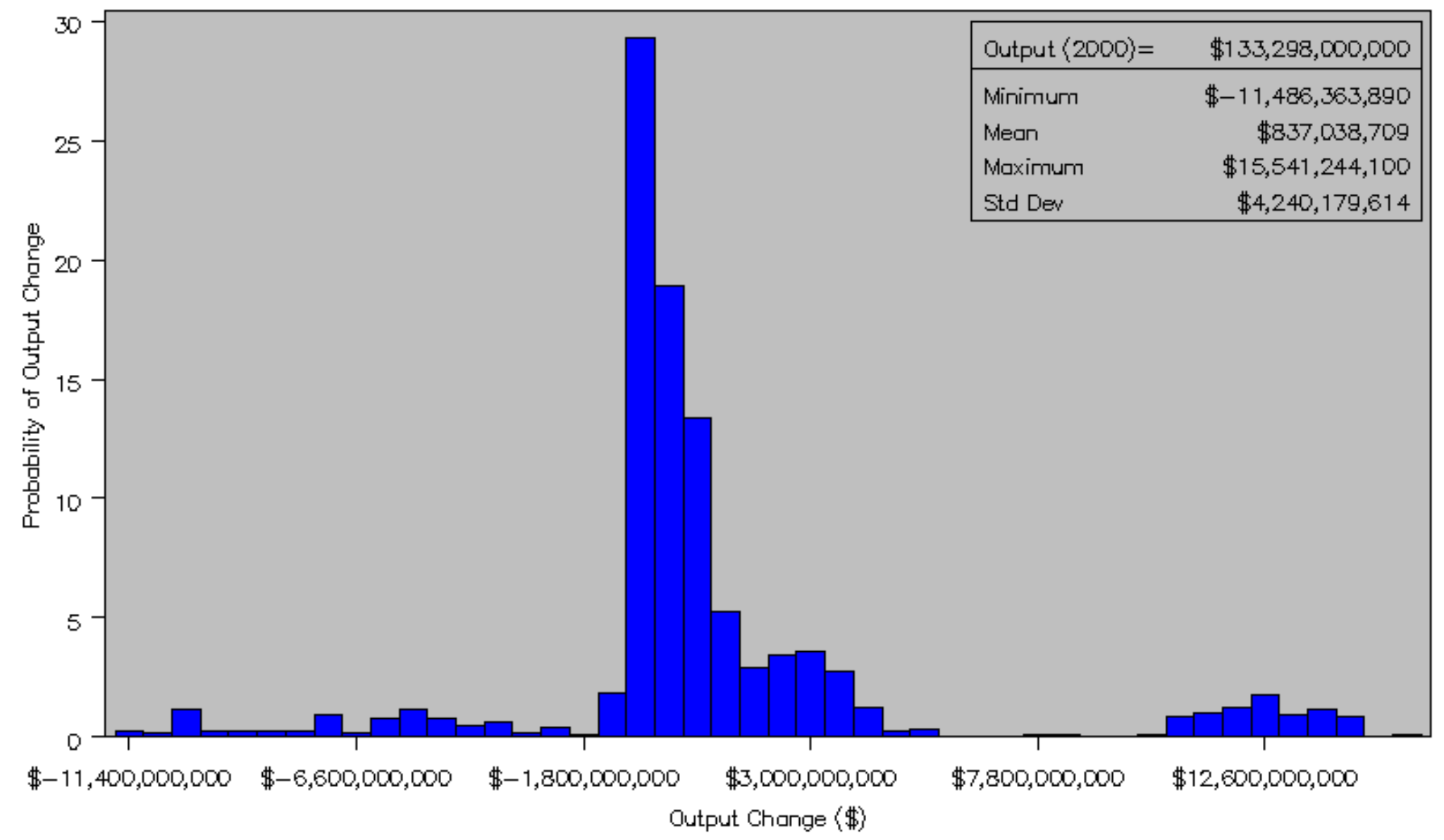




\section{Change to Economic Output from Regional Weather Variability National Estimate Sector: FRE}

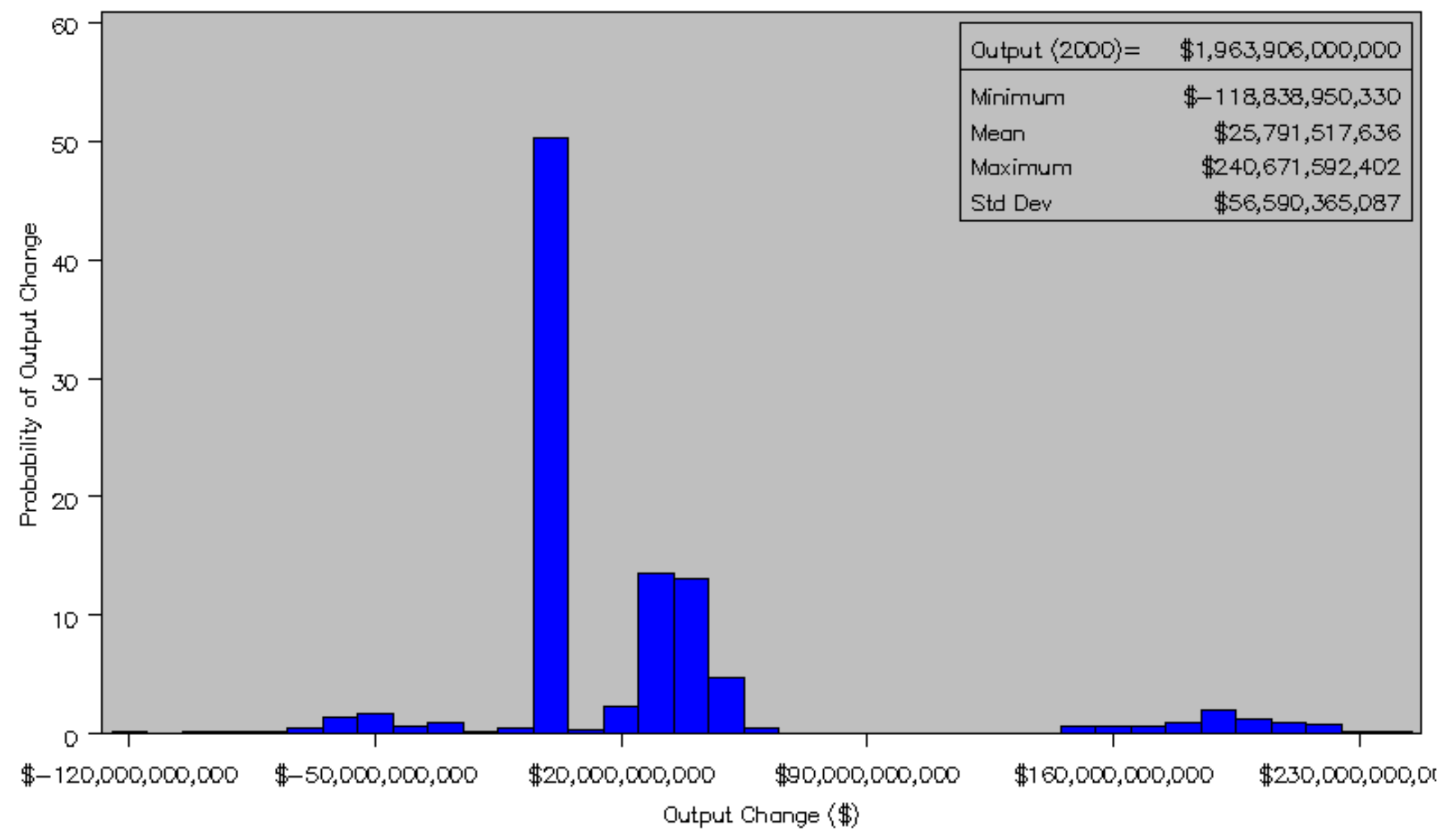

NOTES: Diatribution based on 10,000 repeated and randon drowa of 4 magauras of historical regional weather. Eccnometric ragulta based on a abationary, 31 paramater TRANSLOG aconomatric model. 
Change to Economic Output from Regional Weather Variability National Estimate

Sector: Transportation

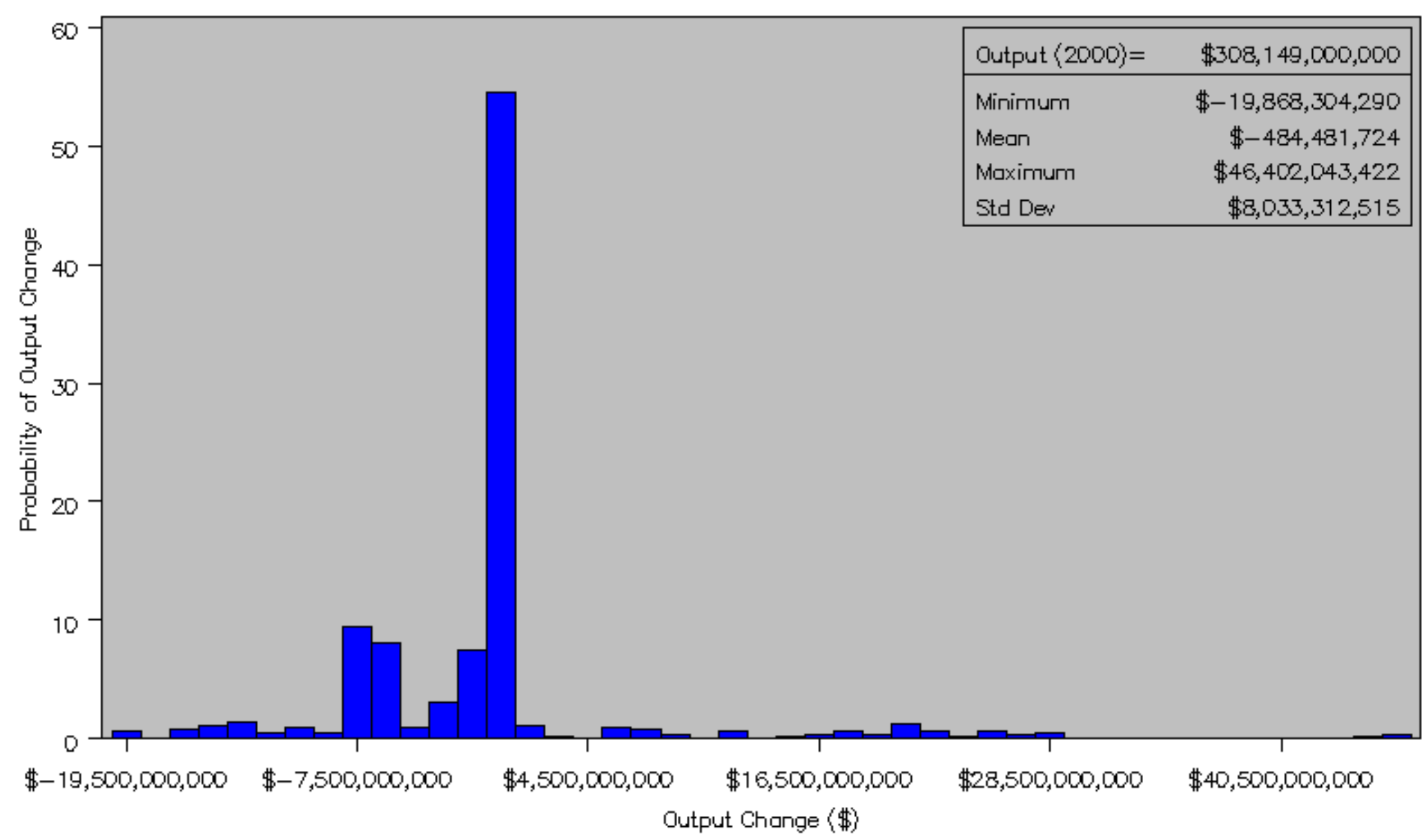

NOTES: Diatribution baagd on 10,000 rapeated and randan drawa of 4 magauras of historical regional weather.

Eccomatistic rasulta based on a stationary, 31 paramater TRANSSLOG aconomatric model. 


\section{Change to Economic Output from Regional Weather Variability National Estimate \\ Sector: Construction}

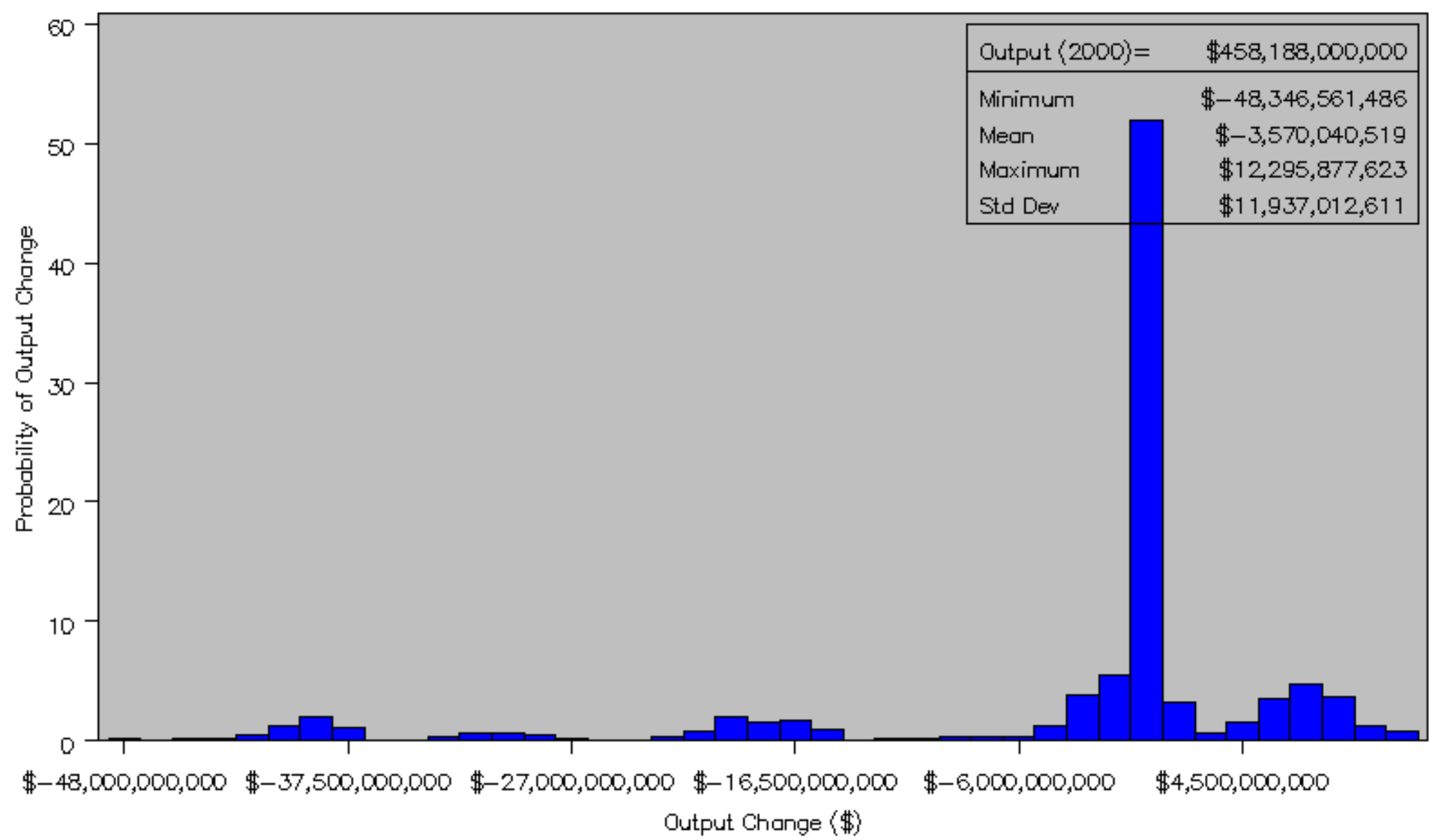


Change to Economic Output from Regional Weather Variability National Estimate Sector: Mining

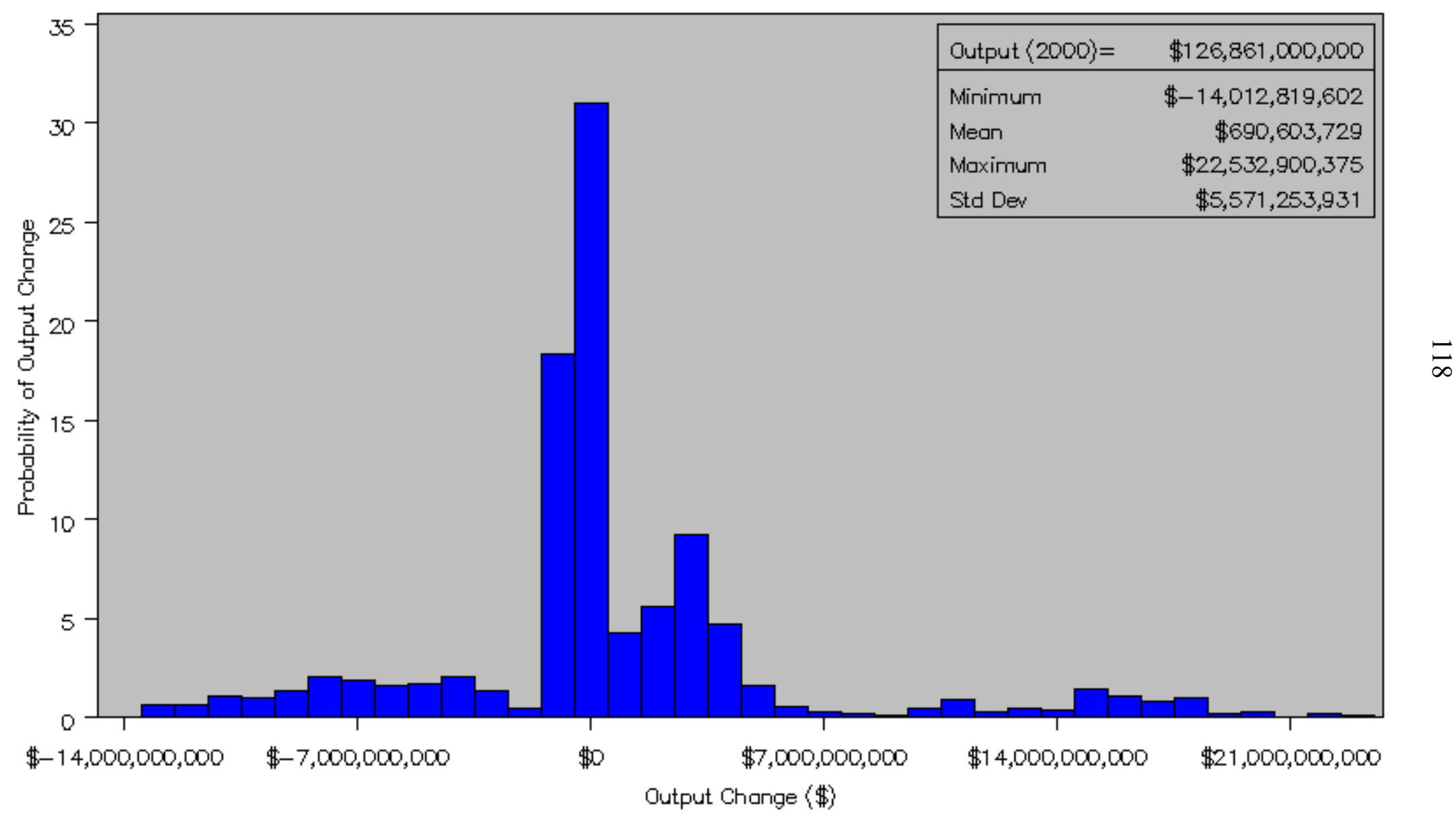

NOTEs: Diatribution baged on 10,000 repeated and randon drawa of 4 magauras of historical regional waother.

Eccnometric reaults based on a stationary, 31 parameter TRANSSLG economatric model. 


\section{Change to Economic Output from Regional Weather Variability National Estimate \\ Sector: Utilities}

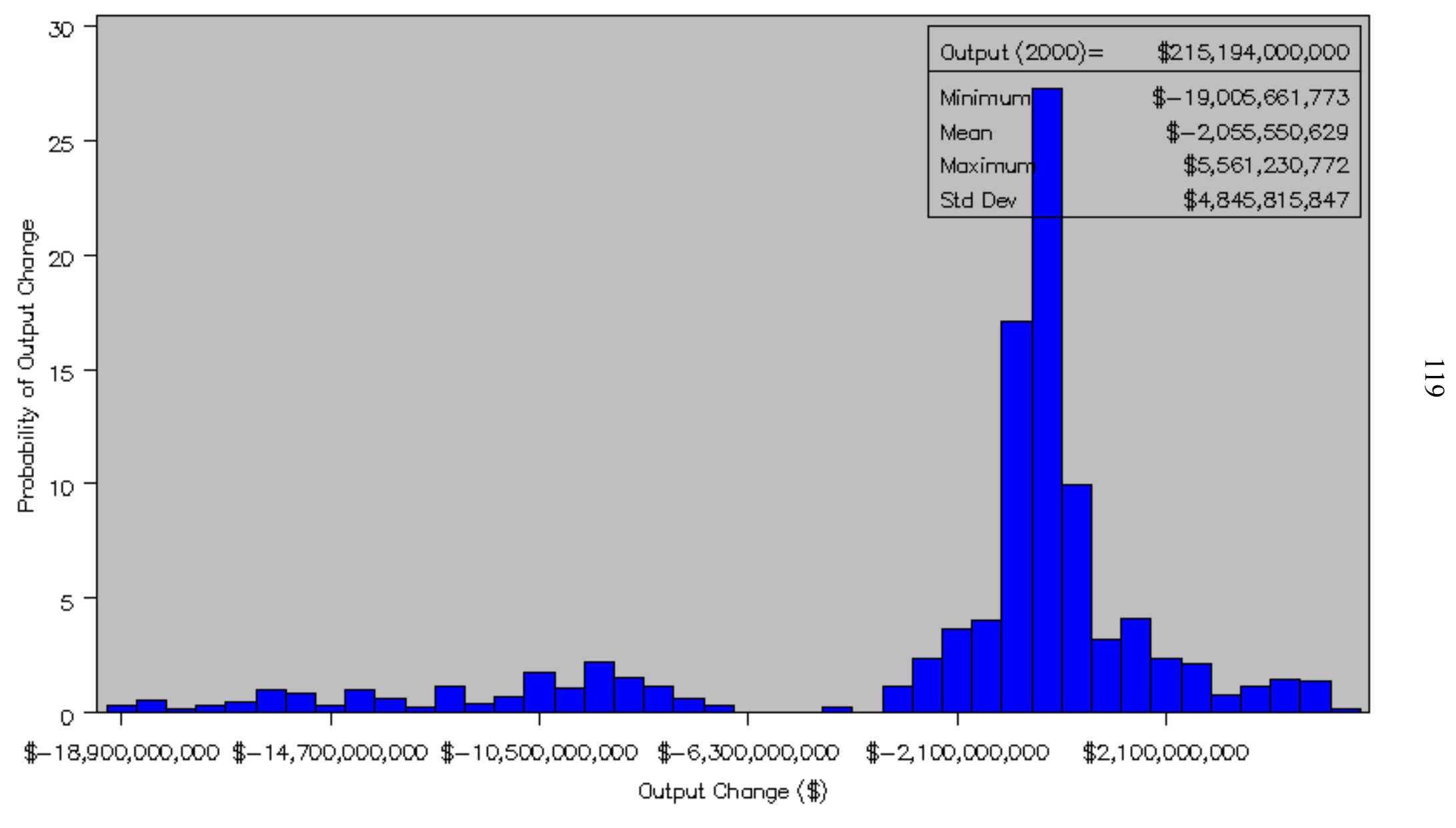

NOTES: Diatribution baged on 10,000 rapeated and randar drawa of 4 measuras of histcrical regional weather.

Eccnometric reaulta based on a abationary, 31 parameter TRAN NLOG economatric model. 


\section{Change to Economic Output from Regional Weather Variability National Estimate \\ Sector: Manufacturing}

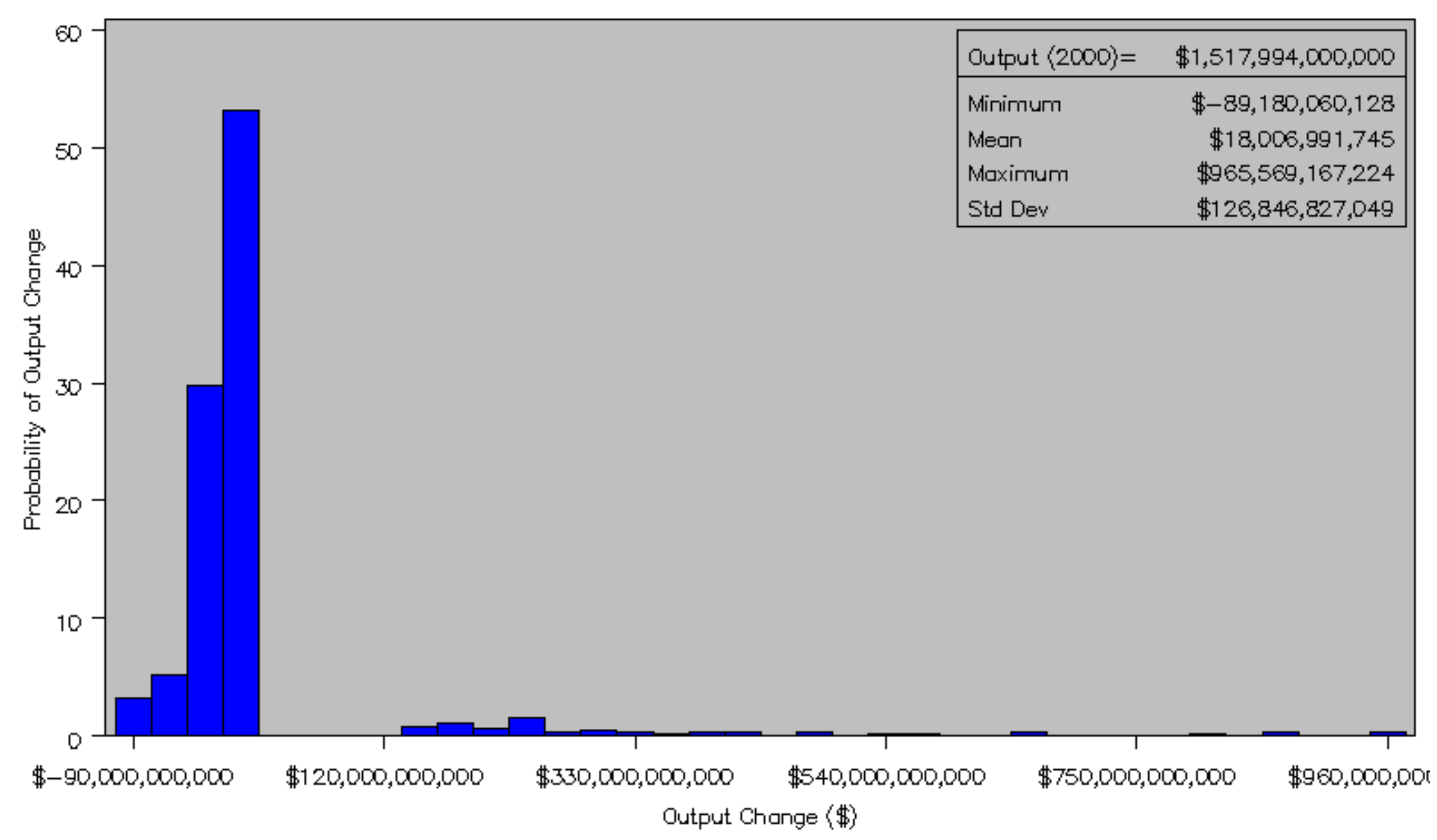

NOTES: Diatribution baged an 10,000 rapeated and randorn drawa of 4 magauras of histcrical regional wather.

Eccnomatric rasulta based on a abationary, 31 paramatar TRANSLOG aconcmatric model. 


\section{REFERENCES}

Arrow, K.J. H. B. Cheney, B. Minhas, and R.M. Solow (1961),: Capital-labor substitution and economic efficiency, Review of Economics and Statistics 43, August $1961,225-250$.

Berndt, E. R. and L.R. Christensen (1973): "The Translog Function and the Substitution of Equipment, Structures, and Labor in U.S. Manufacturing 1929-1968." Journal of Econometrics 1, 81-114.

U.S. Bureau of Economic Analysis (2005a): Regional Economic Accounts; Gross State Product by End-Use Sector, U.S. Department of Commerce. Accessed January 2006 at http://www.bea.gov/bea/regional/gsp/

U.S. Bureau of Economic Analysis (2005b): National Economic Accounts; Fixed Asset Tables, U.S. Department of Commerce. Accessed January 2006 at http://www.bea.gov/bea/dn/FA2004/SelectTable.asp

U.S. Bureau of Economic Analysis (2005c): REIS Database; Farm Employment Figures by U.S. State, U.S. Department of Commerce. Accessed January 2006 at http://www.bea.gov/bea/regional/reis/

U.S. Bureau of Labor Statistics (2005): Labor Hours for Non-Farm Payrolls by Industry Sector, U.S. Department of Labor. Accessed January 2006 at http://www.bls.gov/ces/cesbtabs.htm

Chicago Mercantile Exchange (2005), Statistics on Weather Derivatives Trading Volume, Received via communication with Mr. Toni Partee, CME, Chicago, Illinois.

Christensen, L.R., D.W. Jorgenson and L.J. Lau (1971), “Conjugate Duality and the Transcendental Logarithmic Production Function,” Econometrica 39, 255-256.

Christensen, L.R., D.W. Jorgenson and L.J. Lau (1973), “Transcendental Logarithmic Production Frontiers", Review of Economics and Statistics 55, 28-45.

Cline, W.R., (1992): The Economics of Global Warming. Institute for International Economics, Washington, DC.

C.W. Cobb and P.H. Douglas (1928) "A Theory of Production", American Economic Review, Vol. 18, p.139-65.

Dutton, J. A. (2002): "Opportunities and Priorities in a New Era for Weather and Climate Services." Bulletin of the American Meteorological Society, September, 1303-1311. 
Fankhauser, S., (1995): Valuing Climate Change: The Economics of the Greenhouse. EarthScan, London.

Fraser, I. (2002): "The Cobb-Douglas Production Function: An Antipodean Defence?" Journal of Economic Issues, Vol. 7, Part 1, March, pp.39-58

Greene, W.H. (2003): Econometric Analysis. Fifth edition. Prentice Hall, Upper Saddle River, NJ.

Handsaker M L and Douglas P H (1937): 'The Theory of Marginal Productivity Tested by Data for Manufacturing in Victoria', Quarterly Journal of Economics, 52, 1-36. IPCC (2001): Climate Change 2001, Working Group 1: The Scientific Basis, Appendix 1: Glossary. A.P.M Baede (ed.). Accessed: 10/31/04. http://www.grida.no/climate/ipcc tar/wg1/518.htm

Kasperson, J.X., R.E. Kasperson, B.L. Turner, II, W. Hsieh, and A. Schiller. (2002):

"Vulnerability to Global Environmental Change." In The human dimensions of global environmental change, A. Diekmann, T. Dietz, C. Jaeger, and E. Rosa, eds, Cambridge, MA: MIT Press

Kennedy, P. (2003): A Guide to Econometrics. Fifth Edition. MIT Press.

Mount T.D. and S. Yoo (2002) "Designing Forward Markets for Electricity to Meet the Needs of Customers", Department of Applied Economics, Cornell University. Presented at the Annual Rutgers Eastern Conference, Newport, RI.

Nicholson (1992): Microeconomic Theory: Basic Principles and Extensions. The Dryden Press. Fifth Edition.

Nordhaus, W.D., (1994): Managing the Global Commons: The Economics of Climate Change. The MIT Press, Cambridge.

Nordhaus, W.D., Yang, Z., (1996): RICE: a regional dynamic general equilibrium model of optimal climate-change policy. Am. Econ. Rev. 86 (4) , 741-765.

SAS Institute (2005): Online Documentation for PROC TSCREG Procedure. Cary, NC. http:www.sas.com (Accessed June 22, 2005)

Solomou, Solomos and Wu, Weike, (1999): "Weather Effects on European Agricultural Output 1850-1913," Cambridge Working Papers in Economics 9915, Department of Applied Economics, University of Cambridge.

Starr-McCluer, M., (2000): "The Effects of Weather on Retail Sales," Federal Reserve Board of Governors, Washington D.C. 
Titus, J. G., (1992): "The Costs of Climate Change to the United States," in Global Climate Change: Implications, Challenges and Mitigation Measures, S. K. Majumdar et al., eds. (eds.), Pennsylvania Academy of Science, Easton, pp. 384-409.

Tol, Richard S.J. (ed.), (2000) "Weather Impacts on Natural, Social, and Economic Systems in the Netherlands." Institute for Environmental Studies, Amsterdam, The Netherlands, March.

Tol, R.S.J. (1995), 'The Damage Costs of Climate Change -- Towards More Comprehensive Calculations', Environmental and Resource Economics, 5, 353-374.

UNEP (1995): Climate Change 1995, Working Group 2, Second Assessment Report for the Intergovernmental Panel on Climate Change, World Meteorological Organization, and the United Nations Environment Programme. Accessed: 11/1/04. http:/www.grida.no/climate/vital/25.htm

Williams J (1945): 'Professor Douglas' Production Function', Economic Record, 25, $55-6$

Wooldridge (2002): Econometric Analysis of Cross Section and Panel Data. MIT Press, Cambridge, MA, pp. 377-378. 